\title{
Comparação de algoritmos para o Problema dos $K$ Menores Caminhos
}

\author{
Diogo Haruki Kykuta
}

\author{
Dissertação apresentada \\ ao \\ Instituto de Matemática e Estatística \\ da \\ Universidade de São Paulo \\ para \\ obtenção do título \\ de \\ Mestre em Ciência da Computação
}

Programa:

Mestrado em Ciência da Computação

Orientador:

Prof. Dr. Carlos Eduardo Ferreira

Durante o desenvolvimento deste trabalho o autor recebeu auxílio financeiro da CAPES 



\section{Comparação de algoritmos para o Problema dos $K$ Menores Caminhos}

Esta versão da dissertação contém as correções e alterações sugeridas pela Comissão Julgadora durante a defesa da versão original do trabalho, realizada em 19/02/2018. Uma cópia da versão original está disponível no Instituto de Matemática e Estatística da Universidade de São Paulo.

Comissão Julgadora:

- Prof. Dr. Carlos Eduardo Ferreira - IME-USP

- Prof. Dr. José Coelho de Pina Junior - IME-USP

- Prof. Dr. Álvaro Junio Pereira Franco - UFSC 

A todos aqueles que me ajudaram com sua presença ou compreenderam minha ausência 



\section{Resumo}

Diogo Haruki Kykuta. Comparação de algoritmos para o Problema dos $K$ Menores Caminhos. Instituto de Matemática e Estatística, Universidade de São Paulo, São Paulo, 2018.

O Problema dos $K$ Menores Caminhos é uma generalização do Problema do Menor Caminho, em que desejamos encontrar os $K$ caminhos de menor custo entre dois vértices de um grafo.

Estudamos e implementamos algoritmos que resolvem esse problema em grafos dirigidos, com peso nos arcos e que permitem apenas caminhos sem repetição de vértices na resposta. Comparamos seus desempenhos utilizando grafos do 9th DIMACS Implementation Challenge. Identificamos os pontos fortes e fracos de cada algoritmo, e propusemos uma variante híbrida dos algoritmos de Feng e de Pascoal.

Essa variante proposta obteve desempenho superior aos algoritmos base em alguns grafos, e resultado superior a pelo menos um deles na grande maioria dos testes.

Palavras-chave: grafos, k menores caminhos, caminho mínimo, grafos dirigidos com peso nos arcos 


\section{Abstract}

Diogo Haruki Kykuta. Comparison of algorithms for $K$ Shortest Paths Problem. Instituto de Matemática e Estatística, Universidade de São Paulo, São Paulo, 2018.

The K-Shortest Paths Problem is a generalization of the Shortest Path Problem, in which we must find the $K$ paths between two vertices in a graph that have the lowest costs.

We study some $K$-Shortest Paths Problem algorithms applied to weighted directed graphs, allowing only paths with no repeated vertices. We compare empirically implementation of some algorithms, using instance graphs from the 9th DIMACS Implementation Challenge. We identify the strengths and weaknesses of each algorithm, and we propose a hybrid version of Feng's and Pascoal's algorithms.

This proposed variant achieve better perfomance compared to both base algorithms in some graphs, and it is better than at least one of them in most cases.

Keywords: graphs, k shortest paths, shortest path, weighted directed graph 


\section{Sumário}

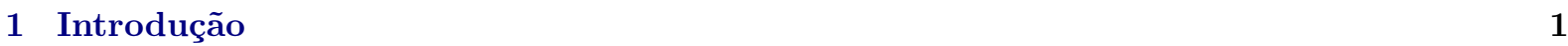

$1.1 \quad$ O Problema . . . . . . . . . . . . . . . . . . . . . . . . . . . . 1

1.2 Aplicações . . . . . . . . . . . . . . . . . . . . . . . . . 2

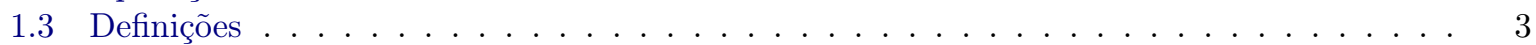

1.4 KSP na Literatura $\ldots \ldots \ldots \ldots \ldots \ldots \ldots \ldots$

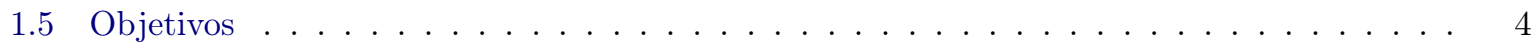

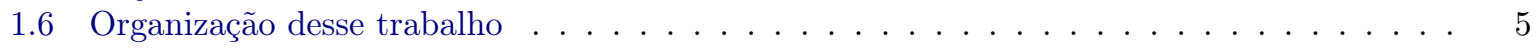

2 Algoritmo de Yen $\quad 7$

2.1 Visão Geral . . . . . . . . . . . . . . . . . . . . . . . . . 7

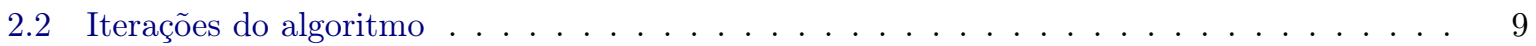

2.3 Corretude e complexidade . . . . . . . . . . . . . . . . . . . . . . . . 11

2.4 Simulação . . . . . . . . . . . . . . . . . . . . . . . . . . . . . 11

3 Algoritmo de Pascoal $\quad 19$

3.1 Visão Geral . . . . . . . . . . . . . . . . . . . . . . . . . . . . . . . . . . . . 19

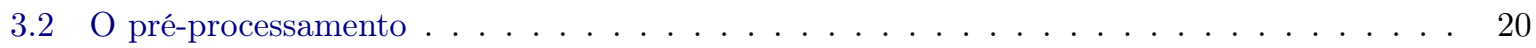

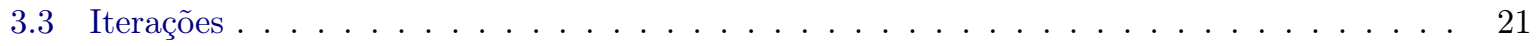

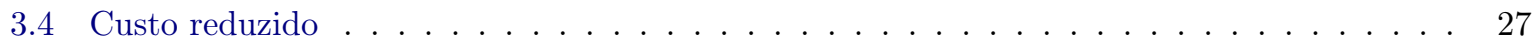

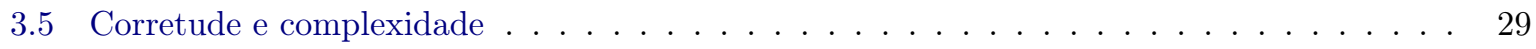

4 Algoritmo de Feng 31

4.1 Visão Geral . . . . . . . . . . . . . . . . . . . . . . . . . . 31

4.2 A classificação dos vértices . . . . . . . . . . . . . . . . . . . . . . . 32

4.3 Executando Dijkstra em um grafo auxiliar baseado em $G \ldots \ldots \ldots \ldots \ldots$

4.3 .1 Custo reduzido . . . . . . . . . . . . . . . . . . . 34

4.3.2 Construindo o subgrafo de $G$ em que será executado o algoritmo de caminho mínimo 34

4.4 Atualizando a classificação para a próxima iteração . . . . . . . . . . . . . . 35

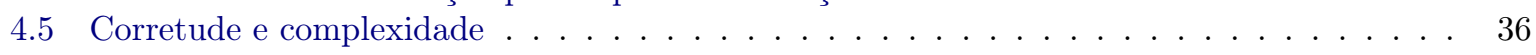

5 Implementação $\quad 37$

5.1 Estruturas de dados . . . . . . . . . . . . . . . . . . . 37

5.1 .1 Representação do grafo . . . . . . . . . . . . . . . . . . . . . 37

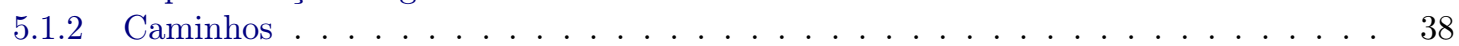

5.2 Conjunto de Candidatos . . . . . . . . . . . . . . . . . . . . . . . . . . 39

5.3 Algoritmos . . . . . . . . . . . . . . . . . . . . . . . . . . . . 39

5.4 Algoritmo de Dijkstra . . . . . . . . . . . . . . . . . . . . . . . . . 39

5.5 Algoritmos de Yen, Pascoal e Feng . . . . . . . . . . . . . . . . . . . 40

5.5.1 Arcos Expressos no Algoritmo de Feng . . . . . . . . . . . . . . . . . . . . . 40

5.6 Algoritmo Híbrido de Feng e Pascoal . . . . . . . . . . . . . . . . . . . . . . . . . 41

6 Resultados 43

6.1 Grids . . . . . . . . . . . . . . . . . . . . . . . . 43

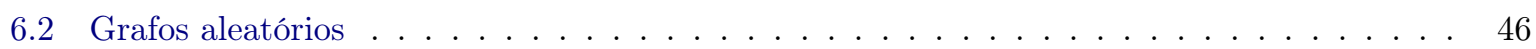

6.3 Grafos de malhas rodoviárias . . . . . . . . . . . . . . . . . 50

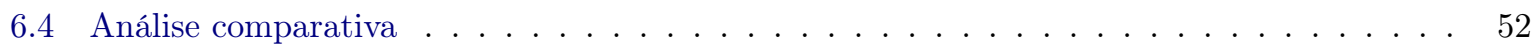


Referências Bibliográficas 


\section{Capítulo 1}

\section{Introdução}

O problema de encontrar os $K$ menores caminhos entre dois vértices de um grafo $(K S P)$ é estudado há tempos, e motivou, no decorrer destes anos, a produção de diversos trabalhos focados em resolvê-lo de formas cada vez mais eficientes [BKH58, HP59, CKR63, Dre69, Yen71, Law72, KIM82, Per86, Epp98, MPS99, RZ05, Pas06, GL09, Rod10, Fen14] ${ }^{1}$, seja no consumo de tempo ou de memória. O primeiro algoritmo de grande importância para esse problema foi desenvolvido por Yen em 1971 [Yen71], e generalizado por Lawler no ano seguinte [Law72]. Por um longo tempo, não foi desenvolvido nenhum algoritmo cuja complexidade fosse menor que a apresentada por esses autores, ainda que alguns apresentassem, na prática, menor tempo de execução, como por exemplo os algoritmos de Pascoal [Pas06] e de Feng [Fen14].

Apenas em 2009 foi alçado um resultado que vencesse essa marca, quando Gotthilf e Lewenstein [GL09] desenvolveram um algoritmo de complexidade pouco melhor que o algoritmo de Yen, baseado no Problema dos Menores Caminhos Entre Todos os Pares de Vértices (em inglês, All-Pair-Shortest-Paths APSP) [CLRS01, Pet04].

Neste trabalho, estudamos o KSP e três algoritmos existentes [Yen71, Pas06, Fen14] para resolvê-lo. Os algoritmos citados foram implementados e testados, comparando seus desempenhos utilizando a base de grafos e ferramentas do 9th DIMACS Implementation Challenge. Por fim, propusemos uma versão híbrida dos algoritmos de Pascoal e Feng, que visa unir as vantagens que os dois algoritmos trazem.

\subsection{O Problema}

Seja $G=(V, E)$ um grafo com pesos não-negativos nos arcos, $s, t$ dois vértices desse grafo e $k$ um inteiro maior ou igual a 1 . Seja $\mathcal{P}_{G}(s, t)$ o conjunto de todos os caminhos de $s$ a $t$ em $G$.

Chamamos de Problema dos $K$ Menores Caminhos (em inglês, $K$-Shortest Paths Problem - KSP) o problema de encontrar um subconjunto $\mathcal{R} \subseteq \mathcal{P}_{G}(s, t)$ contendo exatamente $k$ menores caminhos de $s$ a t. Ou seja, queremos um conjunto $\mathcal{R}$ tal que não exista um caminho $P \in \mathcal{P}_{G}(s, t)$, tal que $P \notin \mathcal{R}$ e cujo custo seja estritamente menor que algum caminho em $\mathcal{R}$.

Essa é uma definição geral do problema, que possui diversas variantes para as diversas características que podemos fixar em relação ao grafo de entrada ou mesmo em relação à saída do problema. Por

\footnotetext{
${ }^{1}$ Esses são apenas alguns dos trabalhos, uma extensa lista, porém desatualizada, encontra-se em http://www.ics.uci.edu/ $\sim$ eppstein/bibs/kpath.bib
} 
exemplo, poderíamos limitar nossa atenção à grafos sem pesos nos arcos, ou de forma equivalente, com pesos unitários. Ao limitar a entrada, podemos explorar essas características para criarmos algoritmos mais eficientes. Neste trabalho, nossa atenção estará voltada à variante em que o grafo de entrada é dirigido e contém pesos nos arcos, e na saída queremos apenas caminhos simples. Falaremos brevemente sobre algumas das variantes em 1.4.

\subsection{Aplicações}

O KSP tem muitas aplicações, diretas e indiretas, muito presentes nas nossas vidas, mesmo que não notemos. Um primeiro exemplo, mais prático e habitual, pode ser visto durante a sugestão de rotas de trânsito. Por vezes, os aplicativos de rotas sugerem mais de uma opção de trajeto ao usuário, e cabe a ele escolher a mais adequada, por quaisquer motivos que sejam.

Outro exemplo de uma aplicação, menos óbvia, no cotidiano das pessoas é o roteamento de pacotes de dados na internet. Esse tráfego está sujeito a outros fatores que não podem ser modelados como um simples grafo com custos nos arcos. Além do custo, também precisamos levar em conta que pacotes podem ser perdidos, ter um atraso na entrega, a probabilidade de termos um erro na transmissão dos dados, etc. Em geral, existem limites aceitáveis para cada um desses fatores, e o problema de encontrar a melhor rota passa a ser limitada por restrições.

O Problema do Menor Custo Restrito a Atraso (em inglês, Delay Constrained Least Cost - DCLC) é um problema bem estudado na literatura [JV06, FDMP02, FMPD02], que sabemos ser $\mathcal{N} \mathcal{P}$-Completo [JV06]. Nesse problema, temos um grafo em que os arcos estão associados a um custo e a um atraso. Queremos encontrar o caminho de menor custo entre dois vértices, limitado a um valor máximo de atraso permitido. Frequentemente, a resolução de outros problemas é utilizada como parte de heurísticas para resolver o $D C L C$ de forma inexata. Jia e Varaiya [JV06] apresentaram uma heurística baseada no KSP, e alegam chegar na solução ótima quase sempre, de acordo com os testes numéricos realizados no mesmo artigo.

Eppstein [Epp98] cita outra aplicação que ocorre com restrições extras. O problema em questão é o de seleção de rota de transmissão de energia [EAEG93]. Em geral, tenta-se fazer as ligações de forma direta, porém, pode haver restrições de difícil modelagem (barreiras naturais, conveniência para a comunidade, etc). Para casos como esse, uma abordagem comum é calcular diversos caminhos mínimos e procurar algum deles que satisfaça as outras condições. Essa abordagem é utilizada em toda uma classe de problemas, em que as restrições extras prejudicam a otimização, mas que a verificação da restrição em um número reduzido de caminhos é viável.

Também podemos citar a importância do KSP na análise de sensibilidade dos problemas de otimização. Alguns problemas apresentam algumas restrições que possuem maior impacto do que outras na resposta ótima. Uma das maneiras de se analisar trechos essenciais da resposta utiliza o KSP. Vários caminhos mínimos são calculados para verificar a ligação de trechos presentes nos caminhos e o custo obtido. Por vezes, alguns trechos são críticos, a ponto de sua ausência significar uma piora drástica no custo. Citado por Eppstein [Epp98] para exemplificar a análise de sensibilidade, temos o caso da análise de alinhamento genético, em que vários "bons" alinhamentos são feitos e comparados, a procura dos trechos que são essenciais para um alinhamento ser considerado bom. 


\subsection{Definições}

Seja G um grafo não-dirigido qualquer, com $n$ vértices e $m$ arcos com pesos. Denotaremos por $c(e)$ o custo de um arco $e$. Um arco $e=(v, w)$ sai do vértice $v$ e entra no vértice $w$. Diremos que a cauda do arco $e$ é o vértice $v$, e a cabeça é o vértice $w$.

Um caminho é uma sequência de arcos, sem repetição. Denotaremos um caminho por $\left\langle v_{1}, v_{2}, \ldots, v_{l}\right\rangle$. Quando um caminho não apresenta vértices repetidos, chamamos de caminho simples. Diremos que o tamanho de um caminho é o número de vértices que o compõe. O custo de um caminho é a soma dos custos de seus arcos.

Dado um vértice $v$ qualquer, diremos que o grau de saída de $v$ é o número de arcos que possuem $v$ como cauda, e o grau de entrada de $v$ é o número de arcos que tem esse vértice como cabeça.

Uma arborescência é um grafo dirigido que tem um único vértice com grau de entrada zero, chamado de raiz, e todos os demais vértices tem grau de entrada exatamente igual a um. Os vértices desse grafo que possuem grau de saída igual a zero são chamados de folhas. Uma arborescência é a estrutura análoga a uma árvore dos grafos dirigidos.

\subsection{KSP na Literatura}

O Problema dos $K$ Menores Caminhos possui diversas variantes, como dito anteriormente. Existem diversas características do grafo de entrada que podemos fixar, e cada grupo de características define uma variante desse problema. Por exemplo, a que consideramos neste trabalho é a variante na qual o grafo de entrada é dirigido e com peso não-negativos nos arcos e na resposta queremos apenas caminhos simples, ou seja, caminhos sem repetição de vértices. Para essa variante, um dos trabalhos mais importantes é o artigo de Yen [Yen71], em que ele apresenta um dos primeiros algoritmos para a resolução desse problema, com complexidade $O(K n(m+n \log n))$. Esse artigo nos fornece uma redução do KSP para $O(K)$ instâncias do Problema dos Caminhos Substitutos (em inglês, Replacement Paths Problem), que discutiremos um pouco mais a frente. Por décadas, a complexidade obtida por Yen não foi superada por nenhum outro algoritmo, até 2009, quando Gotthilf e Lewenstein [GL09] apresentaram um algoritmo de complexidade $O(K n(m+n \log \log n))$. Esse último algoritmo explora um pré-processamento baseado no Problema dos Menores Caminhos Entre Todos os Pares de Vértices (em inglês, All-Pair-Shortest-Paths - APSP). A complexidade obtida por esse algoritmo depende muito da complexidade do algoritmo de APSP escolhido. Os melhores resultados para esse problema são os algoritmos desenvolvidos por Pettie [Pet04] e Chan [Cha07], com complexidades $O(n(m+n \log \log n))$ e $O\left(\frac{n^{3} \log ^{3} \log n}{\log ^{2} n}\right)$, respectivamente. A complexidade anunciada para o algoritmo de Gotthilf e Lewenstein supõe a utilização do algoritmo de Pettie, que é baseado na Árvore de Componentes de Thorup. Até onde sabemos, não é conhecida nenhuma implementação do algoritmo de Gotthilf e Lewenstein na complexidade certa, devido à dificuldade imposta por essa estrutura. Feng, que também estudou esse problema, alega ver um grande valor teórico nesse algoritmo, que diminuiu o limitante superior da complexidade do problema, mas que na prática, esperase um comportamento pior do que muitos outros algoritmos existentes [Fen14]. Acreditamos que essa variante é a mais interessante por ser mais geral, podendo ser utilizado para resolver muitas das outras.

O Problema dos Caminhos Substitutos é resolvido diversas vezes durante a execução do algoritmo de Yen. Nesse problema, desejamos encontrar um conjunto de caminhos substitutos, para os casos de não podermos utilizar o melhor caminho. Em um grafo $G$, e o melhor caminho $P$ que vai de $s$ a $t$, 
para cada arco do caminho $P$, queremos encontrar o melhor caminho que não utilize aquele arco. Este é o chamado "caminho substituto" para aquele arco. Podemos imaginar, de forma mais palpável, que uma rua foi interditada no melhor trajeto de casa para o trabalho. Nesse caso, precisamos encontrar o melhor caminho que não utilize a rua interditada. A redução do KSP para o Problema dos Caminhos Substitutos apresentada por Yen é utilizada por diversos outros algoritmos, que se focam em fazer um algoritmo melhor para o Problema dos Caminhos Substitutos apenas. É o caso dos algoritmos de Pascoal [Pas06] e Feng [Fen14] que serão explicados em detalhes nesse trabalho.

Quando o grafo de entrada não possui peso nos arcos mas o resto é igual à variante anterior, existem algoritmos mais eficientes que aproveitam essa característica. É o que fizeram Roditty e Zwick em seu artigo [RZ05], com um algoritmo probabilístico de complexidade $\tilde{O}(K m \sqrt{n})$. Uma contribuição importante desse artigo é a redução do Problema dos $K$ Menores Caminhos para $O(K)$ resoluções do Problema do Segundo Menor Caminho (em inglês, Second Shortest Path Problem) que seu algoritmo utiliza, permitindo que novos algoritmos possam ser elaborados estudando apenas o Problema do Segundo Menor Caminho.

Para grafos não-dirigidos, o melhor algoritmo foi desenvolvido por Katoh, Ibaraki e Mine [KIM82], com complexidade $O(K(m+n \log n))$. Este algoritmo nos interessa bastante, pois serviu de inspiração para Pascoal [Pas06] realizar uma alteração no algoritmo de Yen e criar, por observação e testes empíricos, um novo algoritmo. O algoritmo de Pascoal será explicado com detalhes nesse trabalho, no capítulo 3. Essa variante também foi foco do estudo da dissertação de mestrado de Pisaruk [Pis09], que nos serviu de inspiração para utilizar a descrição do algoritmo de Yen presente no capítulo 2. Sua dissertação foi motivada em um problema enfrentado por uma empresa de telecomunicações, cuja rede de cabeamento era full-duplex, ou seja, passava dados em ambos os sentidos. Pisaruk modelou essa rede como um grafo não-dirigido e implementou uma ferramenta cujo núcleo era o algoritmo de Katoh, Ibaraki e Mine.

Eppstein estudou uma generalização do $K S P$, em que o grafo de entrada é dirigido e pode possuir múltiplos arcos entre dois vértices, o que chamamos de multigrafos, e os caminhos na resposta podem ter repetições de vértices. O algoritmo proposto [Epp98] tem complexidade $O(m+n \log n+K)$, mas a resposta dos $K$ menores caminhos vem desordenada. Caso seja desejada a ordenação entre os $K$ menores caminhos, o pior caso passa para $O(m+n \log n+K \log K)$.

\subsection{Objetivos}

No presente trabalho, estudamos o Problema dos $K$ Menores Caminhos aplicado a grafos dirigidos, em que os arcos possuem peso e não são permitidos vértices repetidos na resposta. Para essa versão, três algoritmos chamaram bastante a atenção por serem uma evolução um do outro. O primeiro foi o algoritmo de Yen, em 1971. O segundo é o algoritmo apresentado por Pascoal, que utiliza técnicas baseadas no algoritmo de Katoh, Ibaraki e Mine para alterar o algoritmo de Yen e conseguir criar um "atalho" que funciona em algumas iterações do algoritmo. O terceiro é o algoritmo de Feng, que generaliza a ideia do algoritmo de Pascoal para funcionar em todas as iterações.

Esses três algoritmos foram estudados e descritos neste trabalho, e também implementados, para comparação de performance entre eles. Em especial, procura-se entender uma característica já vista nos estudos anteriores a respeito desses algoritmos: em alguns grafos, o algoritmo de Pascoal se comporta melhor que o algoritmo de Yen. Procuramos tentar entender em quais grafos o algoritmo antecessor ganha do sucessor, e quais são as características comuns desses casos. Além disso, a partir dos resultados 
preliminares obtidos nos testes, implementamos uma variante do algoritmo de Feng. Essa versão proposta incorpora a ideia de Pascoal novamente, procurando evitar a atualização das estruturas auxiliares do algoritmo de Feng em toda iteração.

\subsection{Organização desse trabalho}

Vamos descrever brevemente a organização do restante desse trabalho. Inicialmente, descreveremos os algoritmos de interesse. No capítulo 2, detalhamos o algoritmo de Yen utilizando uma linguagem diferente da utilizada no artigo original [Yen71]. Utilizamos as ideias de arborescência do artigo de Hershberger, Maxel e Suri [HMS07] para descrever o algoritmo, fornecendo uma descrição mais ilustrativa que acreditamos ser de melhor entendimento.

No capítulo 3, descrevemos o algoritmo de Pascoal [Pas06], utilizando a mesma linguagem adotada no capítulo anterior. Como o algoritmo de Pascoal é baseado no algoritmo de Yen, algumas partes do algoritmo foram explicadas apenas brevemente, por terem sido detalhas durante a explicação daquele algoritmo.

Descrevemos o algoritmo de Feng no capítulo 4 de uma forma bem próxima à utilizada pelo autor [Fen14], apesar de contar com algumas pequenas alterações em algumas definições para facilitar o entendimento e a implementação.

Seguimos com a descrição da implementação realizada dos algoritmos no capítulo 5. Nesse capítulo, mostramos alguns trechos de código, com o interesse de mostrar detalhes que influenciam a utilização de memória e processamento dos algoritmos. Descrevemos aqui a variante proposta, motivada pelos testes empíricos.

Finalmente, mostramos os resultados dos testes realizados no capítulo 6 , discutindo um pouco o significado dos dados obtidos, e nossas conclusões no capítulo 7 a respeito do estudo realizado. 


\section{Capítulo 2}

\section{Algoritmo de Yen}

\subsection{Visão Geral}

Em 1971, Yen [Yen71] propôs um algoritmo iterativo para resolver o $K S P$, que encontra um caminho em cada uma de suas iterações. Esse algoritmo recebe como entrada um grafo $G$ com peso nos arcos, vértices $s$ e $t$ e um inteiro $K>0$ e devolve os $K$ menores caminhos.

Em cada iteração, o algoritmo de Yen resolve $O(n)$ instâncias do Problema do Menor Caminho. Utilizando uma implementação eficiente de Dijkstra [Dij59], com complexidade $O(m+n \log n)$, em que $n$ é o número de vértices e $m$ o número de $\operatorname{arcos}$ de $G$, o algoritmo de Yen tem no pior caso complexidade $O(K n(m+n \log n))$, como detalharemos adiante.

Inspirados no artigo de Hershberger, Maxel e Suri [HMS07], utilizaremos uma arborescência para representar os caminhos da saída. Acreditamos que a descrição do algoritmo por meio dessa estrutura nos possibilita uma visualização mais intuitiva do seu funcionamento. O fato de tal ideia poder ser transportada para descrever outros algoritmos, como o de Yen, é uma excelente contribuição do artigo desses autores.

Uma arborescência é um grafo dirigido acíclico com um único vértice com grau de entrada zero, chamado de "raiz", e todos os outros vértices têm grau de entrada exatamente 1. Alguns vértices possuem grau de saída igual a zero, que serão chamados de "folhas". No nosso caso, cada vértice da arborescência será associado a um vértice do grafo original. O exemplo da figura 2.1 mostra um grafo $G$ e a arborescência da resposta contendo os 3 menores caminhos de $s$ a $t$ em $G$. Cada vértice da arborescência é associado a um vértice do grafo original $G$, mas cada vértice do grafo original pode ser associado a mais de um vértice da arborescência. Por exemplo, os vértices $c$ e $e$ da arborescência são associados ao vértice 4 do grafo $G$. Temos algumas associações que valem ser destacadas: a raiz $r$ da nossa arborescência, que é associada ao vértice $s$, e todas as folhas, que são associadas ao vértice $t$. Cada caminho da raiz a uma folha é associado a um caminho de $s$ a $t$ em $G$.

Além de ser uma representação da resposta, essa arborescência também nos permite particionar $\mathcal{P}_{G}(s, t)$, o conjunto de todos os caminhos de $s$ a $t$. Cada vértice $v$ da arborescência é associado a um subconjunto de $\mathcal{P}_{G}(s, t)$ dos caminhos cujo prefixo é associado aos vértices de $r$ a $v$ na arborescência, e que não seguem com os vértices associados aos apontados por $v$ na arborescência. No exemplo da figura 2.1, o vértice $c$ da arborescência é associado ao vértice 4 do grafo $G$. Esse vértice $c$ é associado ao conjunto dos 

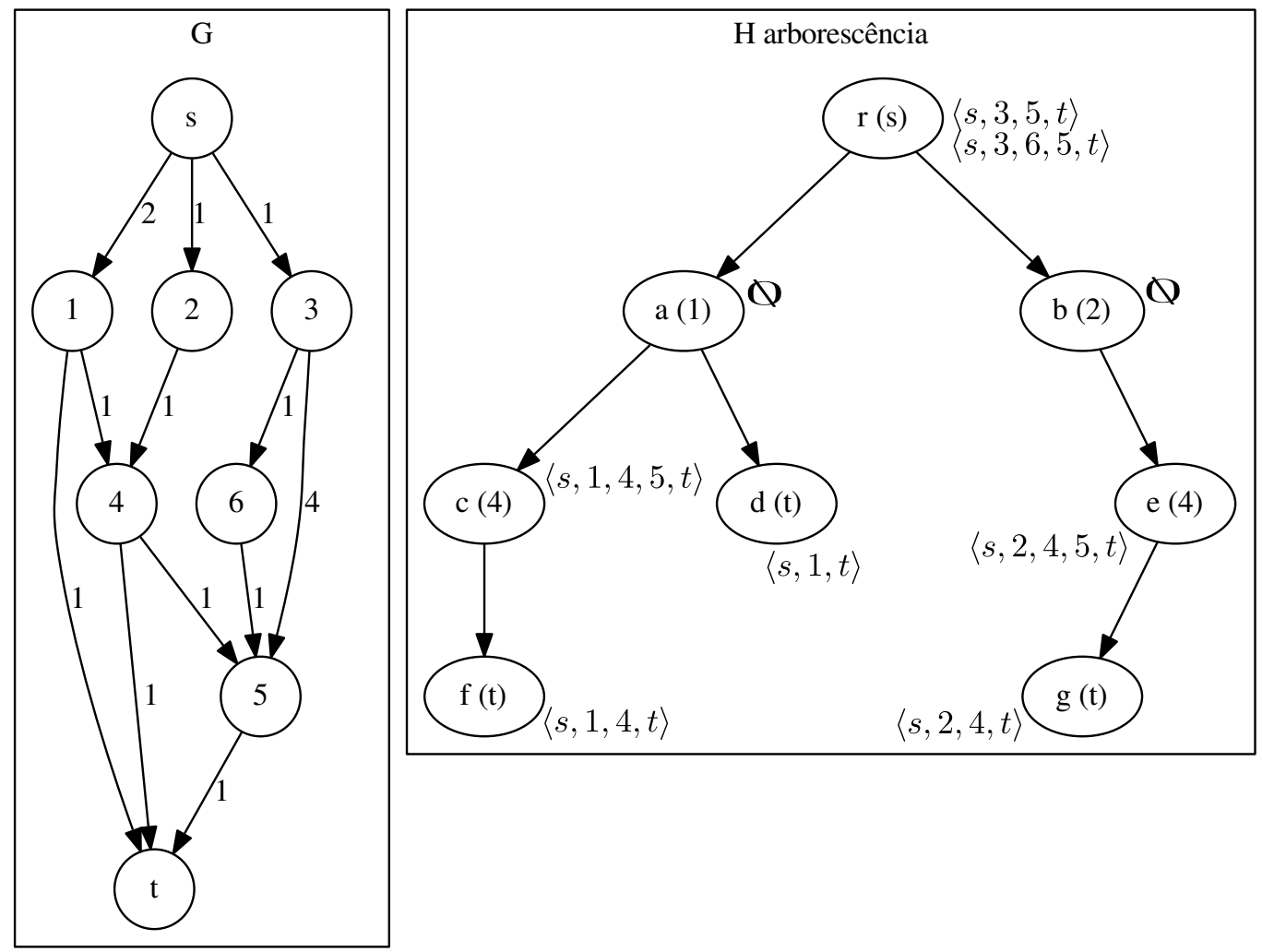

Figura 2.1: Exemplo de arborescência com 3 caminhos na resposta, com todos os seus conjuntos associados destacados

caminhos que possuem o prefixo $\langle s, 1,4\rangle$ e que não usam o arco $(4, t) \in G$, que no nosso caso é apenas o caminho $\langle s, 1,4,5, t\rangle$. A raiz $r$, por sua vez, é associada ao conjunto $\{\langle s, 3,5, t\rangle,\langle s, 3,6,5, t\rangle\}$, que são os caminhos que começam em $s$ e não seguem pelos arcos $(s, 1)$ e $(s, 2)$. Cada folha é associada a um conjunto de apenas um elemento: o caminho em $\mathrm{G}$ associado ao caminho na arborescência da raiz àquela folha, por exemplo, o conjunto associado ao vértice $f$ é formado apenas pelo caminho $\langle s, 1,4, t\rangle$. Como dissemos, esses conjuntos formam uma partição do conjunto de todos os caminhos de $s$ a $t$, tendo a interseção de quaisquer dois conjuntos associados sempre vazia e a união de todos eles formando o conjunto $\mathcal{P}_{G}(s, t)$.

Se considerarmos apenas a união dos conjuntos associados aos vértices não-folhas, o conjunto resultante é composto pelos caminhos que não estão presentes na resposta. Utilizando essa propriedade, podemos encontrar um próximo menor caminho a entrar na resposta. Para cada vértice não-folha da árvore, mantemos o menor caminho do conjunto de caminhos associados a ele. A cada iteração, escolhemos dentre eles o menor e o inserimos na resposta. Com a entrada de um caminho novo na árvore, novos conjuntos surgirão. Por exemplo, na figura 2.2 temos a inserção do caminho $\langle s, 3,6,5, t\rangle$. Neste passo serão incluídos os vértices $l, o, p$ e $q$ na arborescência. Esse caminho estava no conjunto de caminhos associado ao vértice raiz $r$. Após sua inserção na arborescência, o conjunto associado ao vértice $r$ deve sofrer uma alteração. Todos os caminhos que seguem pelo arco $(r, 3)$ devem mudar de conjunto. No caso, o único caminho restante no conjunto é $\langle s, 3,5, t\rangle$, que deve passar a pertencer ao conjunto associado ao vértice $l$. 

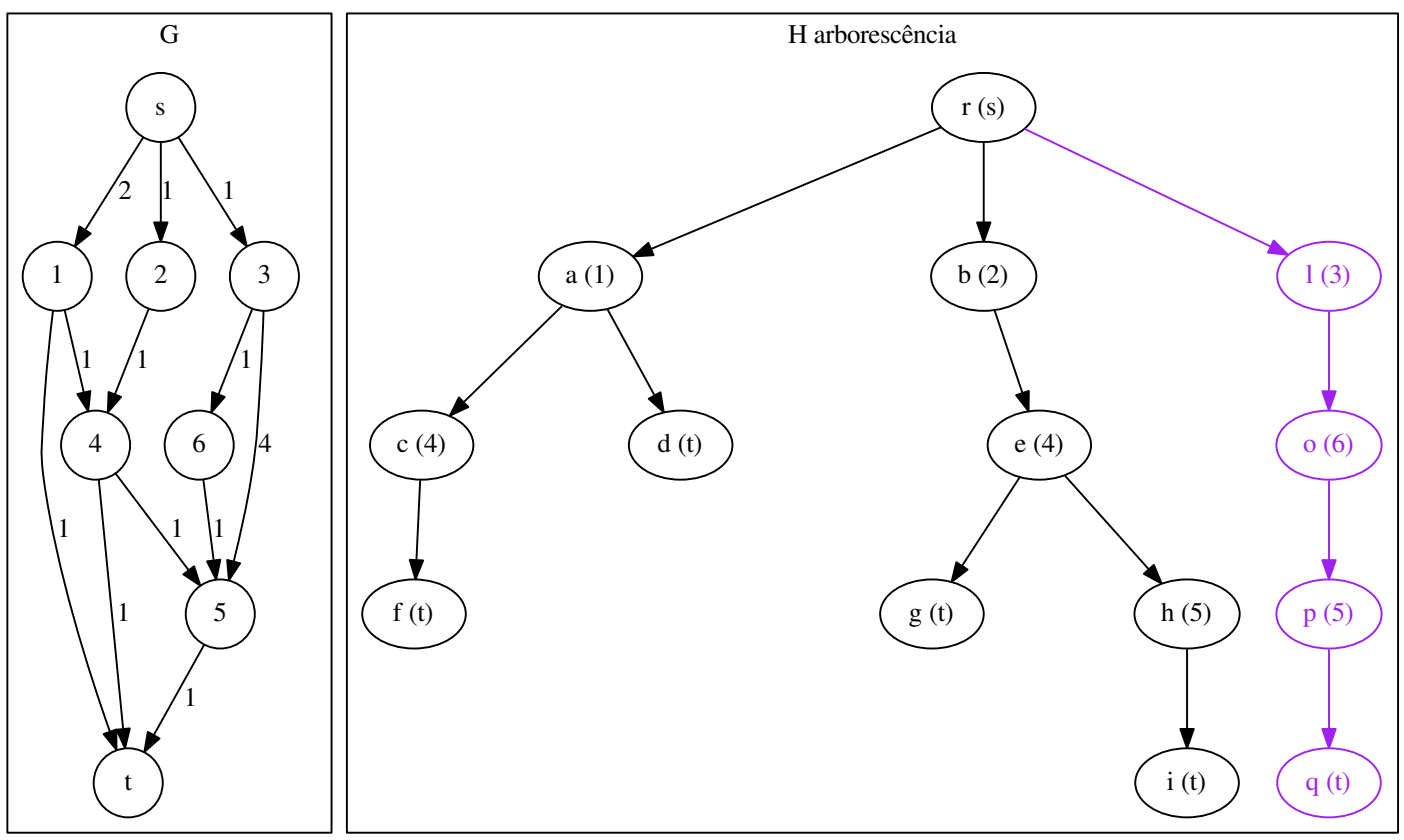

Figura 2.2: Inclusão do quinto menor caminho na arborescência

\subsection{Iterações do algoritmo}

A cada iteração, o algoritmo escolhe um caminho para entrar na resposta e isso causa uma alteração nos conjuntos associados aos vértices da arborescência. Nessa seção, detalharemos como esses passos acontecem, tentando nos aproximar mais de uma descrição que permita uma implementação do algoritmo.

Chamaremos de candidatos os menores caminhos de cada conjunto associado aos vértices não-folha. Chamaremos de resposta o conjunto formado pelos candidatos escolhidos em cada iteração como menores e, consequentemente, que possuem caminhos nos conjuntos associados às folhas da arborescência.

Seja $G=(V, E)$ o grafo de entrada do algoritmo e suponha estarmos em uma iteração qualquer do algoritmo de Yen. Escolhemos o menor dentre os candidatos para entrar na resposta. Chamemos esse caminho de $P_{m}$. A inserção desse caminho na resposta causa a alteração de um conjunto associado e a possível criação de novos conjuntos. Para cada um desses conjuntos, encontraremos um caminho candidato resolvendo uma instância do Problema do Menor Caminho em um subgrafo de $G$ que definiremos a seguir.

Explicando por meio de um exemplo, na figura 2.3, o caminho $P_{m}$ que entrou na resposta é $\langle s, 2,4, t\rangle$. Com a entrada desse caminho na resposta, precisamos encontrar os candidatos dos conjuntos associados aos vértices $r, b$ e $e$ da arborescência. Essa imagem está retratando a geração do candidato do conjunto associado ao vértice $e$, e o único arco que sai desse vértice na arborescência é o arco $(e, g)$, que é associado ao arco $(4, t)$. Relembrando, o candidato desse conjunto deve usar o prefixo $\langle s, 2,4\rangle$ e não pode usar arcos associados àqueles que já estejam na arborescência. Então removemos de $G$ o arco $(4, t)$. Para garantir que não encontraremos vértices repetidos, também removemos de $G$ os vértices $s$ e 2 e procuramos nesse subgrafo de $G$ um menor caminho de 4 até $t$. Juntamos o prefixo $\langle s, 2,4\rangle$ com esse caminho encontrado para formar o candidato $\langle s, 2,4,5, t\rangle$ do conjunto associado ao vértice $e$. 

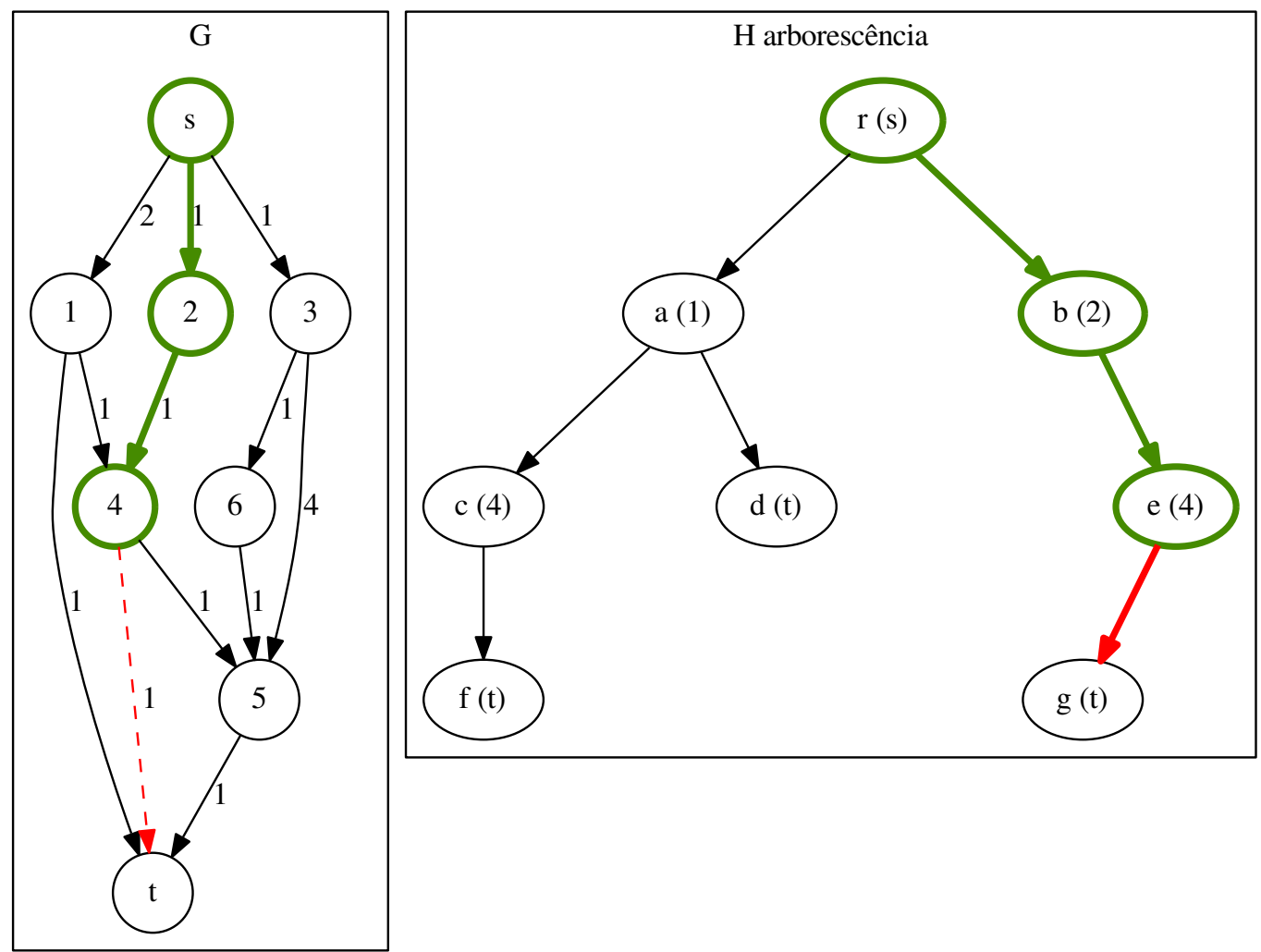

Figura 2.3: Inserção do caminho $P_{m}=\langle s, 2,4, t\rangle$ na resposta. Geração de candidato do conjunto associado ao vértice $e$.

Para encontrarmos o candidato do conjunto associado a um vértice $z$ qualquer da arborescência, olhamos para os arcos que saem de $z$ na arborescência e removemos de $G$ o arco associado.

Ou seja, suponhamos que estamos gerando os candidatos do conjunto associado a um vértice $z$ da arborescência. Digamos que $z$ está associado ao vértice $v$ da arborescência. Então $v$ é o vértice de desvio dessa geração de candidato. Seja $H$ uma cópia de $G$. Olhamos para o conjunto de arcos que saem de $z$ na arborescência e removemos de $H$ os arcos associados. Removemos também todos os vértices anteriores ao vértice de desvio $v$ e procuramos, a partir desse vértice, um menor caminho até $t$ utilizando o algoritmo de Dijkstra. O candidato desse conjunto é o resultado da concatenação do prefixo fixado com o caminho encontrado por essa instância do Problema do Menor Caminho.

Vale destacar a inicialização do algoritmo. No início, temos uma arborescência de apenas um nó, a raiz. O conjunto associado à raiz, neste momento, é $\mathcal{P}_{G}(s, t)$, e o candidato desse conjunto é o menor caminho de $s$ a $t$ em $G$, que pode ser encontrado em uma execução do algoritmo de Dijsktra. 


\subsection{Corretude e complexidade}

Tanto a corretude como a complexidade do algoritmo são fáceis de demonstrar com essa estrutura de resposta. Cada caminho que entra na arborescência acrescenta no máximo seu tamanho em vértices novos. Um caminho em $G$ pode ter no máximo tamanho $n$. Para cada vértice novo na arborescência, precisaremos resolver uma instância do Problema do Menor Caminho. Podemos utilizar uma implementação do algoritmo de Dijkstra com Fibonacci heap, que tem complexidade $O(m+n \log n)$ [FT87, CLRS01]. Realizamos $K$ inserções de caminhos na arborescência. Portanto, a complexidade no pior caso desse algoritmo é, como dito, $O(K n(m+n \log n))$.

Para mostrar que o algoritmo funciona, basta lembrar que os conjuntos associados aos vértices nãofolhas da arborescência correspondem a uma partição do conjunto $\mathcal{P}_{G}(s, t) \backslash \mathcal{R}$, onde $\mathcal{R}$ representa os caminhos presentes na resposta naquele momento. O menor elemento de um conjunto é o menor dentre os menores de cada partição. Portanto, a cada iteração, de fato escolhemos o menor caminho que ainda não está na resposta.

\subsection{Simulação}

Iremos exemplificar o funcionamento do algoritmo de Yen, exibindo o caminho inserido na resposta e a arborescência em cada iteração. Considere o grafo $G$, com 11 vértices e 19 arcos, como exibido na imagem 2.4. A arborescência $H$, inicialmente, contém apenas o vértice raiz. Esse vértice é associado ao vértice $s$ de $G$ e o conjunto associado a ele contém todos os caminhos de $s$ a $t$.

Nas figuras 2.5, a 2.16 são mostradas as iterações do algoritmo de Yen, encontrando todos os 12 caminhos de $s$ a $t$ no grafo $G$. Destacamos em cada iteração o caminho acrescentado na resposta e seu correspondente na arborescência.

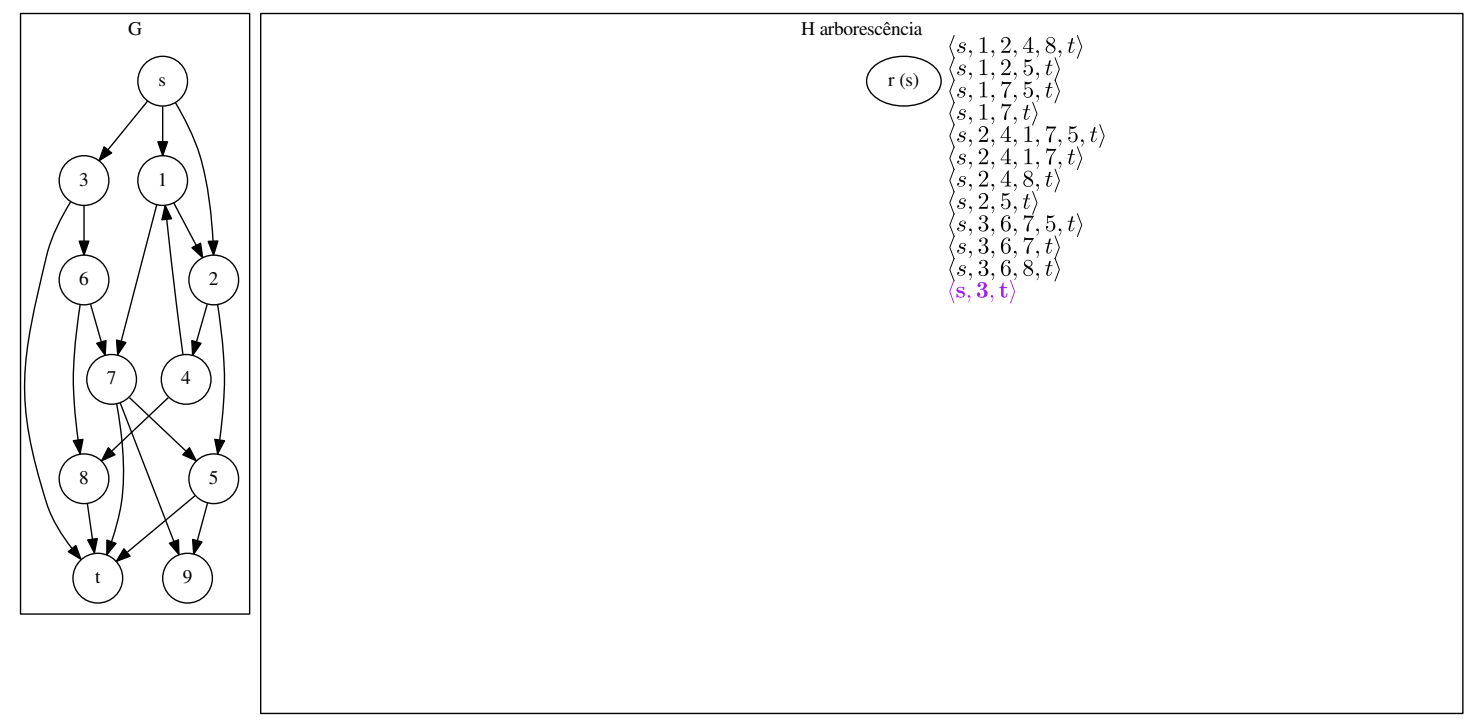

Figura 2.4: Situação inicial. Há somente uma classe, associada ao vértice $r$, que contém todos os caminhos de $s$ a $t$. O menor caminho é encontrado utilizando Dijkstra no grafo $G$. 


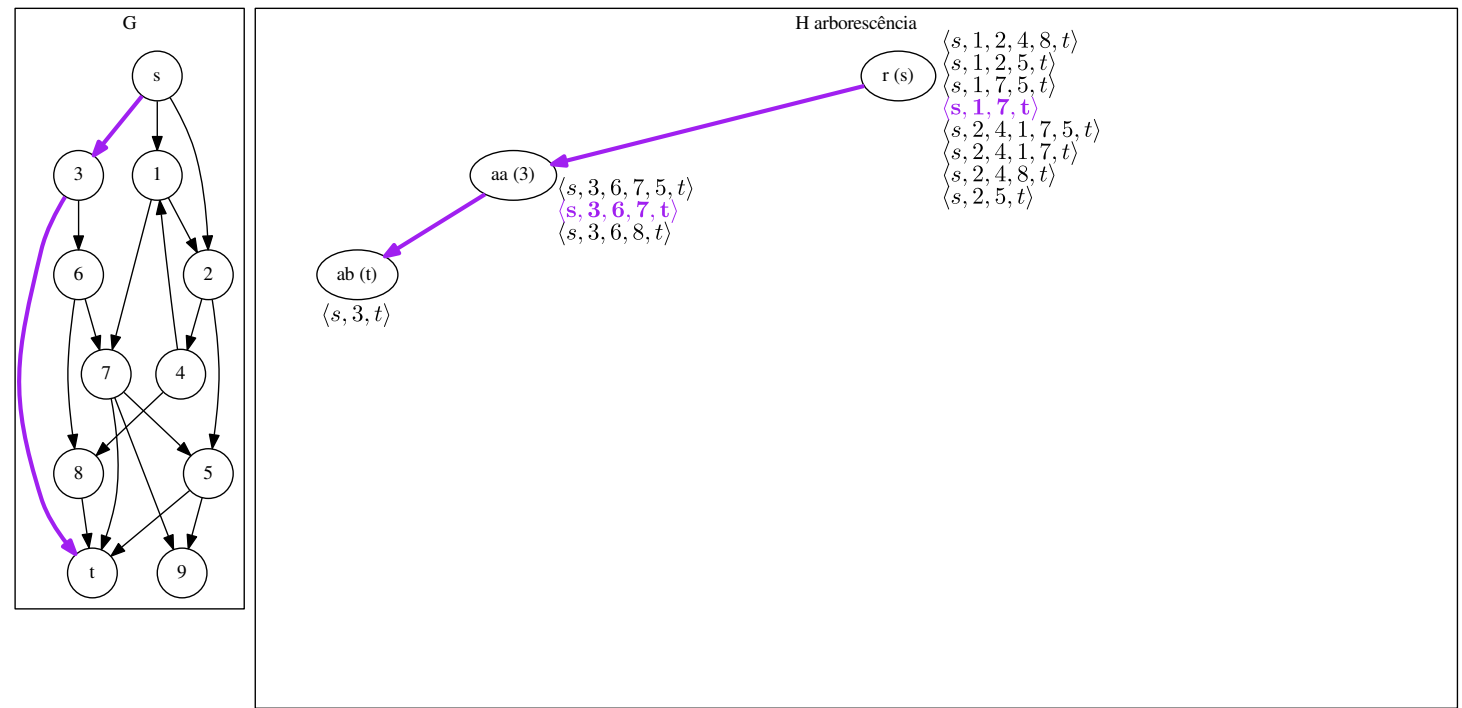

Figura 2.5: Inserção do menor caminho $\langle s, 3, t\rangle$. O conjunto associado ao vértice $r$ é alterado e os conjuntos associados aos vértices $a a$ e $a b$ são criados, contendo caminhos que antes estavam no conjunto associado ao vértice $r$. Os menores caminhos dos conjuntos associados aos vértices $r$ e $a a$ são encontrados utilizando algoritmo de Dijkstra nos subgrafos associados. O conjunto associado ao vértice $a b$ é formado apenas pelo caminho $\langle s, 3, t\rangle$, que acabou de ser inserido na resposta.
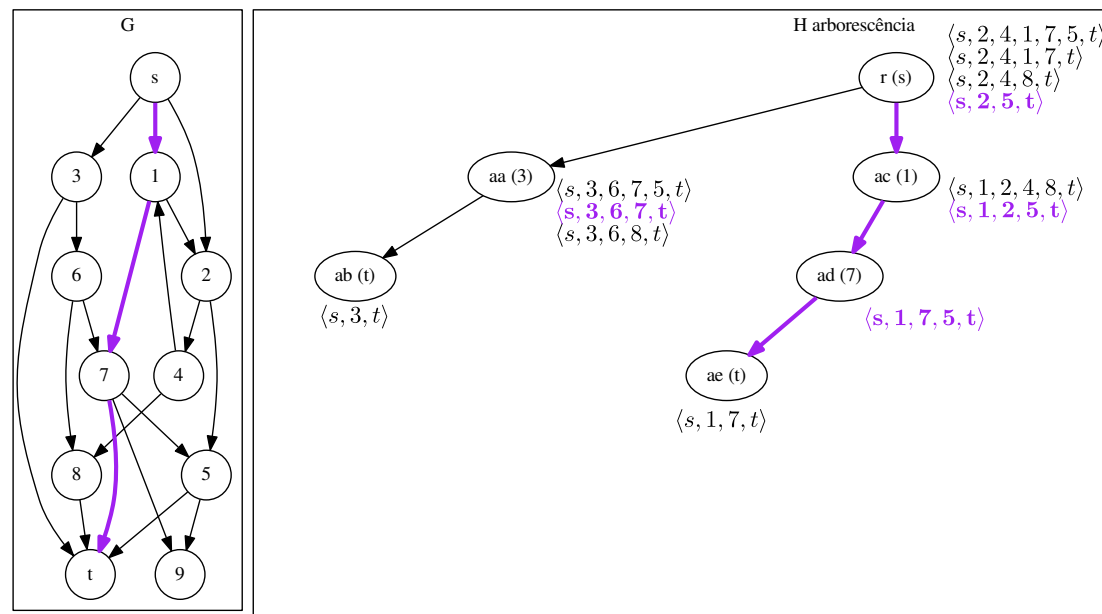

Figura 2.6: Inserção do segundo menor caminho $\langle s, 1,7, t\rangle$. O conjunto associado ao vértice $r$ é ajustado, os conjuntos associados aos vértices $a c$ e $a d$ são criados e os menores caminhos desses conjuntos são encontrados. 


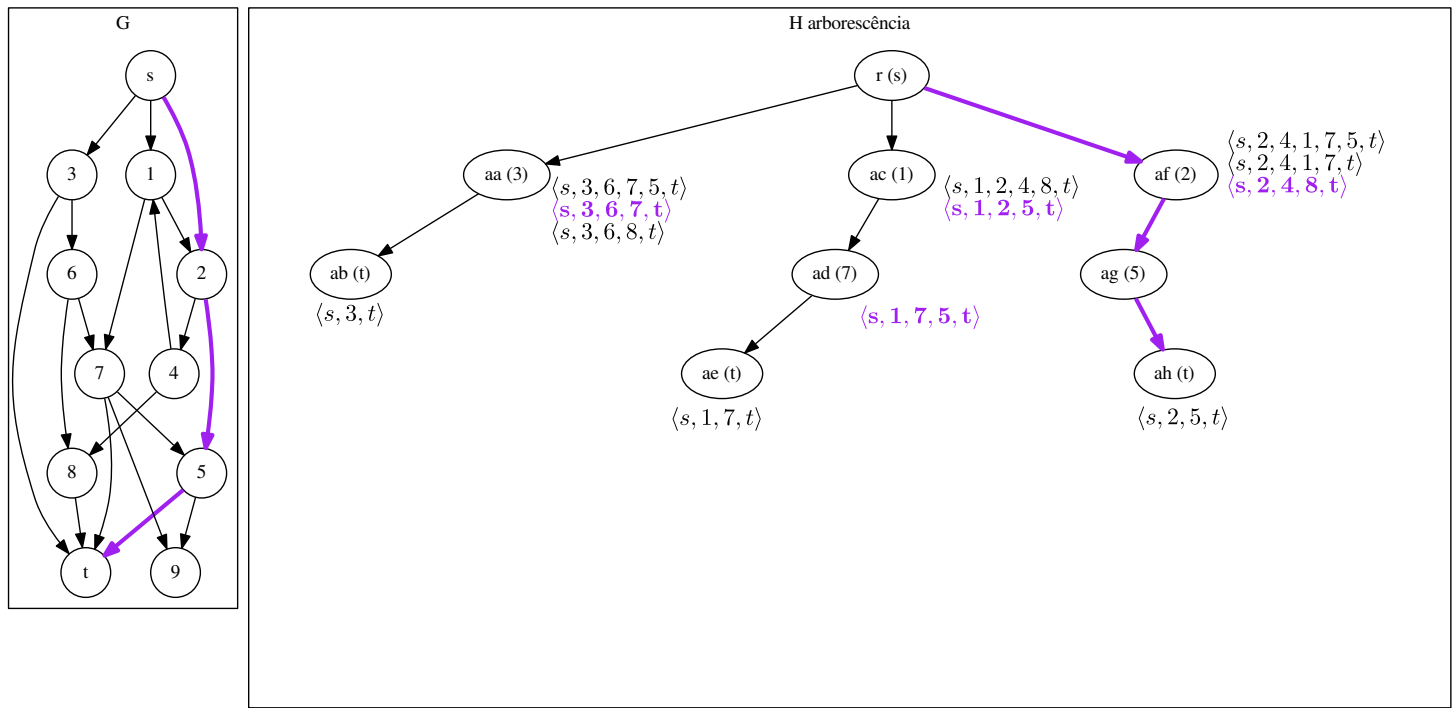

Figura 2.7: Inserção do terceiro menor caminho $\langle s, 2,5, t\rangle$. Nesse momento, todas os arcos de $G$ que começam em $s$ já estão na arborescência $H$, e o conjunto associado ao vértice $r$ fica vazio, assim como o conjunto associado ao vértice $a g$.

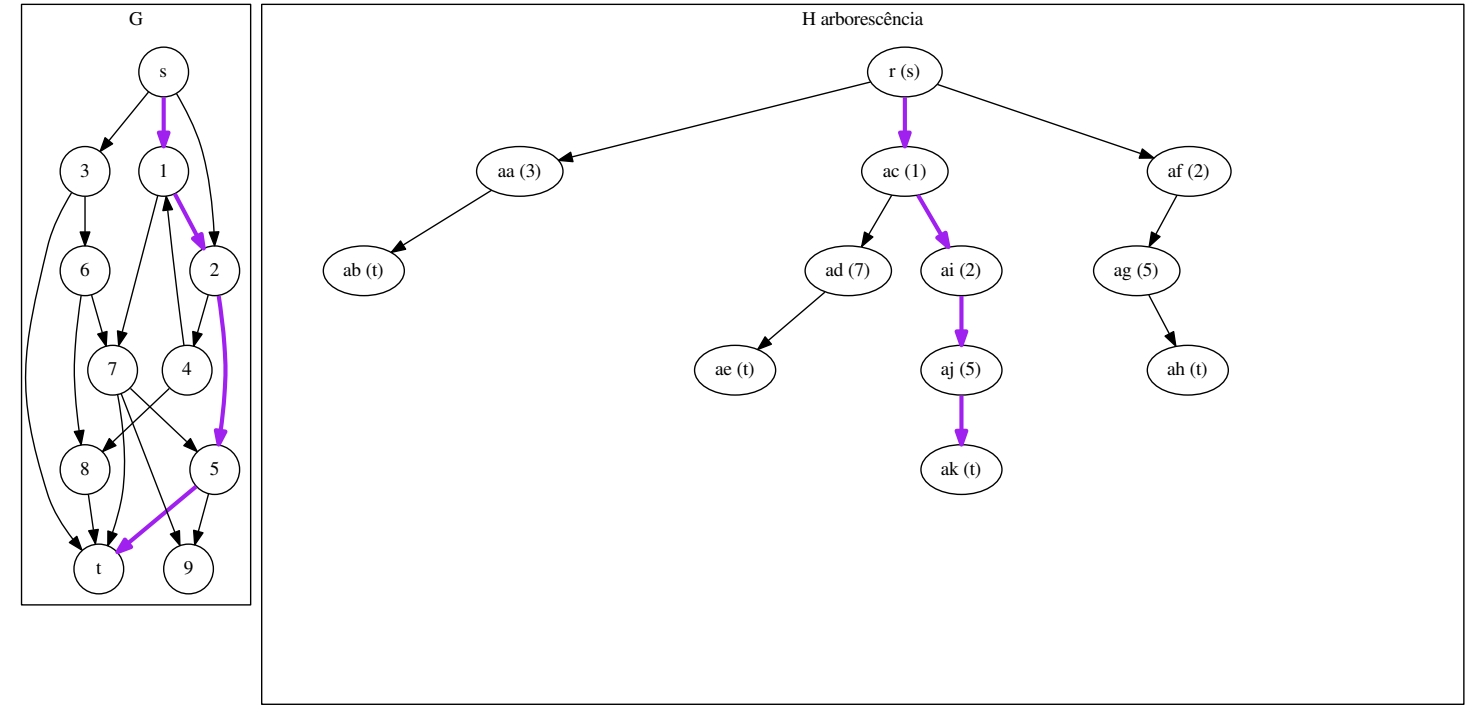

Figura 2.8: Inserção do quarto menor caminho $\langle s, 1,2,5, t\rangle$ 


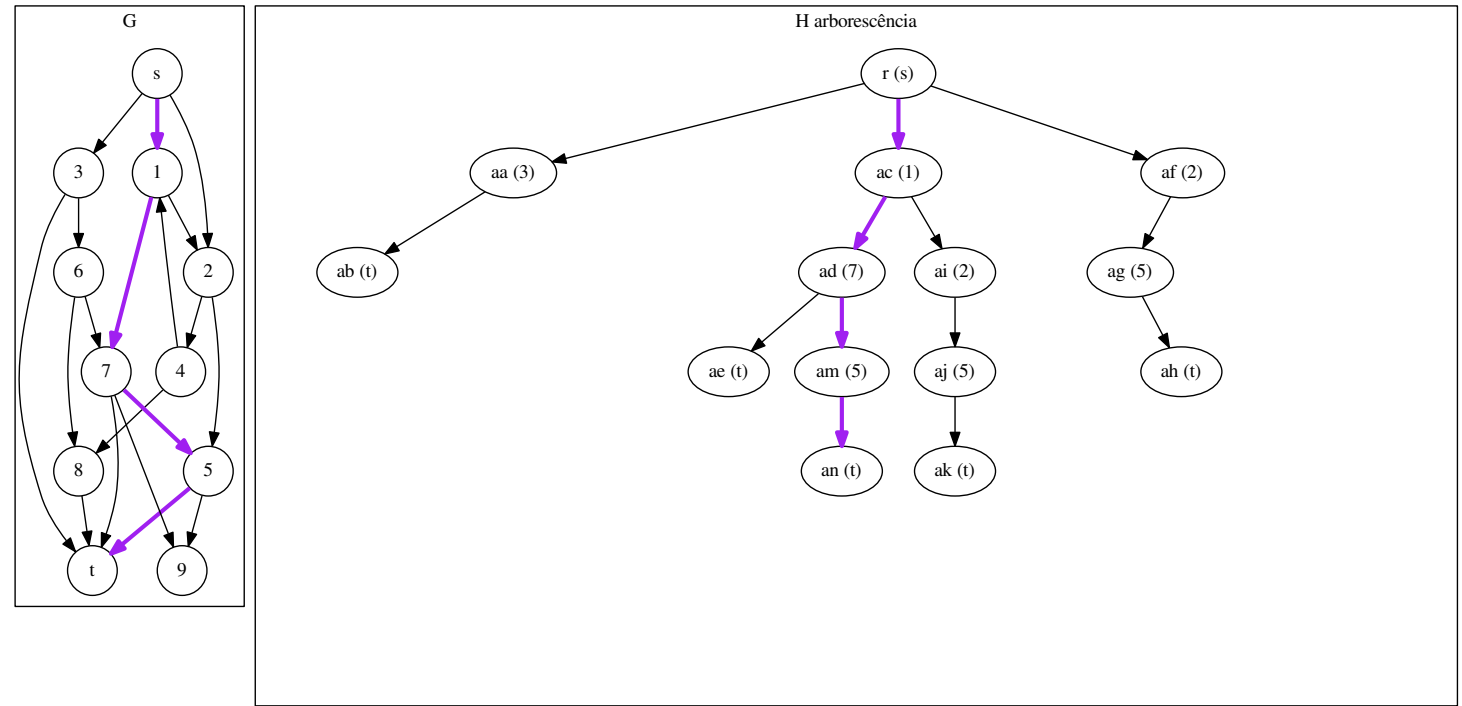

Figura 2.9: Inserção do quinto menor caminho $\langle s, 1,7,5, t\rangle$

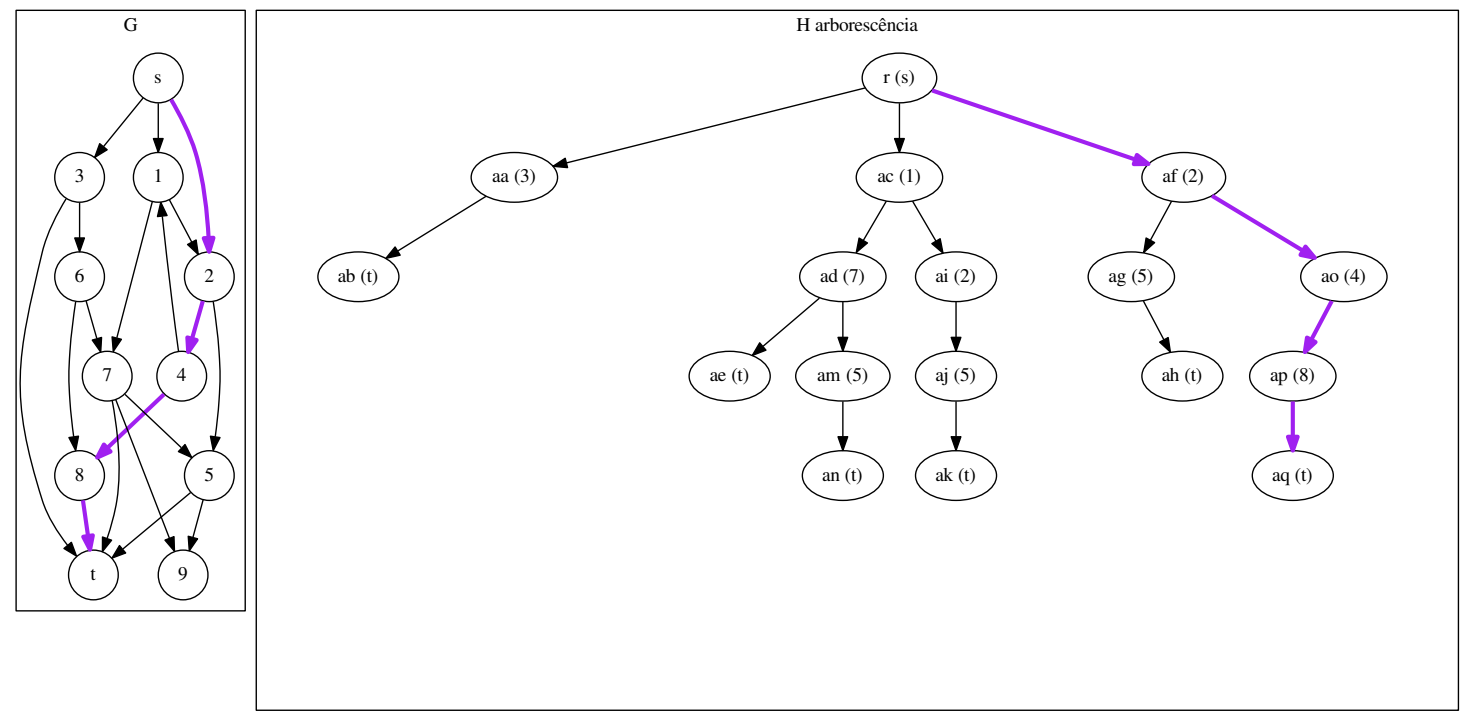

Figura 2.10: Inserção do sexto menor caminho $\langle s, 2,4,8, t\rangle$ 

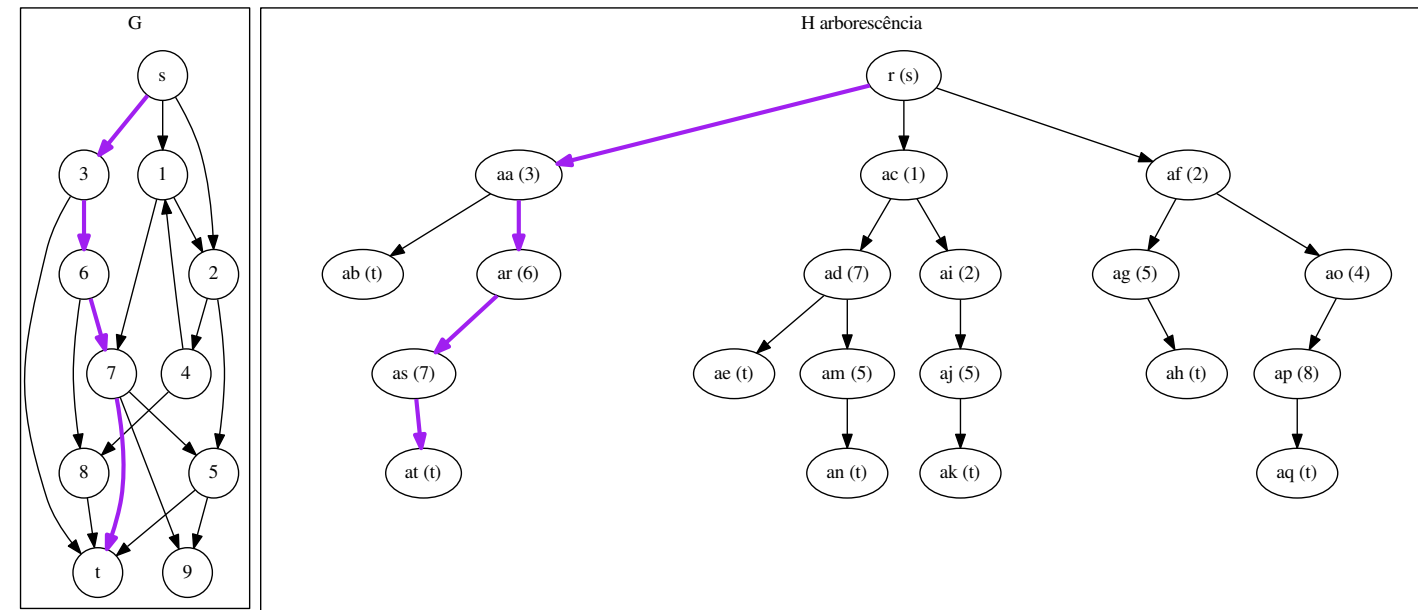

Figura 2.11: Inserção do sétimo menor caminho $\langle s, 3,6,7, t\rangle$
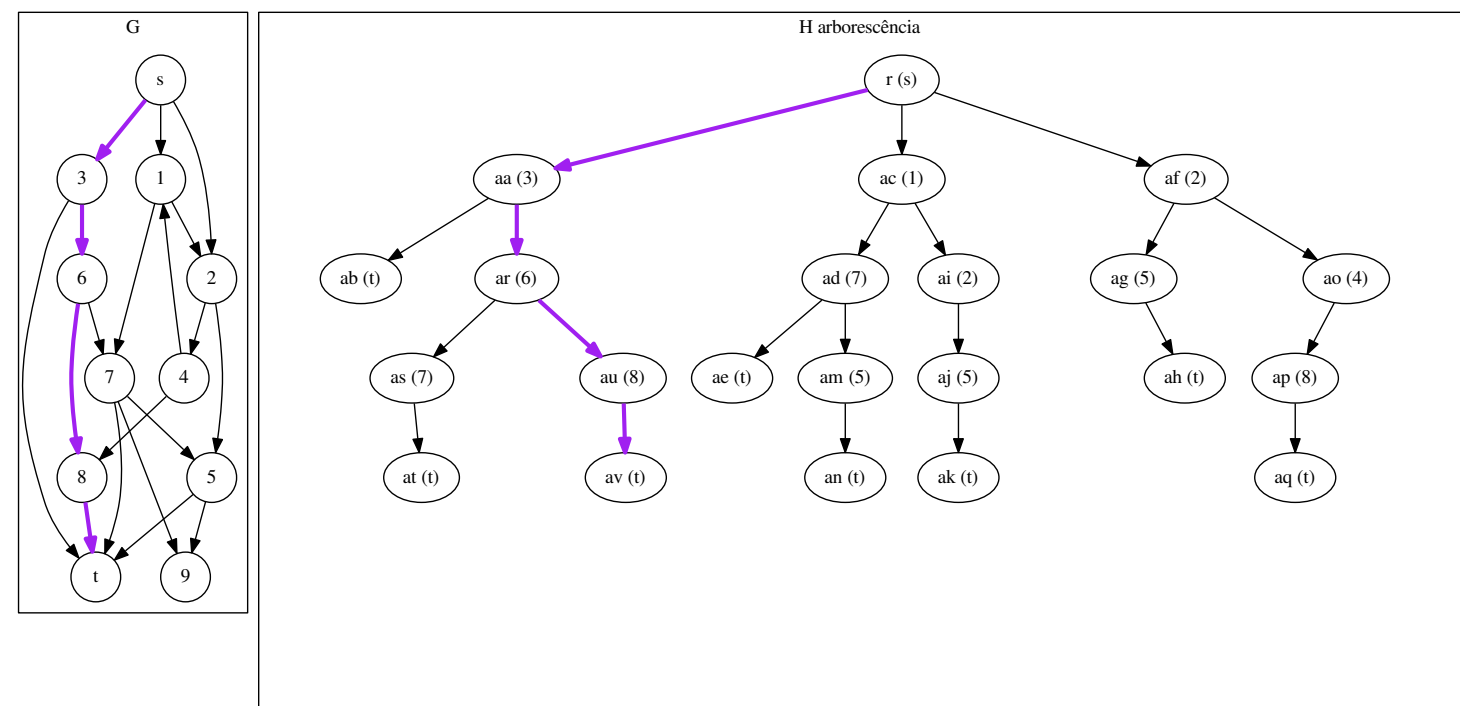

Figura 2.12: Inserção do oitavo menor caminho $\langle s, 3,6,8, t\rangle$ 


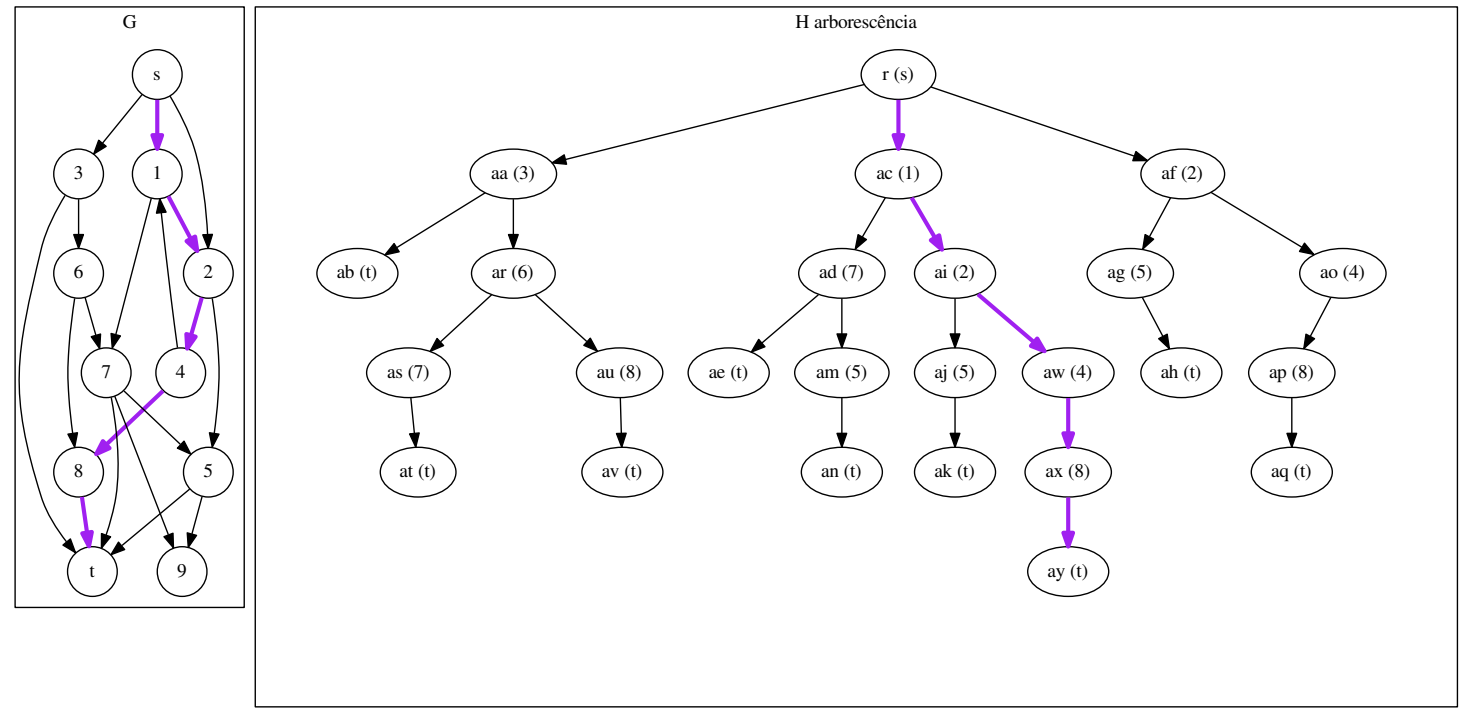

Figura 2.13: Inserção do nono menor caminho $\langle s, 1,2,4,8, t\rangle$

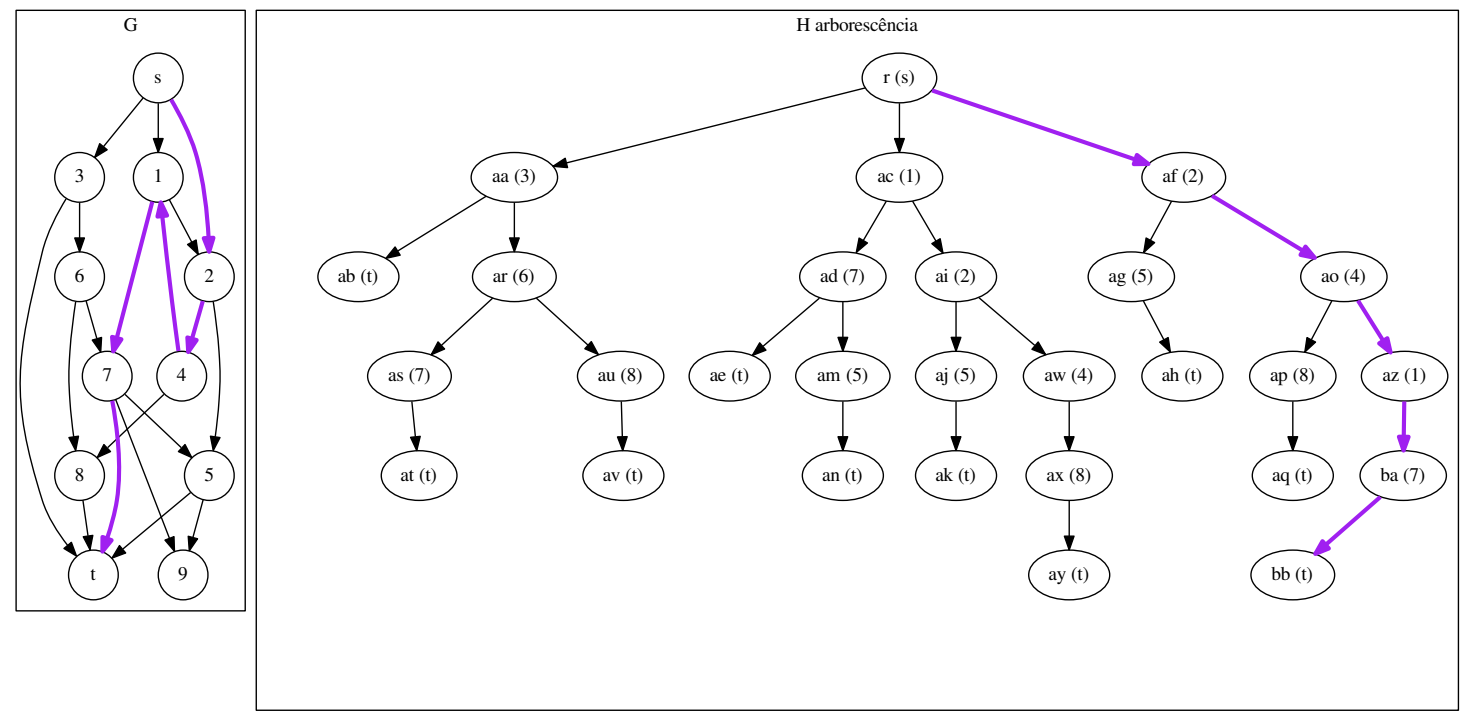

Figura 2.14: Inserção do décimo menor caminho $\langle s, 2,4,1,7, t\rangle$ 


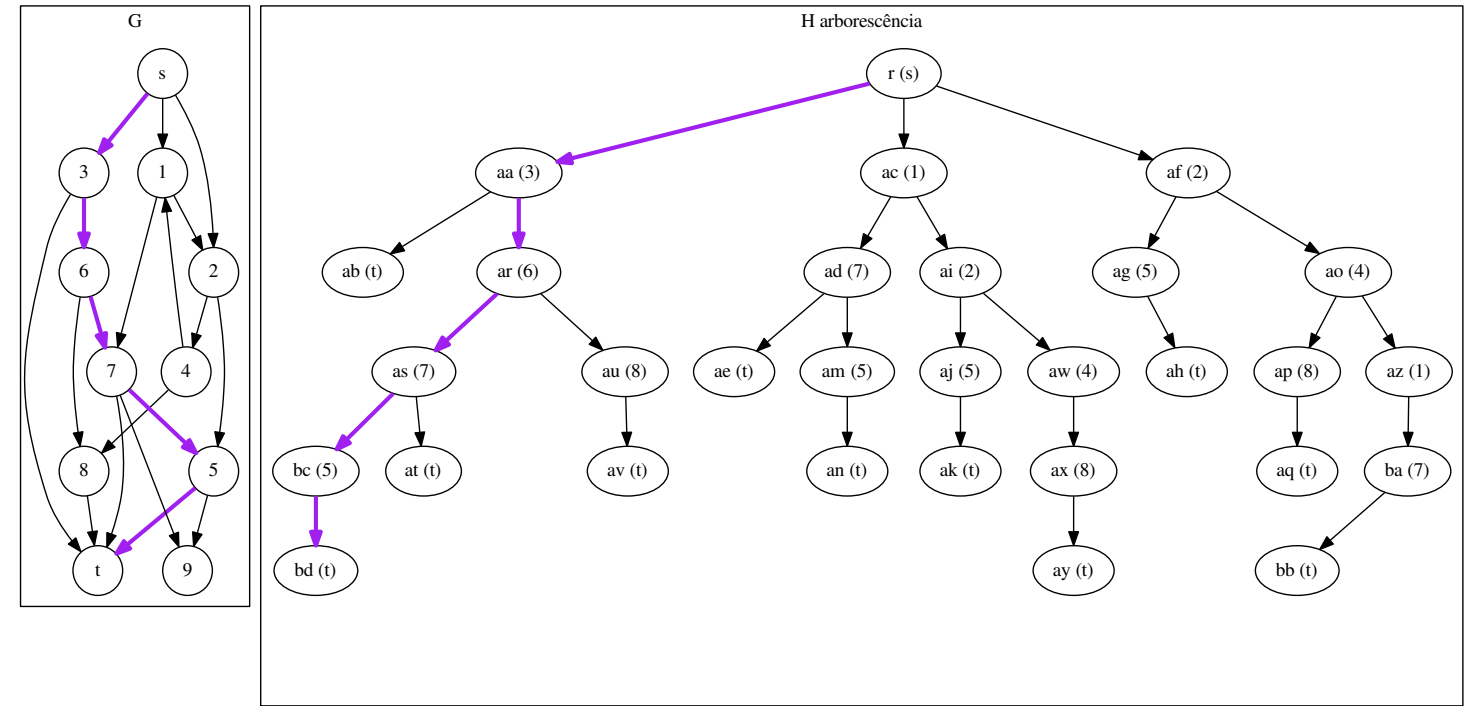

Figura 2.15: Inserção do décimo primeiro menor caminho $\langle s, 3,6,7,5, t\rangle$

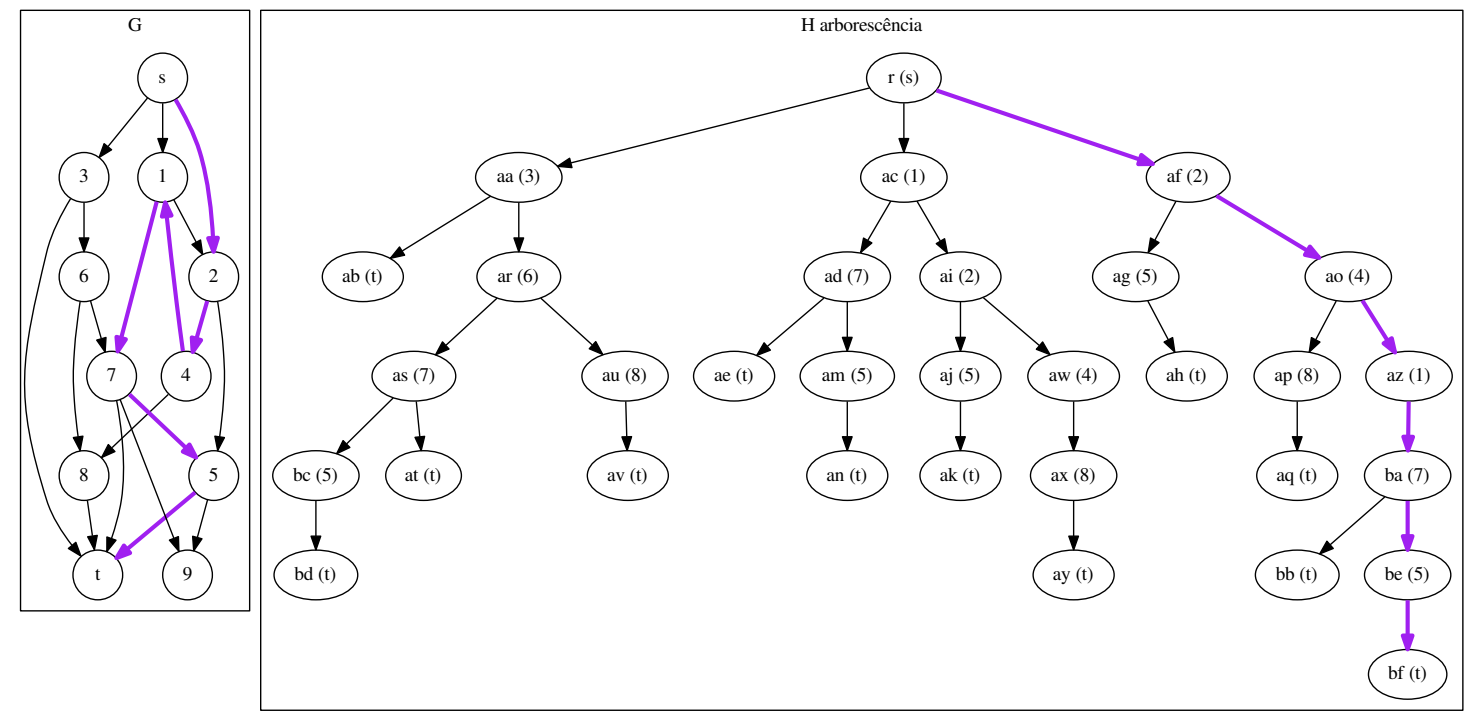

Figura 2.16: Inserção do décimo segundo menor (também o maior) caminho $\langle s, 2,4,1,7,5, t\rangle$ 


\section{Capítulo 3}

\section{Algoritmo de Pascoal}

\subsection{Visão Geral}

Marta Pascoal escreveu em 2006 um artigo [Pas06] fazendo uma comparação entre alguns algoritmos para resolver o KSP. Dentre os algoritmos que ela apresentou, estava o algoritmo de Katoh, Ibaraki e Mine [KIM82]. Esses autores apresentaram uma maneira de resolver o KSP somente em grafos nãodirecionados, mas Pascoal se inspirou em suas ideias para criar um algoritmo que resolve a variante do $K S P$ de nosso interesse.

O algoritmo desenvolvido por essa autora apresenta uma maneira de reduzir o número de execuções do algoritmo de Dijkstra durante o algoritmo de Yen. Isso se dá ao custo de um pré-processamento e maior gasto de memória. Pascoal constrói em seu pré-processamento um grafo dirigido acíclico (DAG) dos menores caminhos de cada vértice de $G$ até $t$, que chamaremos de $\mathcal{T}_{t}$. Utilizaremos a notação $\mathcal{T}_{t}(v)$ para nos referir ao menor caminho de $v$ até $t$ nesse DAG. Com essa estrutura, podemos evitar algumas execuções do algoritmo de Dijkstra, escolhendo apenas um arco, como explicaremos a seguir.

Ao inserir um novo caminho encontrado no conjunto resposta, precisamos encontrar o menor caminho de diversos conjuntos associados a vértices da arborescência. Para cada vértice da arborescência, o algoritmo de Yen procura o menor caminho que utiliza o prefixo até aquele vértice, mas que não segue por nenhum arco associado aos presentes na arborescência. O algoritmo de Pascoal também procura um menor caminho, mas utiliza a seguinte estratégia. Suponha que estamos procurando um menor caminho do conjunto associado ao vértice $w$ pertencente à arborescência. Digamos que esse vértice $w$ é associado ao vértice $v$ de $G$. Para cada $\operatorname{arco}(v, z)$ de $G$ que não tem um arco saindo de $w$ associado na arborescência, construímos a trilha $T=\operatorname{prefix}(s, v) \diamond(v, z) \diamond \mathcal{T}_{t}(z)$, formada pelo prefixo em $G$ associado ao caminho de $r$ a $w$ na arborescência concatenado ao $\operatorname{arco}(v, z)$ e ao menor caminho de $z$ até $t$, que podemos obter pelo DAG criado no pré-processamento. Se a menor trilha não contiver repetição de vértices, então ela é o caminho candidato desse conjunto, e evitamos a execução do algoritmo de Dijkstra. Caso contrário, voltamos à estratégia de Yen e procuramos o menor caminho no subgrafo desse conjunto.

Para que a escolha do arco seja feita de forma rápida, temos a necessidade de outro passo no préprocessamento. Desejamos escolher o arco que forneça a menor trilha, como explicado acima. O custo dessa trilha é a soma do custo do caminho de $s$ ao vértice $v$ com o custo do arco $(v, z)$ e com o custo de $\mathcal{T}_{t}(z)$. Para termos acesso mais rápido ao melhor arco, podemos substituir o custo de cada arco por um 
novo valor, chamado de custo reduzido, que indicará o melhor arco por uma comparação simples entre seus valores. O custo reduzido será definido melhor adiante.

\subsection{O pré-processamento}

Para o funcionamento do algoritmo, precisamos criar um DAG dos menores caminhos de cada vértice de $G$ até $t$. Para criá-lo, vamos partir de um grafo auxiliar baseado no grafo $G$, que chamaremos de $H$. O grafo $H$ tem o mesmo conjunto de vértices de $G$, mas tem os arcos invertidos. Ou seja, se $(v, w)$ era um arco em $G$, então o arco $(w, v)$ está em $H$. Precisamos resolver em $H$ o problema dos menores caminhos para todos os vértices a partir de uma única fonte, no nosso caso o vértice $t$, que pode ser resolvido usando o algoritmo de Dijkstra. Então criamos a árvore de todos os menores caminhos a partir de $t$ até cada vértice em $H$.

Agora podemos definir o DAG $\mathcal{T}_{t}$ desejado nesse pré-processamento utilizando a árvore de menores caminhos encontrada em $H$. Para isso, invertemos a orientação dos arcos dessa árvore. Para cada arco $(v, w)$ na árvore de caminhos mínimos a partir de $t$ em $H$, colocamos o arco $(w, v)$ no DAG $\mathcal{T}_{t}$. O menor caminho de um vértice $v$ qualquer até $t$ pode ser encontrado consultando o único caminho de $v$ até $t$ nesse DAG, e denotaremos esse caminho por $\mathcal{T}_{t}(v)$. Com esse DAG criado, podemos definir o custo reduzido. O custo reduzido de um arco $(v, w)$ será denotado por $\bar{c}((v, w))$ e tem valor igual a $c\left(\mathcal{T}_{t}(w)\right)-c\left(\mathcal{T}_{t}(v)\right)+c((v, w))$. Como dito anteriormente, o custo reduzido tem como objetivo fornecer uma maneira eficiente de escolher o arco que fornece a melhor trilha sem precisar calcular o custo de cada trilha possível. A trilha com menor custo corresponde à trilha formada pela escolha do arco com menor custo reduzido. Para explorar essa propriedade, trocamos o custo de cada arco por seu custo reduzido. Vamos provar adiante, na seção 3.4, que essa troca não altera a resposta do problema e que ela, de fato, permite a escolha da melhor trilha.

Ao final desse pré-processamento, podemos escolher a melhor trilha usando um prefixo apenas analisando alguns arcos e o custo reduzido. 

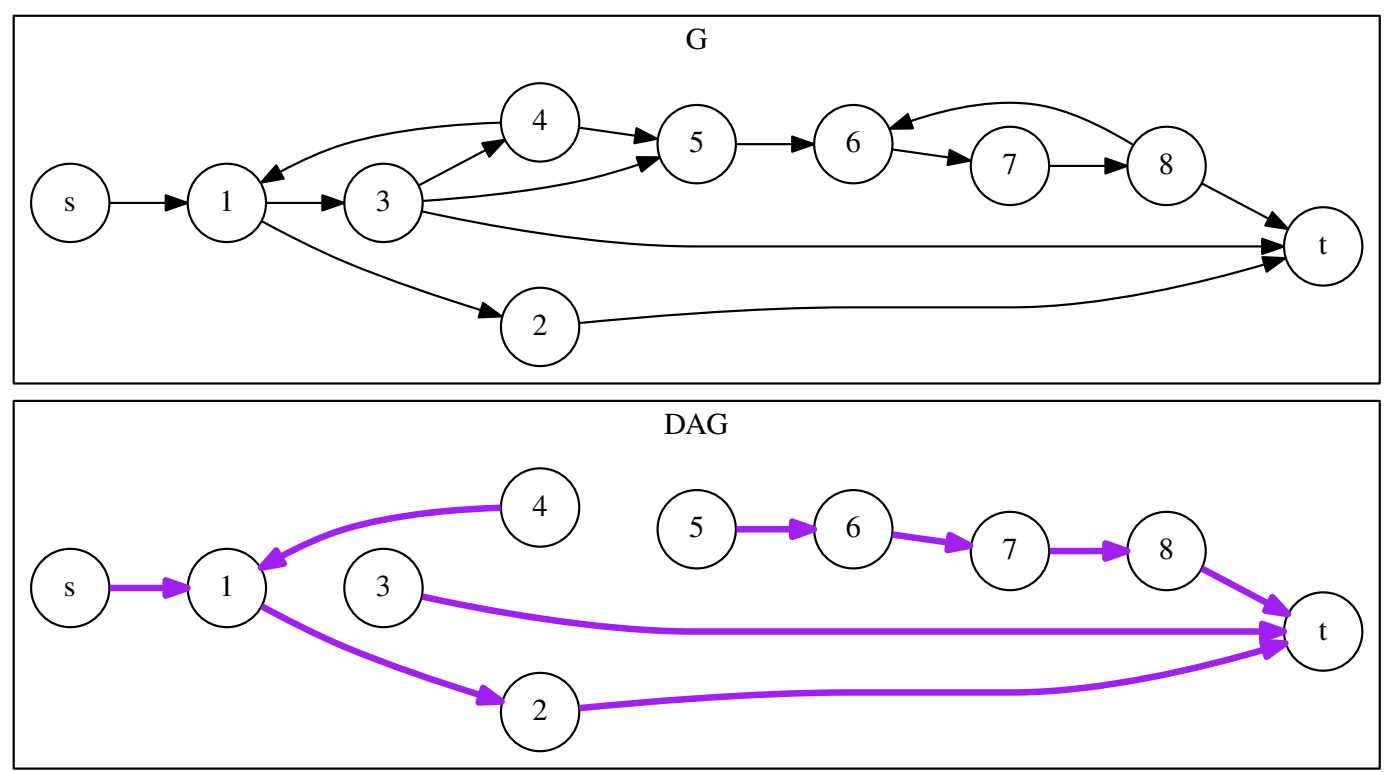

Figura 3.1: DAG criado no pré-processamento do grafo $G$

\subsection{Iterações}

Um exemplo de iterações do algoritmo de Pascoal é dado nas figuras 3.2 a 3.10. As iterações do algoritmo de Pascoal retratadas nessas imagens são iguais às imagens das iterações que o algoritmo de Yen faria, a diferença entre os algoritmos é a forma como o menor caminho de cada conjunto associado é escolhido.

Após o pré-processamento, temos o DAG $\mathcal{T}_{t}$ criado e inicialmente temos apenas o nó $r$ na arborescência, como mostrado na figura 3.2. O conjunto associado a esse vértice nesse momento é composto por todos os caminhos de $s$ a $t$ em $G$. Seguindo o algoritmo de Pascoal, verificamos os arcos que saem de $s$ e que não possuam arco associado na arborescência. No nosso exemplo, o único arco que sai de $s$ é o arco $(s, 1)$ e ele não está na arborescência, portanto podemos utilizá-lo. Montamos o caminho $\langle s\rangle \diamond(s, 1) \diamond \mathcal{T}_{t}(1)=$ $\langle s, 1,2, t\rangle$, que não contém repetição de vértices. E esse caminho é escolhido como o menor caminho do conjunto associado a $r$, utilizando a estratégia desenvolvida por Pascoal.

A entrada do caminho $\langle s, 1,2, t\rangle$ na resposta faz com que tenhamos que atualizar os conjuntos associados. Na figura 3.3, temos o estado da arborescência após a inserção do menor caminho. O conjunto associado ao vértice $r$ fica vazio, pois não há arcos que saem de $s$ que não sigam por arcos já presentes na arborescência. O vértice a possui caminhos, e o menor caminho desse conjunto associado também pode ser encontrado utilizando a estratégia de Pascoal, ao escolher o arco $(1,3)$ e seguir por $\mathcal{T}_{t}(3)$. A trilha montada dessa forma também não contém vértices repetidos e é mantida como o caminho candidato desse conjunto associado. $\mathrm{O}$ vértice $b$ também possui um conjunto associado vazio.

O caminho $\langle s, 1,3, t\rangle$ é inserido na arborescência, como mostrado na imagem 3.5. O conjunto associado ao vértice $a$ fica vazio, pois não há arcos fora da arborescência para seguir. Já o conjunto do vértice $d$ nos mostra um caso em que a estratégia de Pascoal falha e precisamos voltar ao algoritmo de Yen e buscar, 
via Dijkstra, o menor caminho daquele conjunto associado. O vértice $d$ da arborescência corresponde ao vértice 3 do grafo $G$. O conjunto associado a esse vértice é formado pelos caminhos que possuem o prefixo $\langle s, 1,3\rangle$ e que não seguem por $(3, t)$. Podemos seguir por dois arcos: $(3,4)$ ou $(3,5)$. A trilha formada pela escolha do $\operatorname{arco}(3,4)$ é $\langle s, 1,3\rangle \diamond(3,4) \diamond \mathcal{T}_{t}(1)=\langle s, 1,3,4,1,2, t\rangle$, que tem custo 6 , enquanto a trilha formada pela escolha do arco $(3,5)$ é $\langle s, 1,3\rangle \diamond(3,5) \diamond \mathcal{T}_{t}(1)=\langle s, 1,3,5,6,7,8, t\rangle$, com custo 7 . Mas, como a menor trilha $\langle s, 1,3,4,1,2, t\rangle$ possui repetição do vértice 1 , não podemos utilizá-la, então executamos Dijkstra em um subgrafo de $G$, tal como faríamos no algoritmo de Yen, como mostrado nas figuras 3.6 a 3.8. O algoritmo de Dijkstra encontra o caminho $\langle s, 1,3,5,6,7,8, t\rangle$, que se torna o candidato do conjunto associado ao vértice $d$.

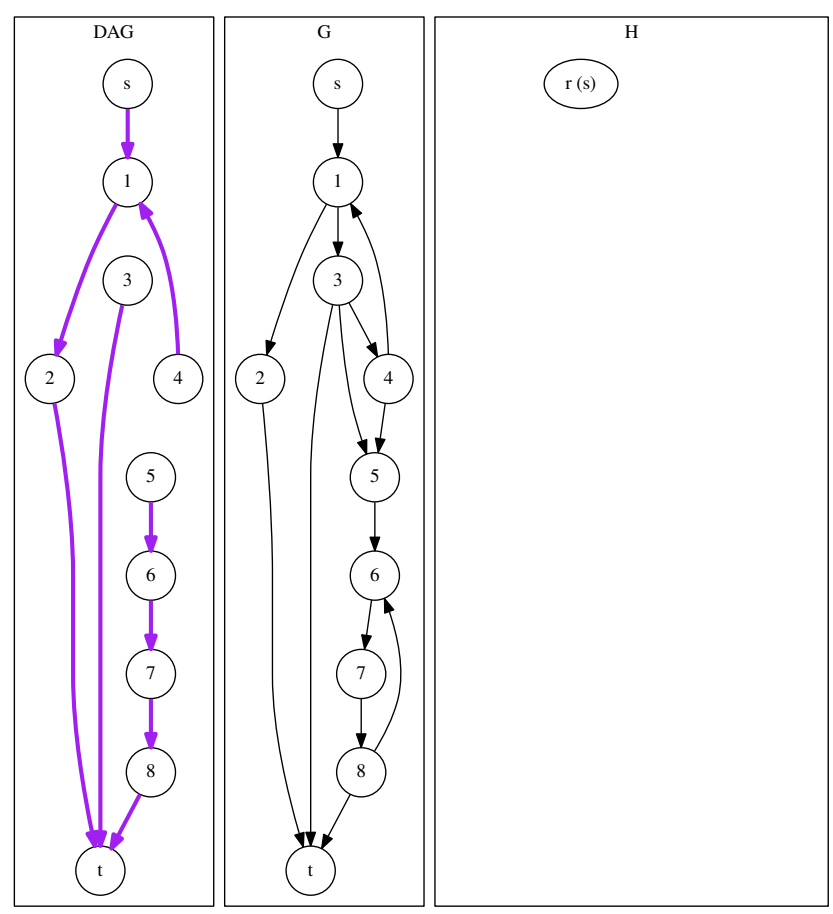

Figura 3.2: Situação inicial da arborescência. Somente o vértice raiz $r$, associado ao vértice $s$ de $G$. O menor caminho é encontrado pela estratégia de Pascoal. 


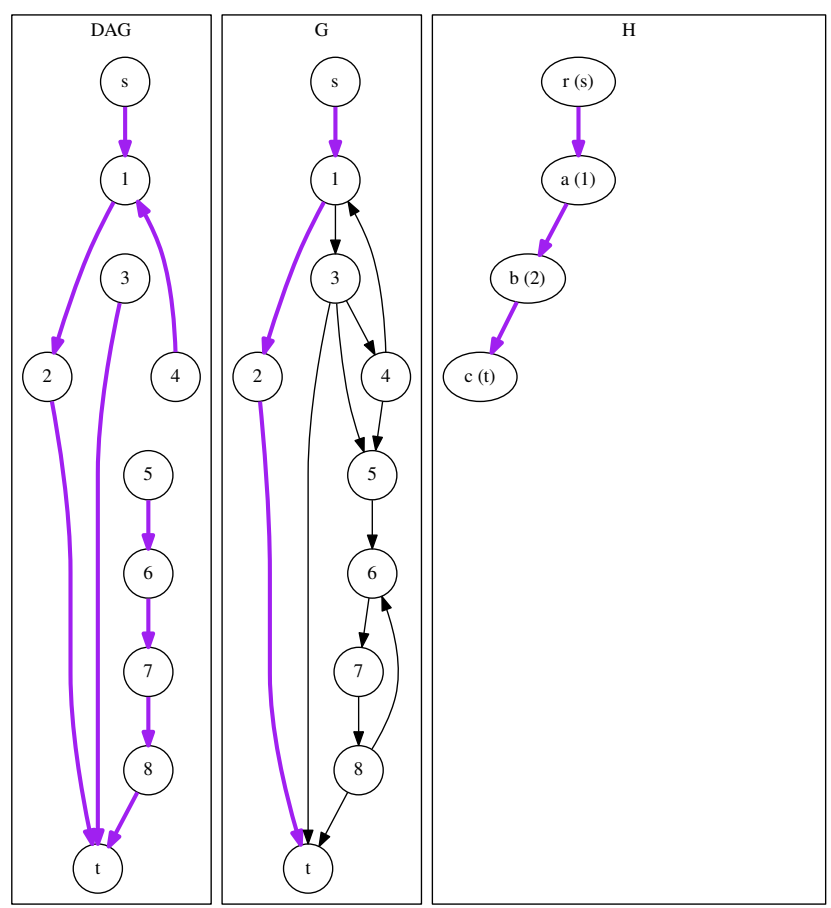

Figura 3.3: Inserção do menor caminho $\langle s, 1,2, t\rangle$ na arborescência.

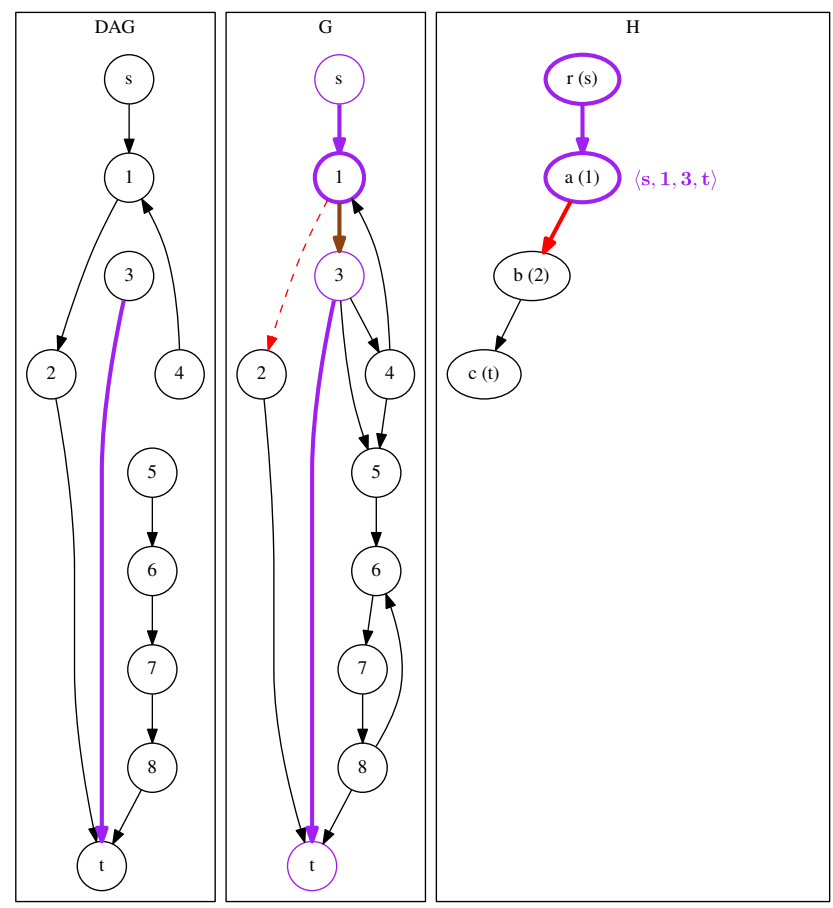

Figura 3.4: Geração de candidato do conjunto associado ao vértice $a$. A estratégia de Pascoal funciona, pois a trilha formado pela concatenação do prefixo $\langle s, 1\rangle$ com o $\operatorname{arco}(1,3)$ e $\mathcal{T}_{t}(3)$ não contém repetição de vértices. 


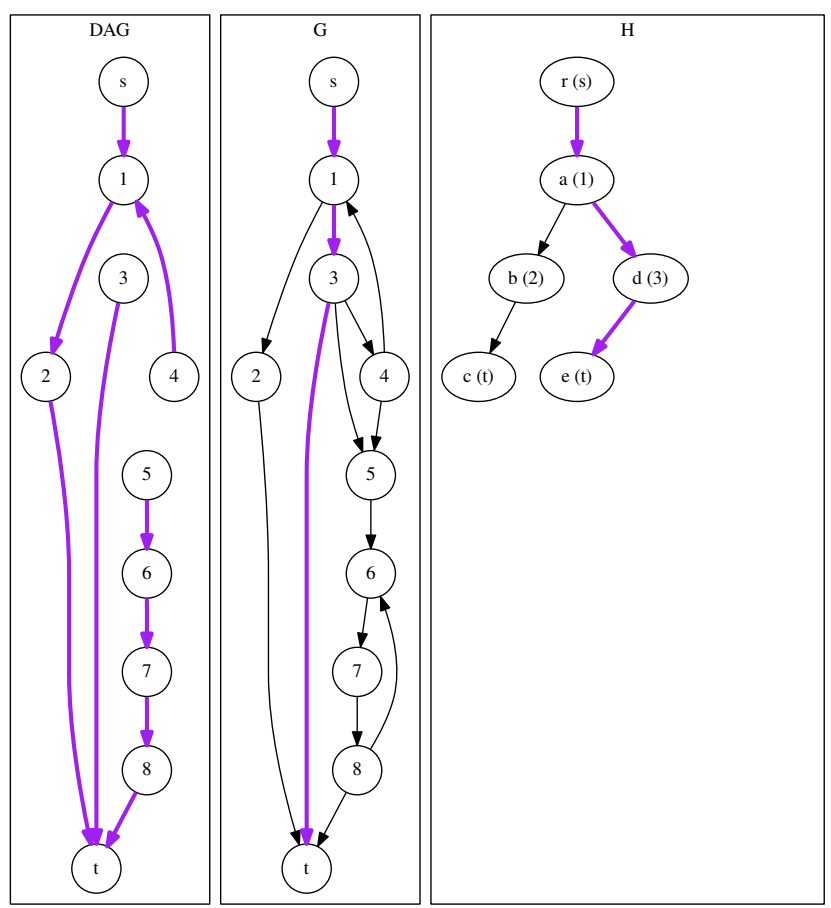

Figura 3.5: Inserção de $\langle s, 1,3, t\rangle$ na arborescência.

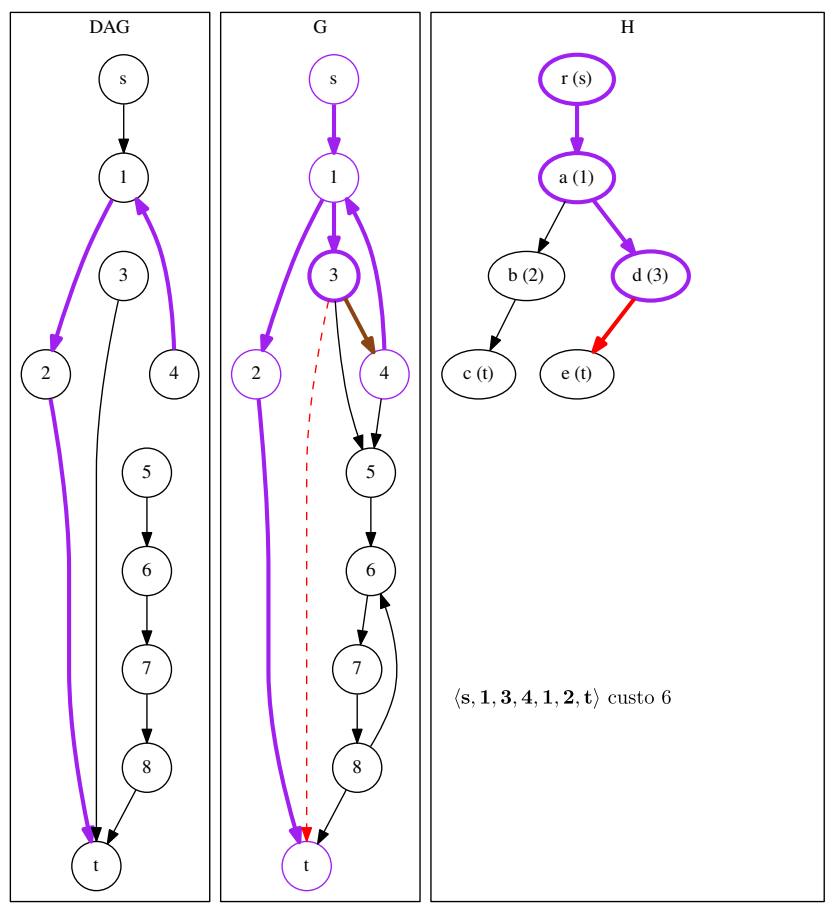

Figura 3.6: Geração de candidato do conjunto associado ao vértice $d$. Trilha formada pela concatenação do prefixo $\langle s, 1,3\rangle$ com o arco $(3,4)$ e $\mathcal{T}_{t}(4)$, com custo 6 


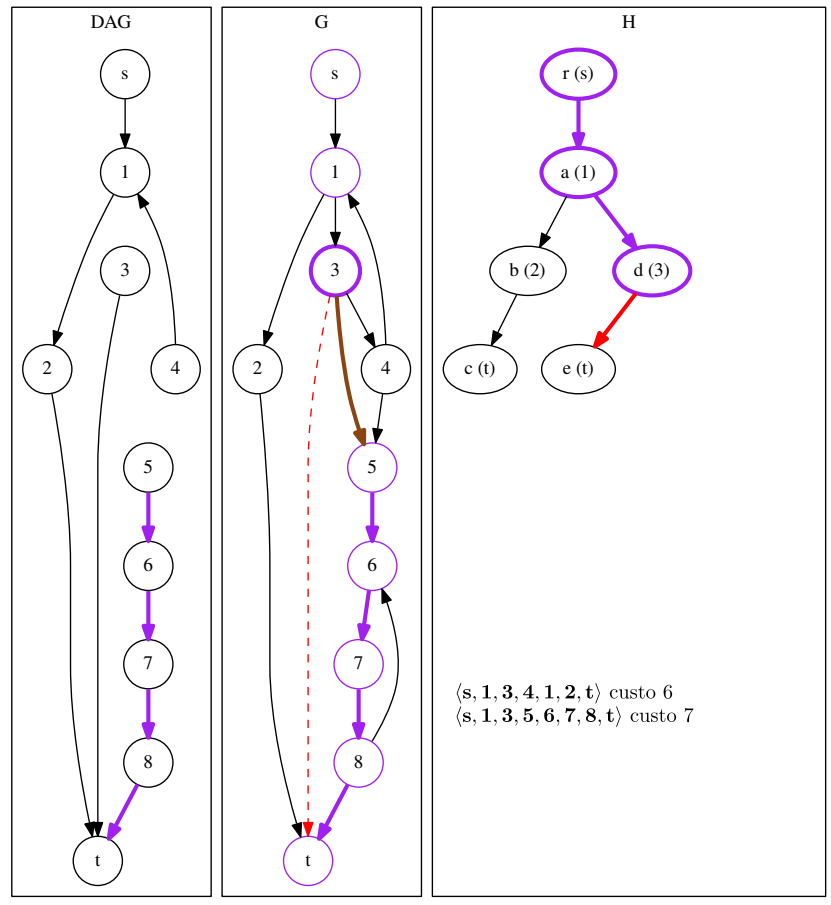

Figura 3.7: Geração de candidato do conjunto associado ao vértice $d$. Trilha formada pela concatenação do prefixo $\langle s, 1,3\rangle$ com o arco $(3,5)$ e $\mathcal{T}_{t}(5)$, com custo 7 .

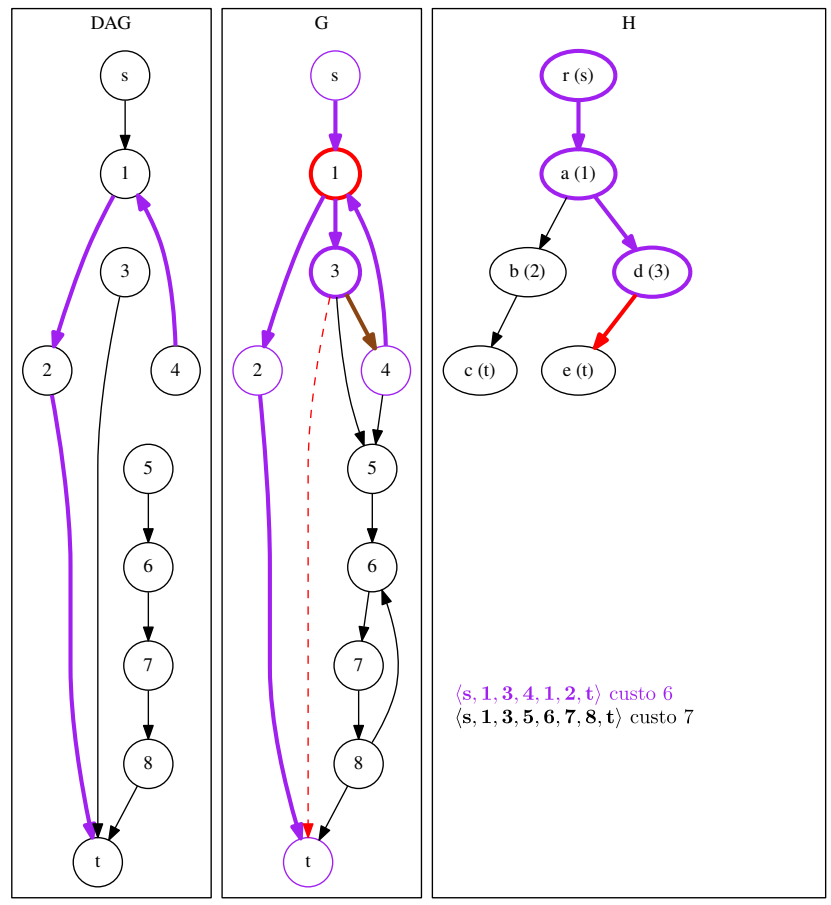

Figura 3.8: Como a trilha formada pela escolha do arco $(3,4)$ tem custo menor, ela é a escolhida pelo algoritmo de Pascoal. Mas a trilha $\langle s, 1,3,4,1,2, t\rangle$ tem repetição de vértice, o que chamamos de falha da estratégia. Nesse caso, para encontrar o candidato do conjunto associado ao vértice $d$, executamos Dijkstra da mesma forma que o algoritmo de Yen faz. 


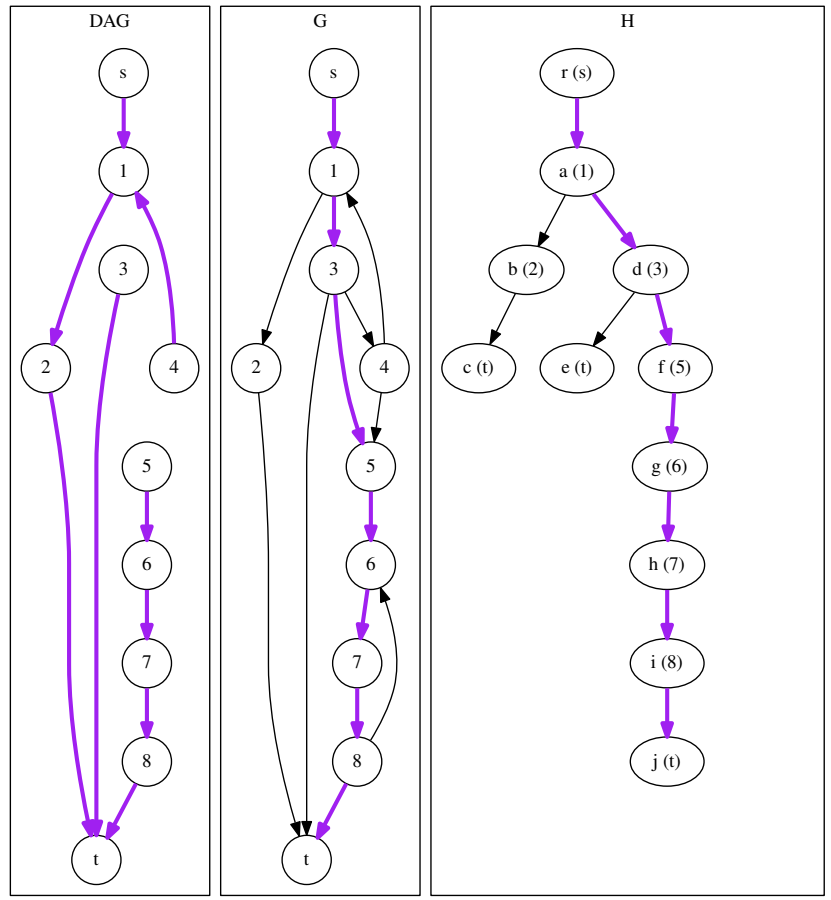

Figura 3.9: Inserção do terceiro menor caminho $\langle s, 1,3,5,6,7,8, t\rangle$ na arborescência. A estratégia de Pascoal também falha e o menor caminho do conjunto associado ao vértice $d$ é novamente escolhido pela mesma estratégia do algoritmo de Yen.

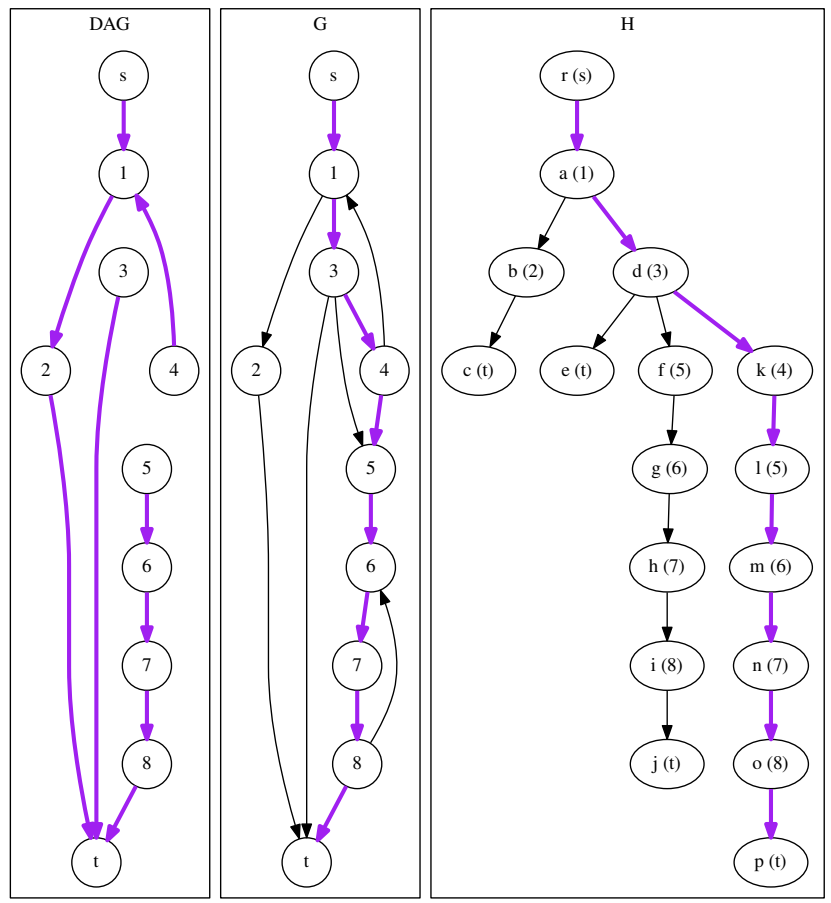

Figura 3.10: Inserção do maior caminho de $s$ a $t$ na arborescência. 


\subsection{Custo reduzido}

Pascoal define o conceito de custo reduzido, que permite que escolhamos de forma rápida ao arco que fornece a melhor trilha. Considerar o custo reduzido fornece um conjunto resposta que também vale para o problema considerando o custo original. Ambas as afirmações serão demonstradas a seguir.

Como dito anteriormente, o custo reduzido de um arco $(v, w)$ tem valor $c\left(\mathcal{T}_{t}(w)\right)-c\left(\mathcal{T}_{t}(v)\right)+c((v, w))$, que denotaremos por $\bar{c}((v, w))$. Para mostrar que a escolha do arco pelo custo reduzido mantém o resultado correto do algoritmo, basta aplicarmos a definição do conceito. Seja $P^{*}=\mathcal{T}_{t}(s)$ um menor caminho de $s$ a $t$ em $G$, e $P_{1}=\left\langle s, v_{1}, \ldots, v_{\alpha}, t\right\rangle$ um caminho qualquer de $s$ a $t$ em $G$ tal que $P_{1} \neq P^{*}$. Olhando para o custo reduzido do caminho $P_{1}$, temos:

$$
\begin{aligned}
\bar{c}\left(P_{1}\right)= & \\
= & \bar{c}\left(\left(s, v_{1}\right)\right)+\sum_{i=1}^{\alpha-1} \bar{c}\left(\left(v_{i}, v_{i+1}\right)\right)+\bar{c}\left(\left(v_{\alpha}, t\right)\right) \\
= & c\left(\mathcal{T}_{t}\left(v_{1}\right)\right)-c\left(\mathcal{T}_{t}(s)\right)+c\left(\left(s, v_{1}\right)\right)+ \\
& \quad+\sum_{i=1}^{\alpha-1} c\left(\mathcal{T}_{t}\left(v_{i+1}\right)\right)-c\left(\mathcal{T}_{t}\left(v_{i}\right)\right)+c\left(\left(v_{i}, v_{i+1}\right)\right)+ \\
& \quad+c\left(\mathcal{T}_{t}(t)\right)-c\left(\mathcal{T}_{t}\left(v_{\alpha}\right)\right)+c\left(\left(v_{\alpha}, t\right)\right) \\
= & c\left(\left(s, v_{1}\right)\right)+\sum_{i=1}^{\alpha-1} c\left(\left(v_{i}, v_{i+1}\right)\right)+c\left(\left(v_{\alpha}, t\right)\right)+c\left(\mathcal{T}_{t}(t)\right)-c\left(\mathcal{T}_{t}(s)\right) \\
= & c\left(P_{1}\right)+0-c\left(P^{*}\right) \\
= & c\left(P_{1}\right)-c\left(P^{*}\right)
\end{aligned}
$$

Ou seja, o custo reduzido de um caminho é igual ao custo dele subtraído do custo do menor caminho de $s$ a $t$. Então o custo reduzido é sempre maior ou igual a zero, assumindo valor zero somente nos caminhos com menor custo de $s$ a $t$, e a ordenação de todos os caminhos se mantém. Uma resposta que vale para o problema utilizando o custo reduzido também vale para o custo original. Portanto, é possível trocar o custo de cada arco pelo seu custo reduzido.

Agora vamos mostrar que a estratégia de Pascoal tem o resultado esperado. Para tal, é necessário apenas mostrar que quando a estratégia dá certo, e encontra uma trilha sem repetição de vértices, esse caminho encontrado pelo algoritmo é o menor caminho daquele subconjunto. Todo caminho simples é uma trilha, mas uma trilha pode não ser um caminho simples. Vamos mostrar uma afirmação mais abrangente: que a trilha escolhida pela estratégia de Pascoal é uma menor trilha de $s$ a $t$. Dessa forma, se ela for um caminho simples, então também é um menor caminho simples de $s$ a $t$.

Lema 3.4.1. Todo arco $(v, w)$ contido no $D A G \mathcal{T}$ tem custo reduzido igual a zero.

Demonstração. Seja $(v, w)$ um arco qualquer do DAG $\mathcal{T}$. Temos que $\mathcal{T}_{t}(v)=(v, w) \diamond \mathcal{T}_{t}(w)$. Aplicando a fórmula do custo reduzido: 


$$
\begin{aligned}
\bar{c}((v, w)) & = \\
& =c\left(\mathcal{T}_{t}(w)\right)-c\left(\mathcal{T}_{t}(v)\right)+c((v, w)) \\
& =c\left(\mathcal{T}_{t}(w)\right)-c\left((v, w) \diamond \mathcal{T}_{t}(w)\right)+c((v, w)) \\
& =c\left(\mathcal{T}_{t}(w)\right)-\left(c((v, w))+c\left(\mathcal{T}_{t}(w)\right)\right)+c((v, w)) \\
& =c\left(\mathcal{T}_{t}(w)\right)-c\left(\mathcal{T}_{t}(w)\right)-c((v, w))+c((v, w)) \\
& =0
\end{aligned}
$$

Então o sufixo da trilha que o algoritmo de Pascoal constrói é composta por um arco que sai do vértice de desvio com custo reduzido $\bar{c}(e)$ e o restante tem custo reduzido igual a zero. Isso nos permite comparar qual arco fornece o melhor complemento para a trilha apenas comparando o custo reduzido dos arcos que saem do vértice de desvio, mostrando assim que a estratégia do algoritmo de Pascoal escolhe, de fato, a melhor trilha.

A figura 3.11 mostra um exemplo do custo reduzido de uma trilha montada pelo algoritmo. Nesse exemplo, estamos procurando os candidatos que desviam no vértice 3 usando o prefixo $\langle s, 1,3\rangle$ e que não usem o arco $(3, t)$. Em destaque, está a trilha formada pelo uso do arco $(3,5)$ e depois pelo caminho $\mathcal{T}_{t}(5)$, que mostramos ter custo reduzido igual a $\bar{c}((3,5))$.

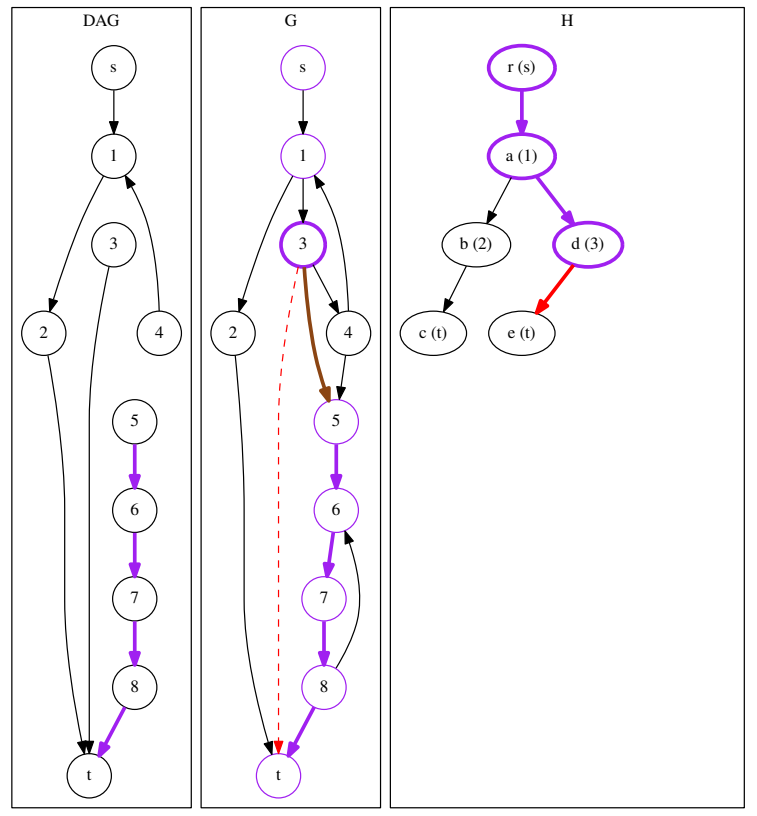

$$
\begin{array}{r}
\bar{c}(\langle 3,5,6,7,8, t\rangle)= \\
=\bar{c}((3,5))+\bar{c}((5,6))+ \\
+\bar{c}((6,7))+ \\
+\bar{c}((7,8))+\bar{c}((8, t))= \\
=\bar{c}((3,5))+0+ \\
+0+0+0= \\
=\bar{c}((3,5))
\end{array}
$$

Figura 3.11: Custo reduzido de uma trilha que o algoritmo de Pascoal constrói é apenas o custo reduzido do arco que sai do vértice de desvio 


\subsection{Corretude e complexidade}

A complexidade do algoritmo de Pascoal é a mesma do algoritmo de Yen, $O(K n(m+n \log n))$, já que em caso de falha de sua estratégia, seu funcionamento é exatamente o mesmo desse algoritmo.

Já provamos tudo que era necessário para mostrar que o algoritmo funciona corretamente. Mostramos que a estratégia de Pascoal escolhe a menor trilha possível, mas as vezes essa trilha não é um caminho simples e não pode entrar para o conjunto resposta. Nesses casos, voltamos à estratégia do algoritmo de Yen para encontrar um caminho simples. Então o algoritmo encontra, de fato, os $K$ menores caminhos simples de $s$ a $t$. 


\section{Capítulo 4}

\section{Algoritmo de Feng}

\subsection{Visão Geral}

O algoritmo desenvolvido por Feng [Fen14] pode ser descrito com base no algoritmo híbrido de Pascoal [Pas06]. Esse algoritmo é uma alteração do algoritmo de Yen que visa reduzir o tamanho do grafo em que procuramos o caminho mínimo durante a geração de candidatos. Para isso, durante essa geração, acrescentamos uma etapa de classificação dos vértices e a utilizamos para criar um grafo auxiliar no qual executaremos o algoritmo de Dijkstra. Geralmente, esse grafo auxiliar é muito menor do que o grafo original, o que faz com que o tempo gasto nesse passo seja muito menor, compensando o tempo de classificação dos vértices.

Introduzimos anteriormente a definição de custo reduzido de um arco 3.2, que também utilizaremos nesse capítulo. O custo reduzido é utilizado no lugar do custo original do problema, mantendo válida a resposta encontrada, e tem valor $c\left(\mathcal{T}_{t}(w)\right)-c\left(\mathcal{T}_{t}(v)\right)+c((v, w))$. Outra definição importante é a de vértice de desvio, explicada em 2.2. Considere uma iteração da geração de candidatos a partir do caminho $P$ fixando o prefixo até $v_{j}$. Esse vértice $v_{j}$ é o vértice de desvio.

O algoritmo de Pascoal realiza uma etapa de pré-processamento, em que é construído um DAG composto pelos menores caminhos de cada vértice de $G$ até $t$. Esse DAG, que chamaremos de $\mathcal{T}$ pode ser criado trocando a orientação de todos os arcos de $G$ e executando Dijkstra a partir de $t$, como explicado na seção 3.2. Então, Pascoal escolhe um melhor arco que sai do vértice de desvio para determinar uma trilha, aquela que após esse arco segue pelo caminho em $\mathcal{T}$. Caso essa trilha não contenha vértices repetidos, então ela é o caminho candidato procurado. Caso contrário, é executado o algoritmo de Dijkstra em um subgrafo de $G$, excluindo os vértices anteriores ao vértice de desvio e arcos que saiam do vértice de desvio e tenha algum caminho na resposta com o mesmo prefixo até esse vértice. Os detalhes do funcionamento desse algoritmo estão descritos no capítulo 3 .

Feng generalizou o funcionamento do algoritmo de Pascoal. Utilizando estruturas criadas em um préprocessamento similar ao de Pascoal, Feng classifica os vértices do grafo em 3 classes, utilizando as cores verde, amarelo e vermelho, em analogia a um semáforo. Feng mostra que necessitamos apenas executar Dijkstra em um grafo auxiliar, induzido pelos vértices amarelos de $G$ com adição de algumas arestas artificiais. A cor atribuída a cada vértice é uma classificação dele em relação ao DAG $\mathcal{T}$, durante a geração de candidatos. 
Em uma certa iteração durante a geração de candidatos, temos um prefixo fixado e procuramos uma maneira de completar esse caminho até $t$, sem repetição. Os vértices vermelhos representam os vértices que não podem ser utilizados por esse complemento de caminho. Ou seja, são os vértices do prefixo do caminho analisado até o vértice de desvio $v$. Os vértices verdes são aqueles que podem ser utilizados e cujo menor caminho até $t$ presente no $\mathrm{DAG}, \mathcal{T}_{t}(v)$, não utilize vértices do prefixo fixado. O restante são os vértices amarelos, que podemos utilizar, mas não podemos utilizar o menor caminho até $t$. Em analogia com um semáforo, são os vértices com que devemos ter cuidado. Daremos um tratamento especial para o vértice de desvio e o classificaremos como amarelo.

Repare que podemos redefinir os casos do algoritmo híbrido de Pascoal da seguinte forma. Caso o arco que sai de $v$ com o menor custo reduzido aponte para um vértice verde, então ele é o candidato procurado. A estratégia falha quando esse arco aponta para um vértice amarelo ou vermelho, e nesse caso o algoritmo de Dijkstra deve ser executado.

\subsection{A classificação dos vértices}

Quando um caminho entra na resposta, ou equivalentemente na arborescência, geramos candidatos a partir dele. Para isso, iteramos pelos vértices desse caminho fixando prefixos e gerando os candidatos. Suponha que estamos gerando os candidatos a partir de um caminho $P_{i}=\left\langle v_{1}, \ldots, v_{l}\right\rangle$, e, em estamos na iteração em que o vértice $v_{j}$ é o vértice de desvio. A classificação dos vértices pode ser então definida para essa iteração.

- Os vértices vermelhos são os vértices que precedem o vértice de desvio $v_{j}$ em $P_{i}$.

- O vértice de desvio é amarelo. Além dele, também são amarelos todos os vértices $v$ cujo menor caminho de $v$ até $t$ presente no DAG, $\mathcal{T}_{t}(v)$, utiliza algum vértice do prefixo de $P_{i}$ até $v_{j}$. Ou seja, todo vértice $v$ que $\mathcal{T}_{t}(v)$ contém algum vértice vermelho ou amarelo é amarelo também.

- Os demais vértices são verdes.

Podemos classificar o grafo $G$ iterativamente, iniciamos com todos os vértices classificados como verdes. Cada vértice no prefixo de $P_{i}$ anterior ao vértice de desvio recebe a cor vermelha. $\mathrm{O}$ vértice de desvio $v_{j}$ recebe a cor amarela. Tanto os vértices vermelhos quanto o vértice amarelo são inseridos em uma fila. Enquanto a fila não estiver vazia, removemos um vértice de lá e analisamos os arcos que entram nesse vértice. $\mathrm{O}$ vértice que está na cauda de cada um desses arcos é classificado como amarelo e é inserido na fila. Ao final desse processo, temos o grafo classificado nas cores, como desejado.

Temos como exemplo o grafo da figura 4.1. Durante a geração de candidatos a partir do menor caminho $P_{1}=\langle s, 1,3,4, t\rangle$, ao fixar o prefixo $\langle s, 1,3\rangle$, temos a classificação dos vértices da seguinte forma. Os vértices $s$ e 1 são classificados como vermelhos por estarem no prefixo fixado. O vértice 3 é amarelo por ser o vértice de desvio e os vértices $2,5,6,11,12$ e 13 são classificados como amarelos, pois o caminho desses vértices até $t$ no DAG $\mathcal{T}$ passa por um vértice vermelho ou amarelo. Os demais vértices, 4, 7, 8, 9, 10 e $t$, são verdes. 


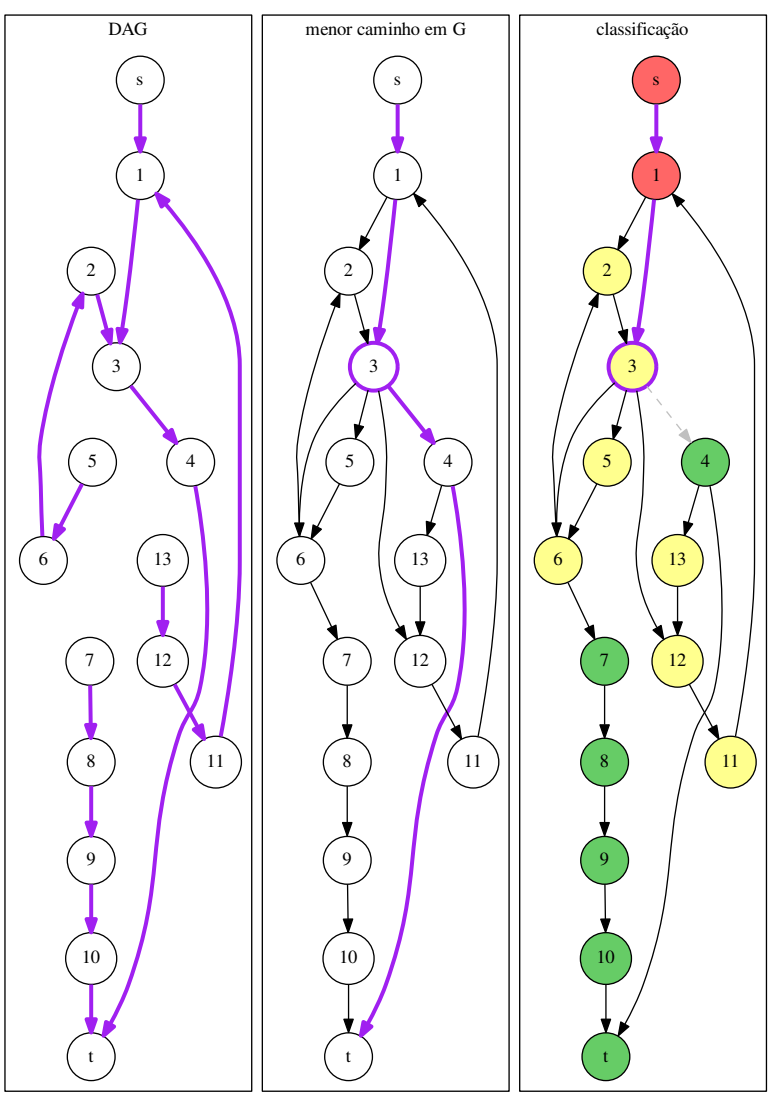

Figura 4.1: Classificação dos vértices de $G$, gerando caminhos a partir do menor caminho, durante a iteração que fixa o prefixo do vértice $s$ até o vértice 3

\subsection{Executando Dijkstra em um grafo auxiliar baseado em $G$}

Ao classificar os vértices dessa maneira, podemos enxergar algumas propriedades interessantes. Uma delas, enunciada por Feng em seu artigo, diz respeito à estrutura de todos os caminhos candidatos.

Teorema 4.3.1. Durante a geração de candidatos a partir de um caminho, se existe pelo menos um caminho atét que desvia em um vértice $v_{2}$, então existe um caminho candidato da forma $P=\left\langle s, \ldots, v_{1}, v_{2}, \ldots, v_{k}, v_{k+1}, \ldots\right.$, em que:

1. Todos os vértices do prefixo $\left\langle s, \ldots, v_{1}\right\rangle$ são vermelhos

2. O subcaminho $\left\langle v_{2}, \ldots, v_{k}\right\rangle$ é formado por vértices amarelos

3. $O$ trecho final $\left\langle v_{k+1}, \ldots, t\right\rangle$ possui apenas vértices verdes

Demonstração. O prefixo é vermelho por definição. Se um caminho não atende essa propriedade, então existem vértices verdes e amarelos misturados. Suponha, por um momento, que a propriedade acima é falsa. Então existe um caminho candidato $P_{1}$ que tem pelo menos um vértice $v_{a}$ amarelo após um certo vértice $v_{v}$ verde. Podemos supor, sem perda de generalidade, que $v_{a}$ seja o primeiro vértice amarelo a aparecer no caminho $P_{1}$ após algum vértice verde. Então escrevemos $P_{1}=\left\langle s, \ldots, v_{v}, v_{a}, \ldots, t\right\rangle$. 
Considere $P_{2}=\left\langle s, \ldots, v_{v}\right\rangle \diamond \mathcal{T}_{t}\left(v_{v}\right)$. Como $\mathcal{T}_{t}(v)$ é um caminho formado apenas por vértices verdes, não existe nenhum vértice amarelo entre $v_{v}$ e $t$. Como supusemos que a propriedade é falsa, então o custo de $P_{1}$ deve ser estritamente menor que $P_{2}$. Mas sabemos que todo arco que está no DAG $\mathcal{T}_{t}$ tem custo zero, portanto o sufixo $\mathcal{T}_{t}\left(v_{v}\right)$ tem custo zero. Pela suposição, $c\left(P_{1}\right)<c\left(P_{2}\right)$ e, portanto, $c\left(\left\langle v_{a}, \ldots, t\right\rangle\right)<c\left(\mathcal{T}_{t}\left(v_{v}\right)\right)$, o que é um absurdo, pois não existe arco com custo, ou custo reduzido, negativo.

Logo, se $P_{1}$ é um possível caminho candidato, $P_{2}$ também é.

O teorema 4.3.1 permite focar nossa busca por candidatos que, ao encontrar um vértice verde, seguem apenas por vértices verdes utilizando o DAG $\mathcal{T}$.

\subsubsection{Custo reduzido}

Feng também utiliza o grafo com custos reduzidos, assim como Pascoal faz. Já mostramos na seção 3.4 que o problema não se altera ao utilizar o custo reduzido no lugar do custo original. Relembrando, o custo reduzido é definido em função do DAG $\mathcal{T}$, da seguinte forma. Para cada arco $(v, w) \in G$, o custo reduzido é $\bar{c}((v, w))=c\left(\mathcal{T}_{t}(w)\right)-c\left(\mathcal{T}_{t}(v)\right)+c((v, w))$.

Outra propriedade interessante também provada na mesma seção diz respeito sobre os arcos que estão no DAG. Se e é um arco do DAG, então $\bar{c}(e)=0$. Vamos agora discutir o que essa propriedade significa para os candidatos da forma desejada.

Suponha que estamos executando o algoritmo de Dijkstra partindo do vértice de desvio $v$ até $t$ e que chegamos até um vértice $v_{v}$ verde. Nesse momento do algoritmo, temos o caminho $\left\langle s, \ldots, v_{v}\right\rangle$ com custo reduzido $\bar{c}\left(\left\langle s, \ldots, v_{v}\right\rangle\right)$ e é o caminho de menor custo até algum vértice verde. Considere o caminho $P=\left\langle s, \ldots, v_{v}\right\rangle \diamond \mathcal{T}_{t}\left(v_{v}\right)$. Esse caminho tem custo reduzido $\bar{c}\left(\left\langle s, \ldots, v_{v}\right\rangle \diamond \mathcal{T}_{t}\left(v_{v}\right)\right)$. Mas sabemos que $\bar{c}\left(\mathcal{T}_{t}\left(v_{v}\right)\right)=0$, então $\bar{c}(P)=\bar{c}\left(\left\langle s, \ldots, v_{v}\right\rangle\right)$.

Portanto, é natural pensar que podemos utilizar essa propriedade para acelerar o funcionamento do algoritmo de Dijkstra. Feng mostrou como utilizar um grafo baseado nos vértices amarelos de $G$ para se beneficiar dessa propriedade.

\subsubsection{Construindo o subgrafo de $G$ em que será executado o algoritmo de caminho mínimo}

O grafo auxiliar em que Feng executa o algoritmo de caminho mínimo não é exatamente um subgrafo de $G$, pois contém arcos que não estão presentes em $G$. Para ser possível parar a execução do algoritmo de Dijkstra ao encontrar um vértice verde, Feng adiciona diversos arcos artificiais para um vértice terminal. Para explicar melhor esse passo, precisamos da seguinte definição.

Definição. Um arco $e=(v, w)$ é chamado de arco expresso se atender a duas condições.

1. $v$ é amarelo.

2. $w$ é verde.

Podemos interpretar os arcos expressos como passagens expressas para a resposta, em que é garantido a partir daquele momento um melhor caminho até $t$. Feng adota uma estratégia de executar o algoritmo 
de caminho mínimo até $t$ procurando chegar até um desses arcos expressos, pois o restante do caminho já é conhecido, está em $\mathcal{T}$ e tem custo zero.

No exemplo que estamos trabalhando nesse capítulo, podemos ver na figura 4.2 os arcos expressos, que são $(3,4)$ e $(6,7)$. Mas $(3,4)$ é removida para evitar que o caminho mínimo atual seja encontrado novamente pelo algoritmo.

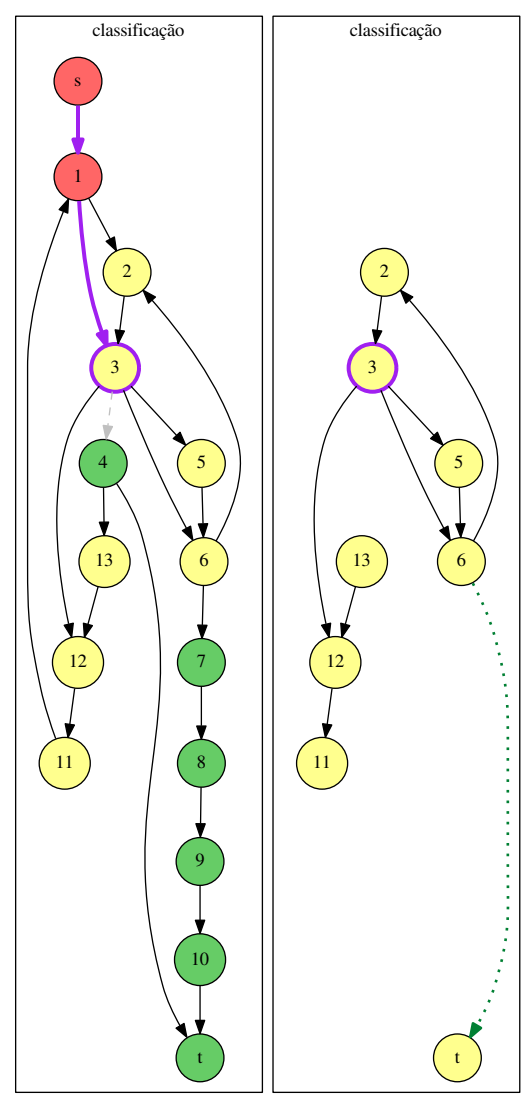

Figura 4.2: Subgrafo de $G$ no qual é executado o algoritmo de Dijkstra

Para conseguir parar ao encontrar um arco expresso, vamos fazer uma modificação no grafo, criando $\operatorname{arcos}$ artificiais até $t$. Podemos então definir o restante do funcionamento desse passo do algoritmo desenvolvido por Feng. Após identificarmos todos os arcos expressos, trocamos a cabeça do arco por $t$. Em outras palavras, para cada arco expresso $(v, w)$ adicionamos um arco artificial $(v, t)$ com mesmo custo do arco expresso. Feng troca a classificação do vértice $t$ para amarelo e executa o algoritmo de Dijkstra, partindo do vértice de desvio, permitindo apenas que o algoritmo passe por vértices amarelos, utilizando o custo reduzido. Na imagem 4.2 temos o grafo do exemplo montado para o algoritmo de Dijkstra ser executado, em que o arco expresso $(6,7)$ deu origem ao arco artificial $(6, t)$.

\subsection{Atualizando a classificação para a próxima iteração}

Quando um caminho candidato de tamanho $l$ é escolhido para entrar para o conjunto resposta, geramos candidatos a partir dele. São gerados até $l$ caminhos candidatos, e para cada um desses $l$ candidatos 
gerados, o grafo admite uma classificação diferente. Mas repare que existe pouca mudança da classificação dos vértices ao longo das $l$ iterações.

Vamos analisar o que muda quando incluímos um novo vértice ao prefixo fixado durante a geração de caminhos. O vértice de desvio anterior se torna vermelho, e é necessário rever os arcos que eram expressos e saiam desse vértice, para remover os arcos artificiais criados. O novo vértice adicionado ao prefixo, antes amarelo ou verde, passa a ser classificado como amarelo por ser o vértice de desvio. No primeiro caso, quando o vértice era amarelo, não precisamos fazer mais nada. Quando o vértice era verde e se torna vermelho, isso afeta outros vértices verdes, que devem ser classificados agora como amarelos. Além disso, devemos também consertar os arcos artificiais que envolviam esse vértice. Para cada arco expresso que entrava nele, devemos remover o respectivo arco artificial. E por fim, como um conjunto de vértices foram classificados como amarelos, outros arcos expressos devem ser identificados e ter sua ligação artificial com $t$ criada.

\subsection{Corretude e complexidade}

Apesar de executarmos uma instância do sub-problema em um grafo geralmente menor do que $G$, no pior caso temos o grafo auxiliar do mesmo tamanho de $G$, portanto a complexidade é a mesma do algoritmo de Yen, $O(K n(m+n \log n))$.

O algoritmo de Feng funciona pois, como mostrado na seção 4.3, encontrar um menor caminho no grafo auxiliar permite construir um menor caminho a partir daquele vértice de desvio. Vimos também, durante o algoritmo de Pascoal, que uma resposta válida para o custo reduzido também é uma resposta válida para o custo original 3.4. Assim, a estratégia adotada por Feng em seu algoritmo fornece uma resposta correta para o Problema dos $K$ Menores Caminhos. 


\section{Capítulo 5}

\section{Implementação}

Para esse trabalho, foram implementados quatro algoritmos: o algoritmo de Yen, o algoritmo de Pascoal, o algoritmo de Feng, descritos nos capítulos 2, 3 e 4, respectivamente, e uma versão híbrida do algoritmo de Feng e de Pascoal, proposta nesse trabalho. Todos os algoritmos foram implementados em linguagem $\mathrm{C}++$ e estão disponíveis em https://github.com/dkykuta/ksp-code.

Todos os algoritmos desenvolvidos compartilham a mesma estrutura geral de processamento do algoritmo de Yen. Sempre que possível, as estruturas de dados e funções auxiliares são compartilhadas entre os algoritmos. Nessa seção, vamos detalhar mais sobre as estruturas de dados e algoritmos utilizados. Quando exibirmos as estruturas utilizadas, mostraremos trechos do código implementado em $\mathrm{C}+$, pois acreditamos ser importante para o entendimento da memória gasta. Para os trechos de código, apresentaremos no formato de pseudo-código.

\subsection{Estruturas de dados}

Além de uma breve explicação sobre a implementação escolhida e sua motivação, vamos mostrar alguns trechos do código para tornar mais concreta a noção de memória gasta pelo programa. Começaremos pela estrutura básica necessária: a representação do grafo. Escolhemos a mesma implementação que Pascoal e Feng utilizaram em seus artigos, por seu ótimo balanço entre desempenho e memória gasta: a representação em Forward e Reverse Stars [AMO93]. Em seguida, apresentaremos a representação dos caminhos e do conjunto de candidatos, discutindo as limitações de cada estrutura.

\subsubsection{Representação do grafo}

Cada maneira de representar um grafo traz consigo benefícios e desvantagens inerentes àquela implementação. Uma representação por matriz de adjacência fornece acesso aos arcos em tempo constante, mas é ineficiente no uso de memória. Já a representação por lista de adjacência mais clássica, apesar de armazenar muito menos informação, é penosa ao buscarmos um arco específico. Escolhemos uma representação que está no meio dessas duas implementações, chamada de Forward e Reverse Stars [AMO93]. Essa estrutura armazena menos informações do que as duas estruturas mencionadas antes, porém ela não apresenta o desperdício que ocorre na matriz de adjacência em um grafo esparso, e nos permite acesso em 
tempo constante ao conjunto de arcos que entram ou saem de um vértice e acesso em tempo logarítmico a um arco específico. Sua maior desvantagem, entretanto, é sua grande rigidez. A adição ou remoção de arcos e vértices no grafo, nessa representação, é extremamente custosa.

Nessa representação, temos como objetivo armazenar os arcos em um vetor, junto com estruturas auxiliares para acessar rapidamente o conjunto de arcos que entram ou saem de um certo vértice. Para isso, armazenamos quatro vetores. Um par de vetores tem como objetivo permitir o acesso ao grupo de arcos incidentes a cada vértice e o outro, aos arcos que saem. Para o par responsável por fornecer o acesso ao conjunto de arcos que saem de cada vértice, temos um vetor de tamanho $m$ que chamaremos de edgeInfoForwardList com todos os arcos do grafo, ordenados pela cauda do arco, e um vetor de tamanho $n$, que para cada vértice $v$ do grafo, armazena o índice do vetor de arcos diretos do primeiro arco que $v$ seja a cauda. Caso $v$ não tenha arcos saindo, armazenamos o índice do primeiro arco com cauda $u>v$. Dessa forma, podemos sempre saber quantos arcos saem de um vértice. Um vértice $v$ tem edgeInfoForwardList $[v+1]$ - edgeInfoForwardList $[v]$ arcos. O outro par de vetores terá organização similar a essa, mas com ordenação pela cabeça do arco. Dessa forma, temos estruturas que nos permitem o acesso aos arcos que saem e que entram em um certo vértice.

Os dois vetores de arcos possuem muita informação redundante. Da maneira explicada acima, cada arco está representado nos dois vetores. Podemos evitar essa redundância fazendo um deles guardar índices do outro. Precisamos também remediar o alto custo de remoção de arcos, uma vez que essa operação é muito frequente nos algoritmos estudados. Adicionamos um vetor booleano para marcar se o arco foi removido.

No código 5.1, edgeInfoForwardList_ guarda as informações dos $m$ arcos, enquanto edgeReverseTrace_ é a outra lista de arcos, que guarda apenas os índices de edgeInfoForwardList_. Os vetores firstEdgeForwardV_ e firstEdgeReverseV_ são os vetores de tamanho $n$ que guardam os índices do primeiro arco que sai e que entra em cada vértice, respectivamente.

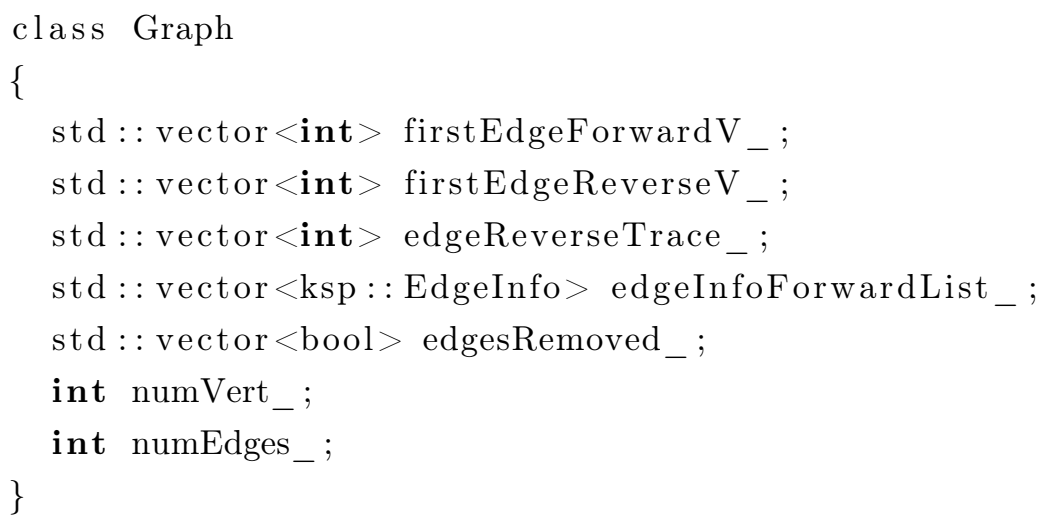

Código 5.1: Representação de um grafo

\subsubsection{Caminhos}

Os caminhos são representados, essencialmente, por dois vetores: um vetor de vértices, de tamanho $l$, e um vetor de custos dos arcos, de tamanho $l-1$. Na representação de grafos escolhida, obter o custo de uma determinado arco é uma operação logarítmica nos vizinhos de um vértice, $O(\log n)$. Portanto, decidimos armazenar o custo de cada arco no próprio caminho, assim como o custo total. Essas decisões 
podem ser vistas no código 5.2 .

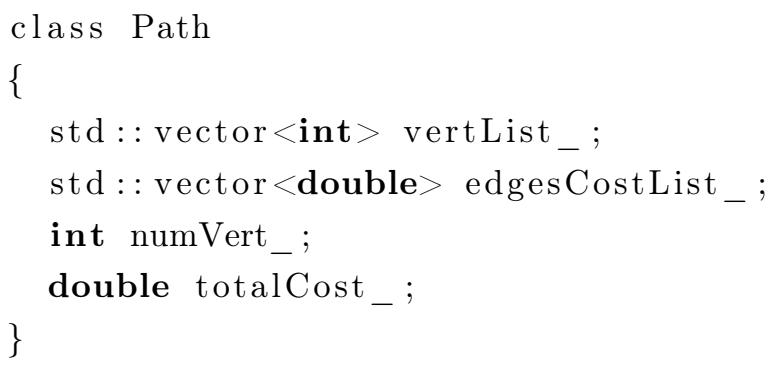

Código 5.2: Representação de um caminho

\subsection{Conjunto de Candidatos}

Utilizamos uma estrutura da standard library de $\mathrm{C}++$ : a priority_queue, que é uma implementação de fila de prioridade em vetor (heap). Com essa fila de prioridades, conseguimos recuperar o candidato a ser adicionado na resposta em tempo logarítmico no tamanho do conjunto de candidatos. Mantemos armazenado o maior candidato já inserido até o momento, assim como a quantidade de caminhos que já foram inseridos. Após a inserção dos $K$ primeiros candidatos, só são inseridos aqueles que tem custo estritamente menor do que o maior inserido.

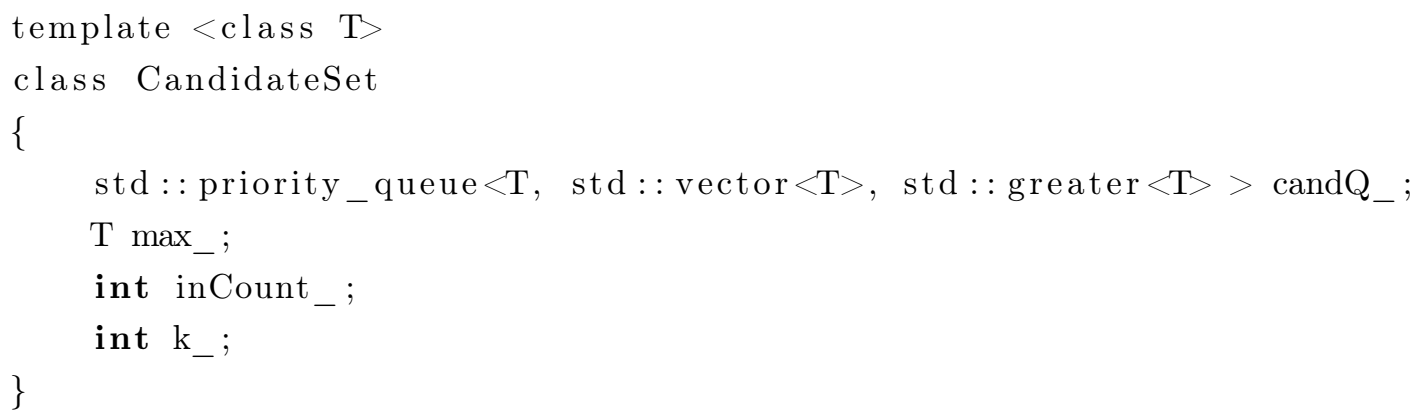

Código 5.3: Representação do conjunto de candidatos

\subsection{Algoritmos}

A descrição dos algoritmos estudados para resolver o KSP implementados já foram apresentados nos capítulos 2, 3 e 4, então nos limitaremos a apresentar detalhes de implementação relevantes ou que fujam das especificações do algoritmo, analisando cada mudança feita. No final desse capítulo, na seção 5.6, descreveremos a variante híbrida dos algoritmos de Feng e Pascoal proposta.

\subsection{Algoritmo de Dijkstra}

A implementação do algoritmo de Dijkstra com melhor complexidade conhecida utiliza Fibonacci Heap, resultando em uma complexidade $O(m+n \log n)$ [FT87, CLRS01]. Mas na prática, essa estrutura apresenta desempenho pior do que a implementação de Dijkstra utilizando um heap binário [BLT12], 
implementado em vetor. Nossa implementação utiliza a priority_queue da standard library de $\mathrm{C}++$, a mesma utilizada no conjunto de candidatos. O algoritmo de Dijkstra, quando implementado utilizando heaps binários, apresenta complexidade $O(m \log m)$. Note que essa decisão muda a complexidade que os algoritmos para $O(K n(m \log n))$, mas empiricamente, temos tempos de execução melhores, o que justifica nossa implementação mais simples.

\subsection{Algoritmos de Yen, Pascoal e Feng}

Esses três algoritmos implementados compartilham a mesma estratégia, que pode ser visualizada no pseudocódigo 1. Todos os algoritmos utilizam esse mesmo trecho de código, sobrescrevendo apenas a geração de candidatos, realizada na função generatecandidates.

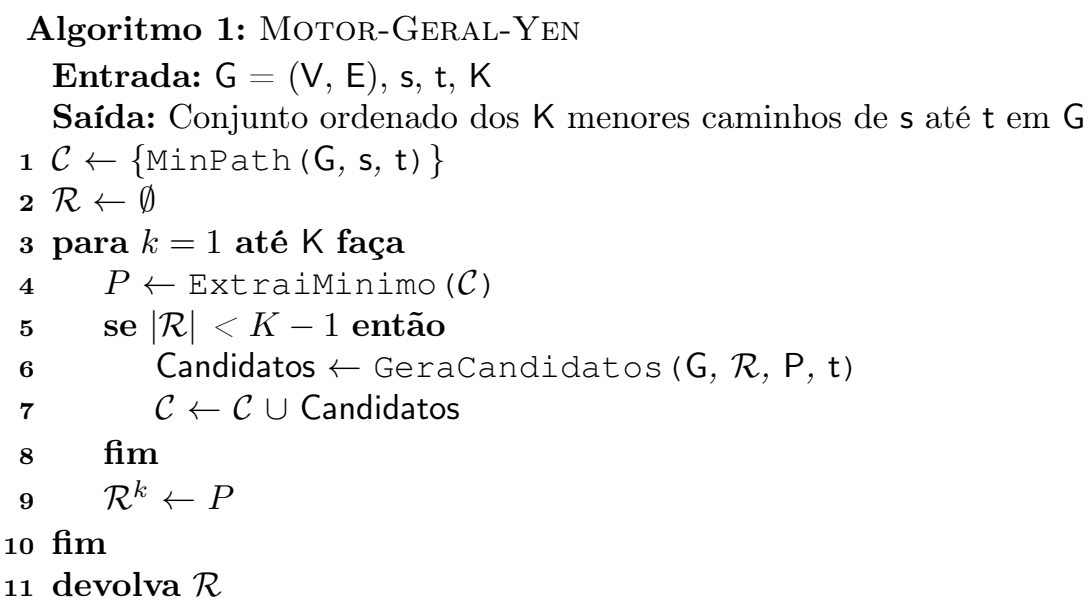

\subsubsection{Arcos Expressos no Algoritmo de Feng}

Falando especificamente do algoritmo de Feng, algumas considerações precisam ser feitas. A primeira diz respeito aos arcos expressos. Um arco expresso, como explicado em 4.3.2, é um arco que tem a cauda amarela e cabeça verde. Para esses arcos, Feng adiciona um arco de mesmo custo, partindo da mesma cauda, mas para $t$. Em nossa implementação, quando nos deparamos com um arco expresso, inserimos dois arcos: o próprio arco, e o arco artificial saindo do vértice verde até $t$, ao invés de sair da cauda do arco expresso. A motivação dessa mudança é a dificuldade em gerenciar múltiplos arcos expressos com a mesma cauda, de modo a manter a capacidade de construir o caminho no final do processamento. Mas, ao contrário dos vértices amarelos, que podem ter vários arcos expressos, um vértice verde tem um único caminho, já conhecido e armazenado durante o pré-processamento.

O algoritmo de Feng é o único dos três algoritmos estudados nesse trabalho que realiza inserções de arcos artificiais. Como dito anteriormente, a atualização do grafo é uma operação muito cara na representação escolhida. Para contornar esse problema, criamos um grafo auxiliar com todos os arcos de $G$ e esses arcos artificiais, permitindo que simulemos a inserção e remoção de arcos utilizando o vetor booleano, com custo baixo. Criamos o grafo auxiliar com todos os arcos do grafo $G$ original, um vértice extra, $v_{a}$ e arcos de cada vértice de $G$ para $v_{a}$ com custo zero. Esse vértice artificial será usado como novo destino ao invés de $t$, e os arcos artificiais servirão quando processarmos um arco expresso. 
Inicialmente, deixamos todos os arcos do subgrafo marcados como removidas no vetor booleano. Conforme os prefixos de um caminho vão sendo analisados, esse subgrafo é atualizado. Diferente da descrição original do algoritmo de Feng, além de removemos a marcação booleana de remoção dos arcos expressos no subgrafo, também desmarcamos o arco artificial que leva da cabeça do arco expresso até $v_{a}$.

\subsection{Algoritmo Híbrido de Feng e Pascoal}

Como iremos mostrar no capítulo 6, existem casos em que o algoritmo de Pascoal é mais rápido que o algoritmo de Feng, mesmo este último podendo ser considerado uma generalização do primeiro. Nesses casos, o esforço necessário para atualizar e manter a classificação das cores dos vértices e o subgrafo induzido pelos vértices amarelos é muito grande perto das vezes em que a estratégia de Pascoal não funciona e precisa gerar o candidato com a mesma estratégia do algoritmo de Yen.

Para estudar o impacto da manutenção do grafo auxiliar, implementamos uma variação híbrida do algoritmo apresentado por Pascoal e do algoritmo de Feng. O Algoritmo de Pascoal procura reduzir o número de execuções do subproblema, mas mantém inalterado o tamanho do grafo no qual o subproblema é executado. O algoritmo de Feng procura reduzir o tamanho do subgrafo em que o algoritmo de Dijkstra atua, mas mantém o mesmo número de chamadas a essa sub-rotina. Procuramos criar uma versão que une as duas características: realizar menos execuções de Dijkstra em subgrafos menores.

Nessa versão, realizaremos a manutenção da classificação de cores como o algoritmo de Feng faz, mas não atualizaremos o grafo auxiliar. Ao invés disso, tentaremos a estratégia de Pascoal primeiro. Aproveitando que o pré-processamento gera o mesmo DAG que Pascoal utiliza, escolhemos o arco com menor custo reduzido e verificamos se a trilha formada não possui repetição de vértices. Como já explicado em 4.1, podemos identificar esse caso olhando para a classificação da cabeça do arco escolhido. Caso seja verde, essa trilha é um caminho simples e podemos utilizá-lo. Caso contrário, Pascoal iria pela estratégia de Yen. No caso do algoritmo proposto, iremos para a estratégia de Feng.

Quando a estratégia de Pascoal falha, nosso algoritmo monta o grafo auxiliar. Para isso, iteramos por todas as arestas de $G$. Se a aresta tem cauda e cabeça amarela, ela é inserida no grafo amarelo. Se a cauda é amarela e a cabeça é verde, essa é uma aresta expressa, e ela é inserida no grafo amarelo, junto com a aresta artificial que liga a cabeça dessa aresta até o vértice final artificial, como no algoritmo de Feng. 


\section{Capítulo 6}

\section{Resultados}

Nesse capítulo, apresentaremos os resultados dos testes de desempenho realizados. Executamos a nossa implementação do algoritmo de Yen, do algoritmo de Pascoal, do algoritmo de Feng e da variante híbrida proposta para comparação.

Os pré-processamentos dos algoritmos de Pascoal e de Feng foram explicados nas seções 3.2 e 4.1 , respectivamente. $\mathrm{O}$ algoritmo de Yen não possui etapa de pré-processamento, assim como não possui pósprocessamento. Os algoritmos de Pascoal e Feng realizam um pequeno pós-processamento para consertar os custos dos caminhos encontrados, uma vez que se utilizam do custo reduzido, explicado na seção 3.4.

Todos os algoritmos foram escritos na linguagem $\mathrm{C}++$, utilizando as mesmas estruturas e funções, sempre que possível. Utilizamos o compilador gcc com a flag de otimização -03. Os detalhes de implementação dos algoritmos foram descritos no capítulo 5.

Todos os testes foram executados na mesma máquina, um servidor com 2 processadores Intel@ Xeon $\mathbb{R}$ E5620, cada um com 4 núcleos de 2.4GHz, com 64GB de RAM, sistema operacional Debian e GCC versão 4.9.2. Apesar da abundância de memória, a bateria de testes foi programada para falhar caso excedesse o limite de 8 GB de memória, para testar sua viabilidade em uma quantidade de memória RAM limitada. Os grafos de entrada foram obtidos pela base de grafos e pelas ferramentas do 9th DIMACS Implementation Challenge ${ }^{1}$.

A seguir, exibiremos os resultados obtidos para cada tipo de grafo, explicando melhor quais classes de grafo foram utilizadas para teste. Depois, na seção 6.4, essas informações serão consolidadas e discutidas em conjunto.

\subsection{Grids}

Os grids foram gerados utilizando a ferramenta spgrid disponibilizada no pacote de benchmark do 9th DIMACS Implementation Challenge. Foram gerados grids quadrados de tamanho $10 \times 10,50 \times 50$, $75 \times 75,100 \times 100,125 \times 125,150 \times 150$. Para cada tamanho de grid, foram gerados 30 grafos com custo aleatório, variando de 1 a 1000, e fizemos uma cópia de cada mas com custos unitários. Os resultados apresentados nessa seção são resultados da média das execuções em que os grafos foram criados com os

\footnotetext{
${ }^{1}$ http://www.diag.uniroma1.it/challenge9/
} 
parâmetros. Todos os algoritmos foram executados para $K=10,20,50,100,200,300,400,500$, com $s=1$ e $t=n$.

Nos grids $10 \times 10$, o grafo gerado é tão pequeno que todos os algoritmos apresentam um desempenho muito similar, como vemos na figura 6.1. Conforme o tamanho do grid aumenta, conseguimos ver a melhora que as estratégias adotadas pelos algoritmos fornecem. O algoritmo de Feng se mostra vantajoso em relação ao algoritmo de Pascoal para essa classe de grafos. Isso pode ser compreendido quando olhamos as tabelas 6.1 e 6.2, com baixas taxas médias de sucesso da estratégia do algoritmo de Pascoal.

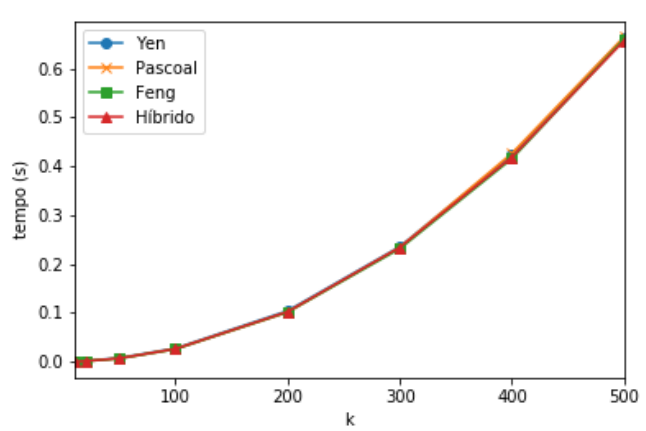

(a) Custo unitário

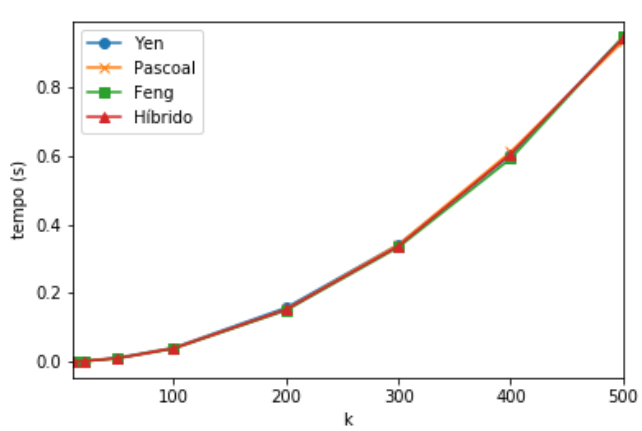

(b) Custo aleatório

Figura 6.1: Grid $10 \times 10$

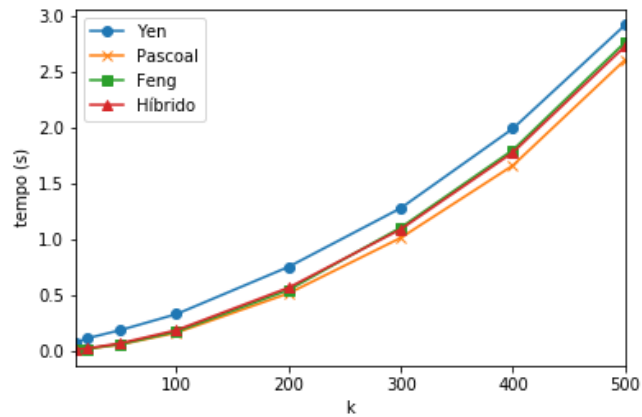

(a) Custo unitário

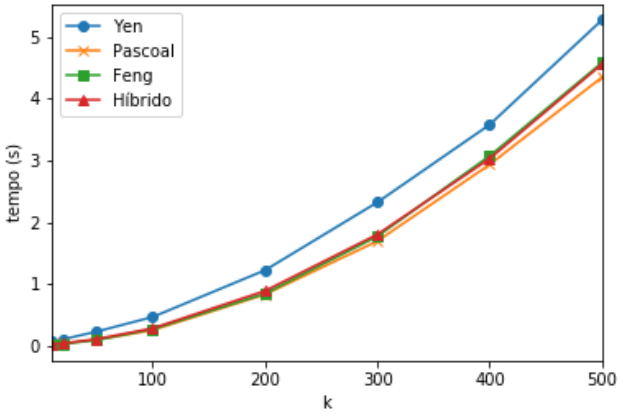

(b) Custo aleatório

Figura 6.2: Grid $50 \times 50$

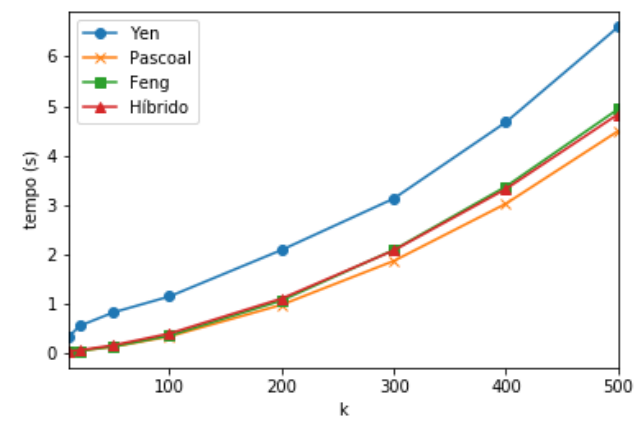

(a) Custo unitário

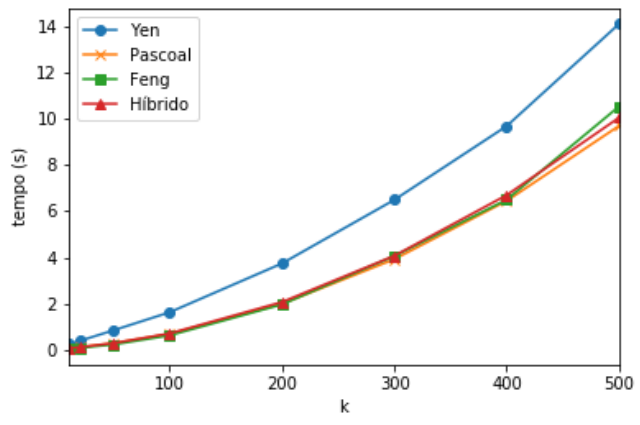

(b) Custo aleatório

Figura 6.3: Grid $75 \times 75$ 


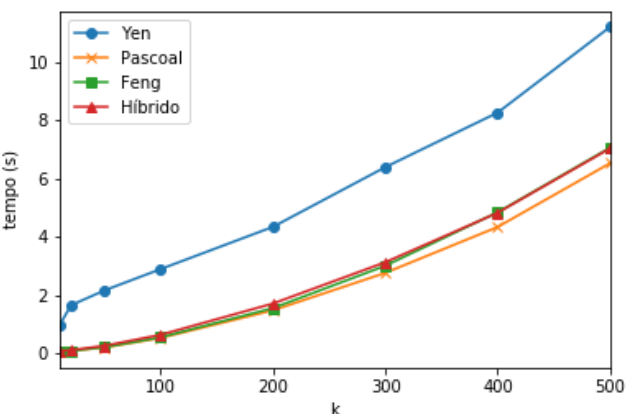

(a) Custo unitário

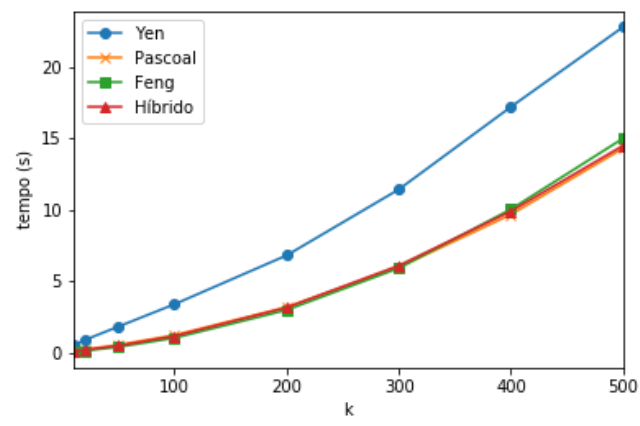

(b) Custo aleatório

Figura 6.4: Grid $100 \times 100$

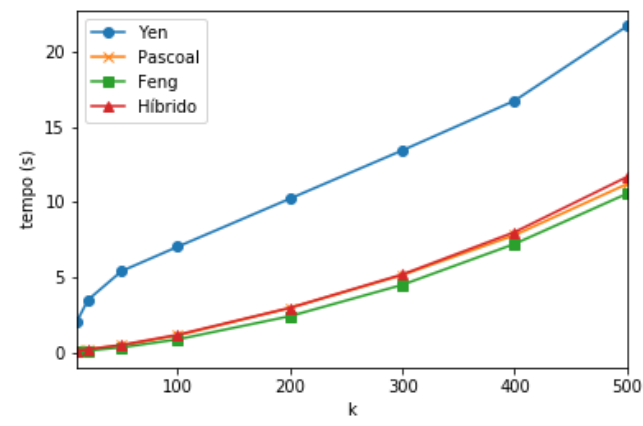

(a) Custo unitário

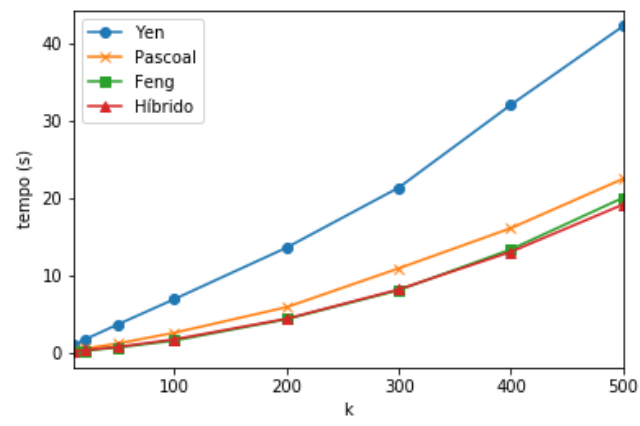

(b) Custo aleatório

Figura 6.5: Grid $125 \times 125$

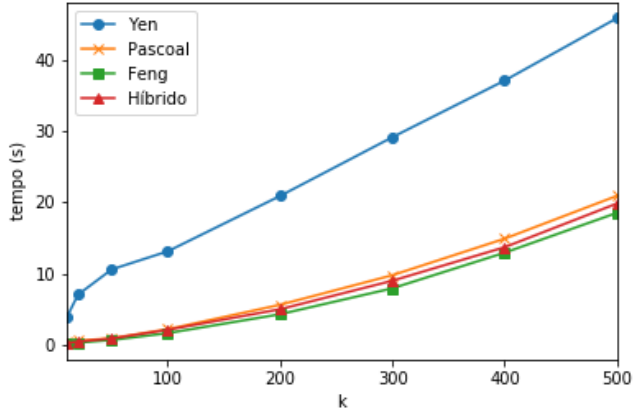

(a) Custo unitário

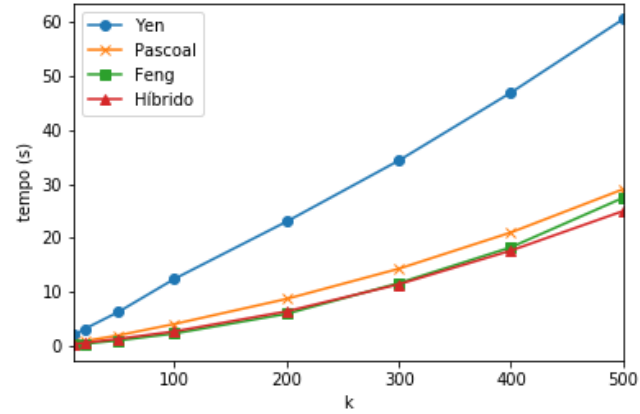

(b) Custo aleatório

Figura 6.6: Grid $150 \times 150$

Ainda pelas tabelas 6.1 e 6.2, conseguimos ver que a taxa média de sucesso do algoritmo de Pascoal está, na maioria dos casos, abaixo dos $50 \%$. Isso significa que nosso algoritmo proposto precisou construir o grafo auxiliar, formado pelos vértices amarelos e arestas artificiais, em mais de $50 \%$ dos casos. Mesmo assim, ele apresenta um desempenho competitivo com relação aos algoritmos base, tendo cenários em que ele apresenta o melhor resultado, como no caso dos grids de custo aleatórios com tamanhos $100 \times 100$, $125 \times 125$ e $150 \times 150$, sendo mais clara a diferença com valores mais altos de $K$. 


\begin{tabular}{c|c|c|c|c|c|c|c|c}
\multirow{2}{*}{ Tamanho } & \multicolumn{10}{|c}{$\mathrm{k}$} \\
\cline { 2 - 9 } & 10 & 20 & 50 & 100 & 200 & 300 & 400 & 500 \\
\hline $10 \times 10$ & $38.84 \%$ & $36.63 \%$ & $34.04 \%$ & $32.99 \%$ & $32.16 \%$ & $31.47 \%$ & $30.93 \%$ & $30.75 \%$ \\
$50 \times 50$ & $56.04 \%$ & $51.04 \%$ & $46.17 \%$ & $44.08 \%$ & $42.87 \%$ & $42.83 \%$ & $42.68 \%$ & $42.63 \%$ \\
$75 \times 75$ & $55.63 \%$ & $49.92 \%$ & $44.48 \%$ & $41.66 \%$ & $40.39 \%$ & $40.04 \%$ & $39.78 \%$ & $39.43 \%$ \\
$100 \times 100$ & $63.89 \%$ & $57.33 \%$ & $49.11 \%$ & $45.33 \%$ & $42.67 \%$ & $42.03 \%$ & $41.79 \%$ & $41.45 \%$ \\
$125 \times 125$ & $55.51 \%$ & $49.30 \%$ & $41.93 \%$ & $38.66 \%$ & $36.59 \%$ & $36.16 \%$ & $35.84 \%$ & $35.62 \%$ \\
$150 \times 150$ & $56.41 \%$ & $50.61 \%$ & $43.48 \%$ & $39.44 \%$ & $37.85 \%$ & $37.50 \%$ & $37.31 \%$ & $37.16 \%$
\end{tabular}

Tabela 6.1: Taxa média de sucesso da estratégia de Pascoal em grafos grid com custo unitário

\begin{tabular}{c|c|c|c|c|c|c|c|c}
\multirow{2}{*}{ Tamanho } & \multicolumn{7}{|c}{$\mathrm{k}$} \\
\cline { 2 - 9 } & 10 & 20 & 50 & 100 & 200 & 300 & 400 & 500 \\
\hline $10 \times 10$ & $31.88 \%$ & $30.86 \%$ & $28.66 \%$ & $27.22 \%$ & $26.44 \%$ & $25.94 \%$ & $25.68 \%$ & $25.38 \%$ \\
$50 \times 50$ & $45.12 \%$ & $44.23 \%$ & $43.13 \%$ & $42.56 \%$ & $41.95 \%$ & $41.51 \%$ & $41.34 \%$ & $41.12 \%$ \\
$75 \times 75$ & $40.81 \%$ & $40.25 \%$ & $39.22 \%$ & $38.52 \%$ & $38.15 \%$ & $37.89 \%$ & $37.77 \%$ & $37.64 \%$ \\
$100 \times 100$ & $45.95 \%$ & $44.76 \%$ & $43.94 \%$ & $43.49 \%$ & $42.95 \%$ & $42.69 \%$ & $42.53 \%$ & $42.35 \%$ \\
$125 \times 125$ & $45.41 \%$ & $44.42 \%$ & $43.68 \%$ & $42.93 \%$ & $42.65 \%$ & $42.34 \%$ & $42.12 \%$ & $42.06 \%$ \\
$150 \times 150$ & $44.96 \%$ & $44.73 \%$ & $44.17 \%$ & $43.94 \%$ & $43.73 \%$ & $43.73 \%$ & $43.64 \%$ & $43.55 \%$
\end{tabular}

Tabela 6.2: Taxa média de sucesso da estratégia de Pascoal em grafos grid com custo aleatório

\subsection{Grafos aleatórios}

Assim como nos grids, geramos os grafos aleatórios utilizando uma ferramenta de benchmark do 9th DIMACS Implementation Challenge, a sprand. Para essa ferramenta, devemos fornecer os tamanhos de $n$ e $m$. Geramos grafos com $n=1000,2000,3000,4000,5000$ e $m=10 n, 20 n, 30 n, 40 n, 50 n$. Geramos 30 grafos com custo aleatório, entre 1 e 1000, e uma cópia de cada mas com custos unitários. Os resultados apresentados nessa seção são resultados da média das execuções em que os grafos foram criados com os parâmetros. Utilizamos valores para $K=10,20,50,100,200,300,400,500$, com vértice de início $s=1$ e $t=n$.

Como o conjunto de teste dessa classe de grafos é muito grande, separamos uma parte das informações para serem exibidos no texto. O comportamento exibido quando aumentamos o número de arcos para um certo $n$ é consistente entre todos os valores de $n$, então essa amostragem não causa perda de informação. Para as estatísticas globais apresentadas na seção 6.4, os dados de todos os experimentos foram utilizados.

Nas figuras 6.7 a 6.11 podemos ver o comportamento apresentado pelos algoritmos quando aumentamos o número de arcos, sem mudar o número de vértices. Já nas figuras 6.12, 6.13 e 6.14, podemos ver o comportamento quando fixamos o número de arcos e aumentamos o número de vértices. Ou seja, ao contrário das imagens anteriores, estamos diminuindo a razão $\frac{m}{n}$. Dessas figuras, conseguimos ver que o algoritmo de Pascoal apresenta melhor desempenho, quando comparado aos demais algoritmos, quanto maior for a razão $\frac{m}{n}$. 


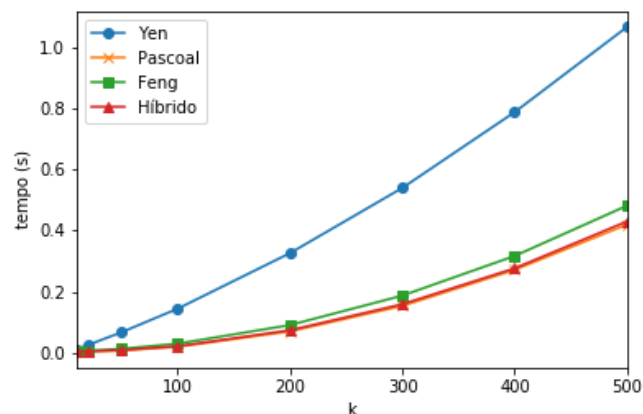

(a) Custo unitário

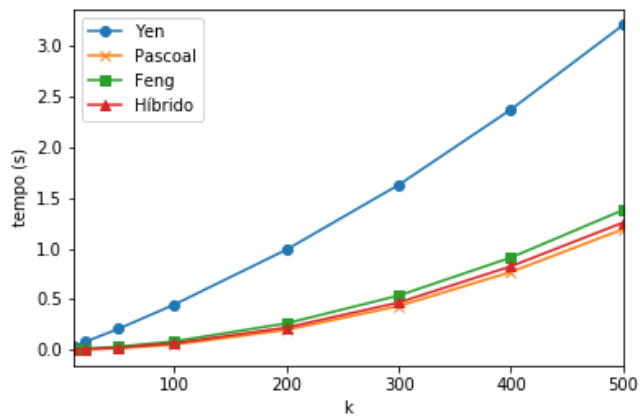

(b) Custo aleatório

Figura 6.7: Grafo aleatório $n=1000 \mathrm{~m}=10000$

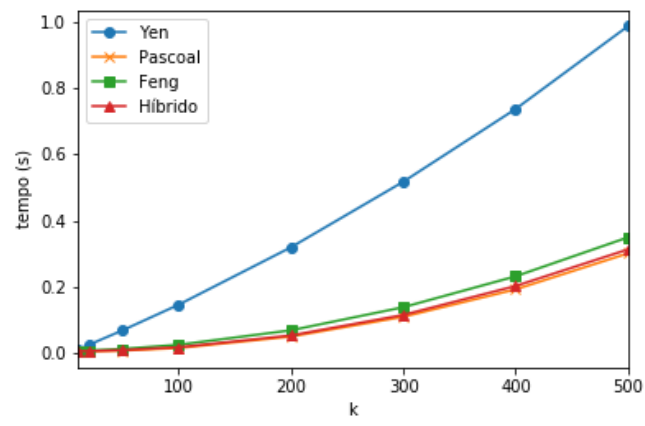

(a) Custo unitário

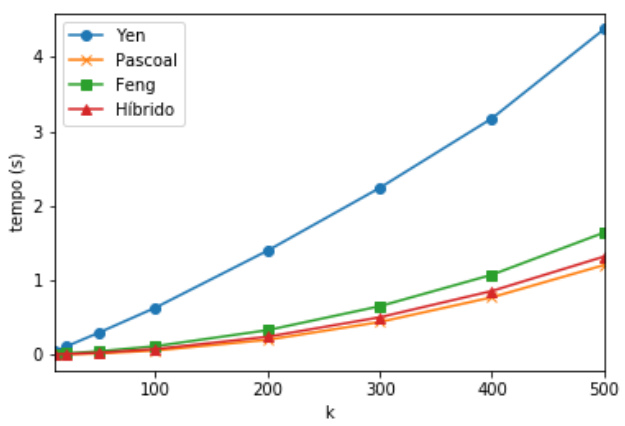

(b) Custo aleatório

Figura 6.8: Grafo aleatório $n=1000 \mathrm{~m}=20000$

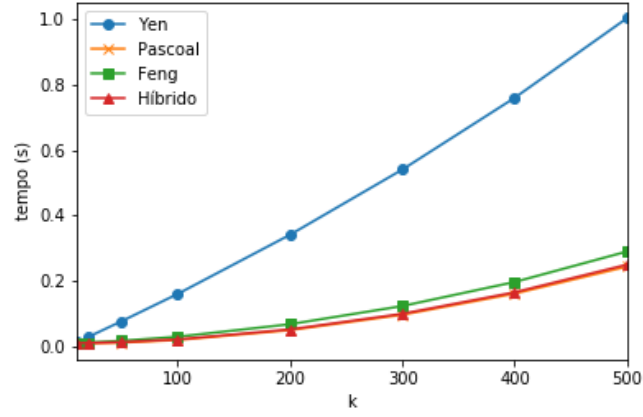

(a) Custo unitário

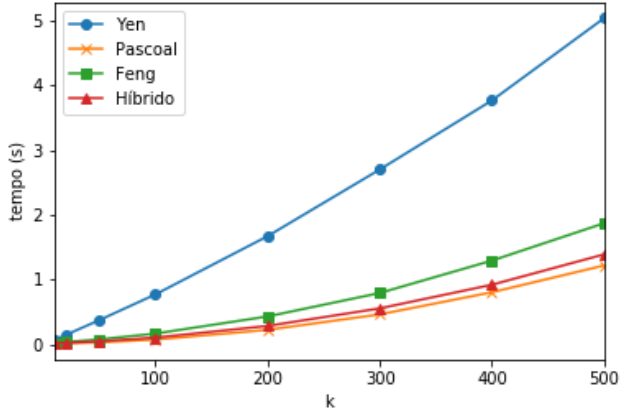

(b) Custo aleatório

Figura 6.9: Grafo aleatório $n=1000 \mathrm{~m}=30000$ 


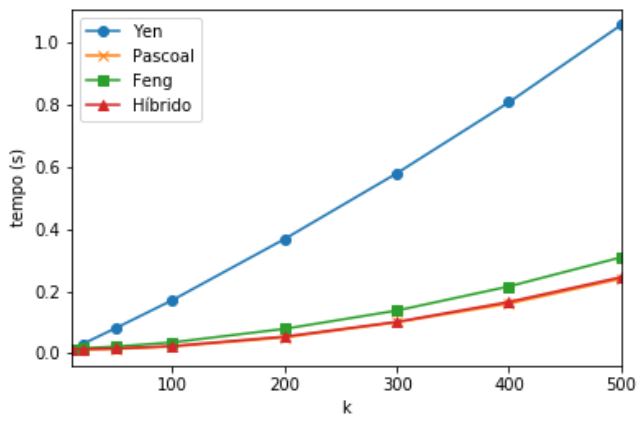

(a) Custo unitário

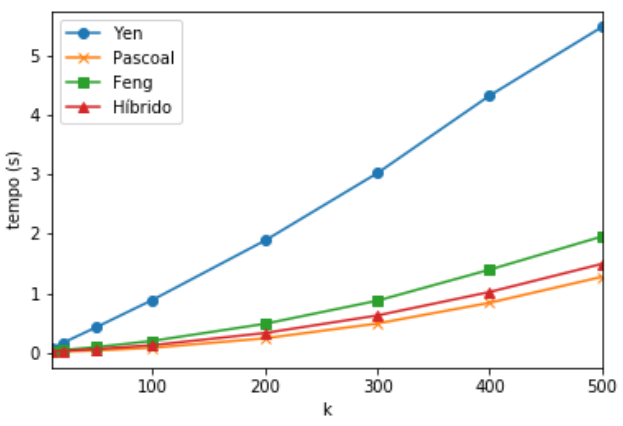

(b) Custo aleatório

Figura 6.10: Grafo aleatório $n=1000 \mathrm{~m}=40000$

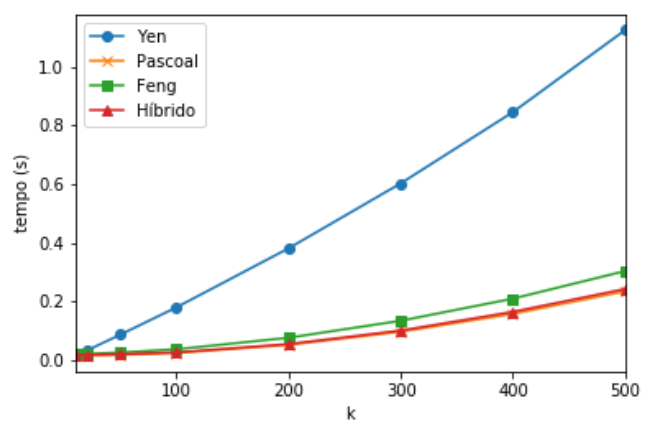

(a) Custo unitário

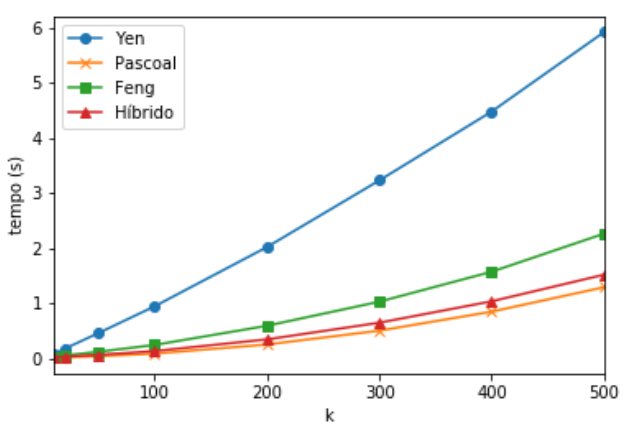

(b) Custo aleatório

Figura 6.11: Grafo aleatório $n=1000 \mathrm{~m}=50000$

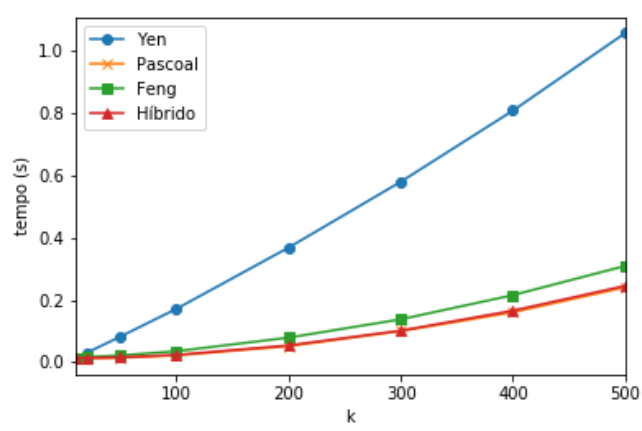

(a) Custo unitário

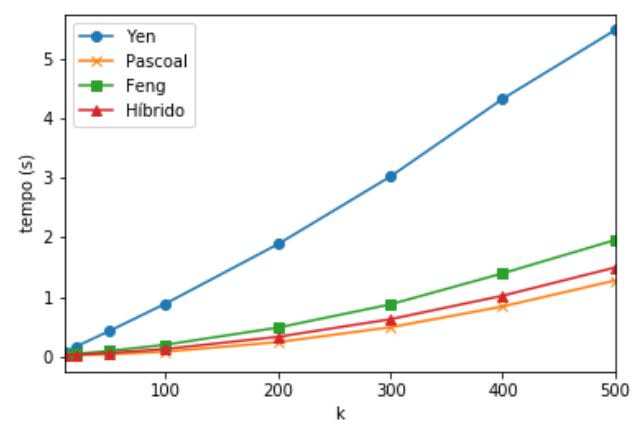

(b) Custo aleatório

Figura 6.12: Grafo aleatório $n=1000 \mathrm{~m}=40000$ 


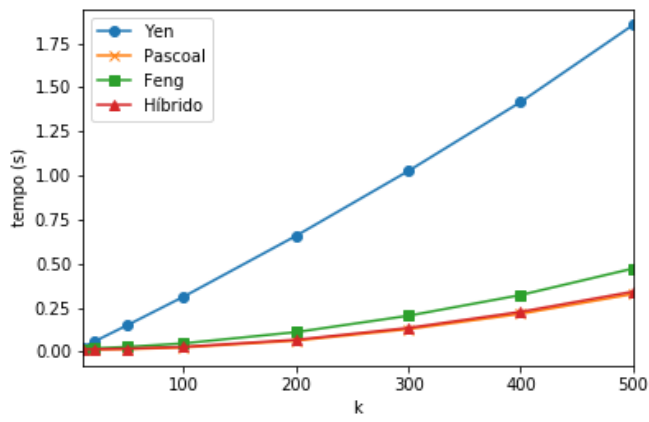

(a) Custo unitário

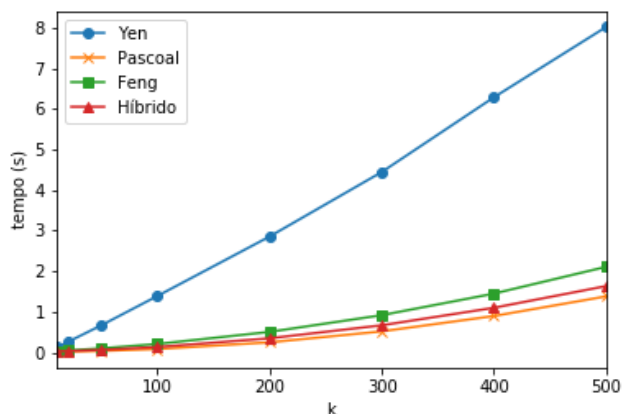

(b) Custo aleatório

Figura 6.13: Grafo aleatório $n=2000 \mathrm{~m}=40000$

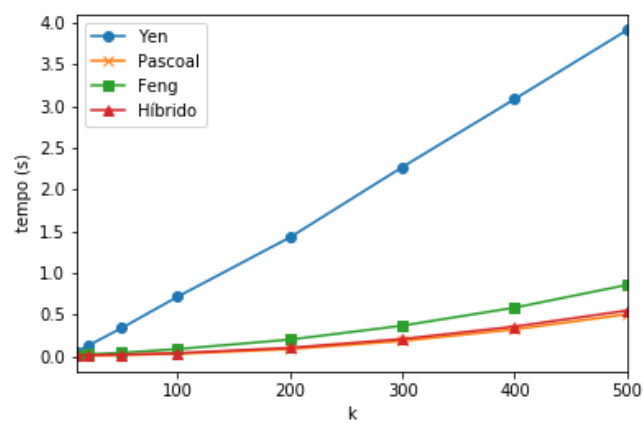

(a) Custo unitário

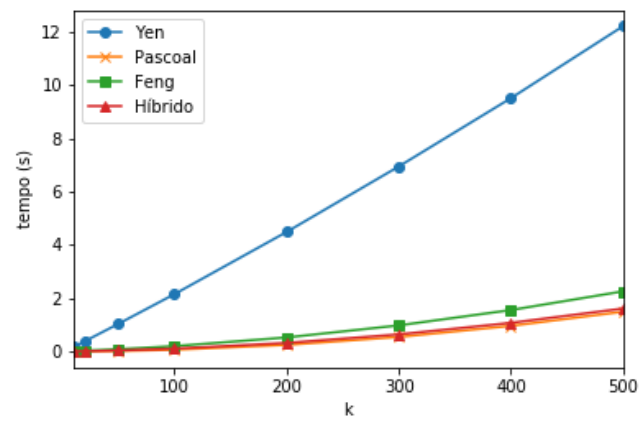

(b) Custo aleatório

Figura 6.14: Grafo aleatório $n=4000 \mathrm{~m}=40000$

\begin{tabular}{c|c|c|c|c|c|c|c|c}
\multirow{2}{*}{ Tamanho } & \multicolumn{7}{|c}{$\mathrm{k}$} \\
\cline { 2 - 9 } & 10 & 20 & 50 & 100 & 200 & 300 & 400 & 500 \\
\hline $\mathrm{n}=1000 \mathrm{~m}=10000$ & $95.95 \%$ & $96.29 \%$ & $94.99 \%$ & $94.90 \%$ & $94.54 \%$ & $94.48 \%$ & $94.22 \%$ & $94.27 \%$ \\
$\mathrm{n}=1000 \mathrm{~m}=20000$ & $98.77 \%$ & $98.43 \%$ & $98.18 \%$ & $97.96 \%$ & $97.74 \%$ & $97.71 \%$ & $97.65 \%$ & $97.62 \%$ \\
$\mathrm{n}=1000 \mathrm{~m}=30000$ & $98.11 \%$ & $98.60 \%$ & $98.20 \%$ & $98.30 \%$ & $97.43 \%$ & $97.44 \%$ & $97.67 \%$ & $97.75 \%$ \\
$\mathrm{n}=1000 \mathrm{~m}=40000$ & $98.57 \%$ & $98.90 \%$ & $98.97 \%$ & $98.23 \%$ & $97.37 \%$ & $97.00 \%$ & $96.93 \%$ & $97.06 \%$ \\
$\mathrm{n}=1000 \mathrm{~m}=50000$ & $98.89 \%$ & $98.96 \%$ & $99.02 \%$ & $98.89 \%$ & $98.42 \%$ & $98.23 \%$ & $97.80 \%$ & $97.92 \%$ \\
$\mathrm{n}=2000 \mathrm{~m}=20000$ & $95.89 \%$ & $96.03 \%$ & $95.75 \%$ & $95.77 \%$ & $95.55 \%$ & $95.59 \%$ & $95.73 \%$ & $95.64 \%$ \\
$\mathrm{n}=2000 \mathrm{~m}=40000$ & $98.45 \%$ & $98.46 \%$ & $98.33 \%$ & $98.38 \%$ & $98.07 \%$ & $98.03 \%$ & $98.05 \%$ & $97.99 \%$ \\
$\mathrm{n}=2000 \mathrm{~m}=60000$ & $99.21 \%$ & $98.69 \%$ & $98.71 \%$ & $98.80 \%$ & $98.80 \%$ & $98.83 \%$ & $98.78 \%$ & $98.58 \%$ \\
$\mathrm{n}=2000 \mathrm{~m}=80000$ & $98.53 \%$ & $98.06 \%$ & $98.27 \%$ & $97.98 \%$ & $98.10 \%$ & $97.93 \%$ & $97.74 \%$ & $97.76 \%$ \\
$\mathrm{n}=2000 \mathrm{~m}=100000$ & $99.43 \%$ & $98.97 \%$ & $98.97 \%$ & $98.83 \%$ & $98.69 \%$ & $98.72 \%$ & $98.63 \%$ & $98.60 \%$ \\
$\mathrm{n}=5000 \mathrm{~m}=50000$ & $96.90 \%$ & $96.79 \%$ & $96.07 \%$ & $96.05 \%$ & $95.95 \%$ & $95.92 \%$ & $95.91 \%$ & $95.87 \%$ \\
$\mathrm{n}=5000 \mathrm{~m}=100000$ & $98.71 \%$ & $98.45 \%$ & $98.22 \%$ & $98.20 \%$ & $97.99 \%$ & $98.00 \%$ & $97.98 \%$ & $97.99 \%$ \\
$\mathrm{n}=5000 \mathrm{~m}=150000$ & $98.11 \%$ & $98.37 \%$ & $98.67 \%$ & $98.69 \%$ & $98.58 \%$ & $98.49 \%$ & $98.44 \%$ & $98.38 \%$ \\
$\mathrm{n}=5000 \mathrm{~m}=200000$ & $98.58 \%$ & $99.03 \%$ & $99.09 \%$ & $99.16 \%$ & $99.07 \%$ & $99.12 \%$ & $99.12 \%$ & $99.07 \%$ \\
$\mathrm{n}=5000 \mathrm{~m}=250000$ & $99.21 \%$ & $99.25 \%$ & $99.17 \%$ & $99.18 \%$ & $99.05 \%$ & $99.10 \%$ & $99.16 \%$ & $99.17 \%$
\end{tabular}

Tabela 6.3: Taxa de sucesso média da estratégia de Pascoal em grafos aleatórios com custo unitário 


\begin{tabular}{c|c|c|c|c|c|c|c|c}
\multirow{2}{*}{ Tamanho } & \multicolumn{7}{|c}{$\mathrm{k}$} \\
\cline { 2 - 9 } & 10 & 20 & 50 & 100 & 200 & 300 & 400 & 500 \\
\hline $\mathrm{n}=1000 \mathrm{~m}=10000$ & $81.55 \%$ & $80.95 \%$ & $81.15 \%$ & $81.18 \%$ & $80.94 \%$ & $80.66 \%$ & $80.38 \%$ & $80.16 \%$ \\
$\mathrm{n}=1000 \mathrm{~m}=20000$ & $85.68 \%$ & $84.44 \%$ & $84.00 \%$ & $83.64 \%$ & $83.44 \%$ & $83.17 \%$ & $82.92 \%$ & $82.80 \%$ \\
$\mathrm{n}=1000 \mathrm{~m}=30000$ & $84.28 \%$ & $83.77 \%$ & $82.95 \%$ & $82.47 \%$ & $82.11 \%$ & $81.94 \%$ & $81.76 \%$ & $81.68 \%$ \\
$\mathrm{n}=1000 \mathrm{~m}=40000$ & $81.69 \%$ & $82.23 \%$ & $81.73 \%$ & $81.42 \%$ & $81.10 \%$ & $80.90 \%$ & $80.80 \%$ & $80.64 \%$ \\
$\mathrm{n}=1000 \mathrm{~m}=50000$ & $84.53 \%$ & $83.54 \%$ & $83.47 \%$ & $83.25 \%$ & $82.71 \%$ & $82.41 \%$ & $82.23 \%$ & $82.06 \%$ \\
$\mathrm{n}=2000 \mathrm{~m}=20000$ & $86.96 \%$ & $86.56 \%$ & $86.12 \%$ & $85.74 \%$ & $85.22 \%$ & $84.93 \%$ & $84.93 \%$ & $84.92 \%$ \\
$\mathrm{n}=2000 \mathrm{~m}=40000$ & $83.57 \%$ & $82.29 \%$ & $82.17 \%$ & $81.95 \%$ & $81.84 \%$ & $81.75 \%$ & $81.69 \%$ & $81.52 \%$ \\
$\mathrm{n}=2000 \mathrm{~m}=60000$ & $86.43 \%$ & $86.40 \%$ & $85.78 \%$ & $85.78 \%$ & $85.32 \%$ & $85.20 \%$ & $85.12 \%$ & $85.04 \%$ \\
$\mathrm{n}=2000 \mathrm{~m}=80000$ & $88.66 \%$ & $88.05 \%$ & $87.39 \%$ & $87.38 \%$ & $86.85 \%$ & $86.85 \%$ & $86.77 \%$ & $86.64 \%$ \\
$\mathrm{n}=2000 \mathrm{~m}=100000$ & $85.25 \%$ & $84.59 \%$ & $84.69 \%$ & $84.46 \%$ & $84.26 \%$ & $84.06 \%$ & $83.94 \%$ & $83.86 \%$ \\
$\mathrm{n}=5000 \mathrm{~m}=50000$ & $89.67 \%$ & $89.60 \%$ & $89.19 \%$ & $89.07 \%$ & $88.59 \%$ & $88.47 \%$ & $88.41 \%$ & $88.36 \%$ \\
$\mathrm{n}=5000 \mathrm{~m}=100000$ & $90.14 \%$ & $89.70 \%$ & $89.28 \%$ & $88.87 \%$ & $88.64 \%$ & $88.50 \%$ & $88.38 \%$ & $88.34 \%$ \\
$\mathrm{n}=5000 \mathrm{~m}=150000$ & $88.83 \%$ & $88.53 \%$ & $88.08 \%$ & $87.96 \%$ & $87.85 \%$ & $87.89 \%$ & $87.69 \%$ & $87.64 \%$ \\
$\mathrm{n}=5000 \mathrm{~m}=200000$ & $87.62 \%$ & $87.39 \%$ & $87.31 \%$ & $87.07 \%$ & $86.92 \%$ & $86.90 \%$ & $86.79 \%$ & $86.75 \%$ \\
$\mathrm{n}=5000 \mathrm{~m}=250000$ & $87.70 \%$ & $86.84 \%$ & $87.06 \%$ & $87.13 \%$ & $86.96 \%$ & $86.85 \%$ & $86.74 \%$ & $86.70 \%$
\end{tabular}

Tabela 6.4: Taxa de sucesso média da estratégia de Pascoal em grafos aleatórios com custo aleatório

Pelas tabelas 6.3 e 6.4, vemos que a taxa de sucesso da estratégia de Pascoal é muito alta, com valores próximos a 90\%. Essa alta taxa de sucesso faz com que os algoritmos de Feng e Pascoal tenham desempenhos bem similares, com Pascoal apresentando ligeira superioridade. Nos grafos com custo unitário, as taxas de sucesso da estratégia de Pascoal são próximas a 100\%, e nossa variante proposta apresenta um desempenho muito similar ao algoritmo de Pascoal. Já nos grafos com custo aleatório, em que a estratégia possui taxas de sucesso um pouco mais baixas, Pascoal apresenta um desempenho superior, evidenciando o trabalho extra em montar o grafo auxiliar do algoritmo proposto.

\subsection{Grafos de malhas rodoviárias}

Os grafos de malhas rodoviárias dos Estados Unidos foram obtidos na página do 9th DIMACS Implementation Challenge. Nessa página, encontramos grafos de dois tipos para malha: distância e tempo. Realizamos os experimentos nos grafos de distâncias da cidades de Nova York (NY), da região da baía de San Francisco (BAY) e do estado do Colorado (COL). Realizamos 5 execuções para cada grafo, com vértice inicial $s=1$ e vértice final aleatório, tendo pelo menos uma execução com $t=n$. Os resultados são apresentados nos gráficos $6.15,6.16$ e 6.17 .

Podemos ver que o algoritmo de Pascoal tem um desempenho próximo ao de Yen em todos os mapas, enquanto o algoritmo de Feng e o híbrido proposto tiveram um desempenho muito superior. Analisando a tabela 6.5, percebemos que a taxa de sucesso do algoritmo de Pascoal está abaixo dos $20 \%$ em todos os mapas, deixando seu comportamento próximo ao do algoritmo de Yen, e bem abaixo do algoritmo de Feng, que ainda consegue encontrar os caminhos no grafo auxiliar com poucos vértices.

Vemos que a variante proposta tem um comportamento muito similar ao algoritmo de Feng mesmo com taxas baixas de sucesso do algoritmo de Pascoal. Isso nos revela que a manutenção do grafo auxiliar é quase tão cara quanto criá-lo em toda iteração, mas certamente é mais vantajosa. Isso é revelado 


\begin{tabular}{|c|c|c|c|c|c|}
\hline Tipo de grafo & $\mathbf{n}$ & $\mathbf{m}$ & $\begin{array}{c}\text { Tamanho médio } \\
\text { caminho } \\
\text { da resposta }\end{array}$ & $\begin{array}{l}\text { Sucesso } \\
\text { médio } \\
\text { Pascoal }\end{array}$ & $\begin{array}{l}\text { Tamanho médio } \\
\text { caminho } \\
\text { amarelo (Feng) }\end{array}$ \\
\hline $\begin{array}{l}\text { New York } \\
(\mathbf{N Y})\end{array}$ & 264346 & & 419.98 & $13.16 \%$ & 4.86 \\
\hline $\begin{array}{c}\text { San Francisco Bay } \\
\text { Area }(\mathbf{B A Y})\end{array}$ & 321270 & 800172 & 468.68 & $16.97 \%$ & 18.15 \\
\hline $\begin{array}{l}\text { Colorado } \\
\text { (COL) }\end{array}$ & 435666 & 1057066 & 56.79 & $8.99 \%$ & 7.85 \\
\hline
\end{tabular}

Tabela 6.5: Estatísticas dos grafos das malhas rodoviárias

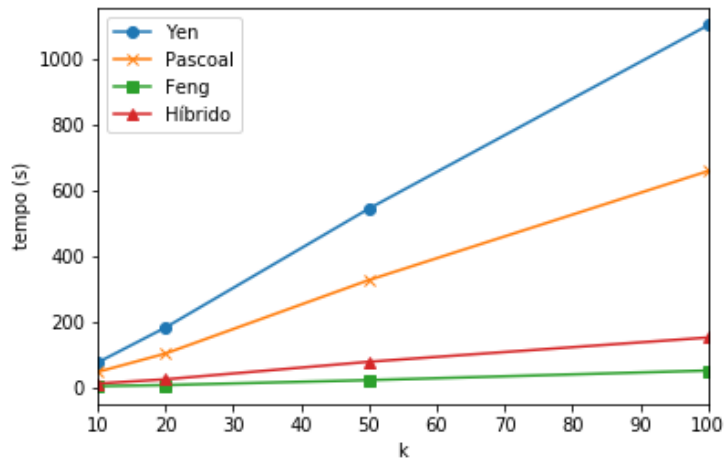

\begin{tabular}{|c|c|}
\hline Algoritmo & $\begin{array}{l}\text { Tempo médio } \\
\text { de execução }\end{array}$ \\
\hline Yen & $475.52 \mathrm{~s}$ \\
\hline Pascoàl & $-\overline{28} \overline{3} . \overline{40} \overline{\mathrm{s}}$ \\
\hline${ }^{-} \overline{\text { Feng }}-\overline{-}$ & ${ }^{-}{ }^{-} \overline{2} 0.7 \overline{8} \mathrm{~s}^{-}$ \\
\hline 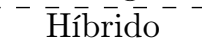 & $\overline{6} 6.2 \overline{9} \mathrm{~s}^{-}$ \\
\hline
\end{tabular}

Figura 6.15: Resultados sobre o mapa de distâncias de Nova York

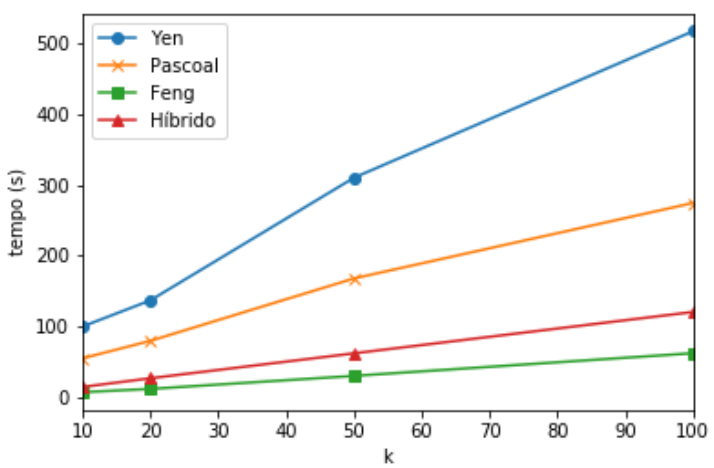

\begin{tabular}{|c|c|}
\hline Algoritmo & $\begin{array}{l}\text { Tempo médio } \\
\text { de execução }\end{array}$ \\
\hline 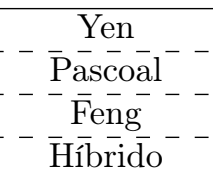 & 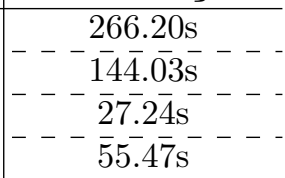 \\
\hline
\end{tabular}

Figura 6.16: Resultados sobre o mapa de distâncias da baía de San Francisco

principalmente pelas execuções nos grafos do Colorado, já que nesses grafos criamos o grafo em mais de 90\% das iterações, mas o algoritmo híbrido apresenta um desempenho próximo ao de Feng. 


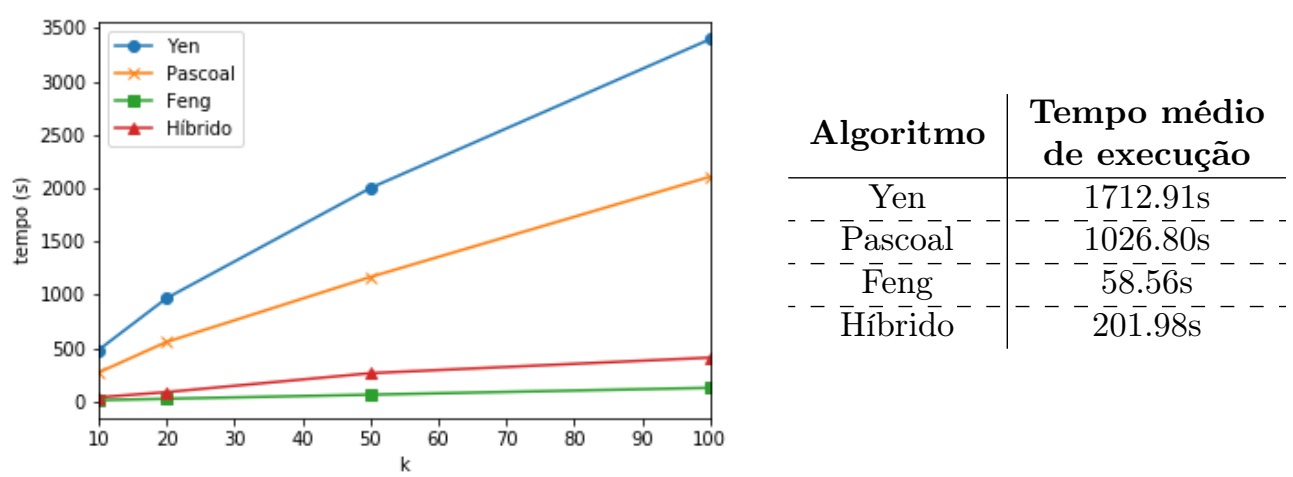

Figura 6.17: Resultados sobre o mapa de distâncias de Colorado

\subsection{Análise comparativa}

Analisando os resultados em conjunto, utilizando os dados sumarizados apresentados nas figuras 6.18 e 6.19, observamos que o número de vértices dos caminhos na resposta tem grande influência no desempenho do algoritmo de Pascoal. Se interpretarmos esse algoritmo utilizando os termos que apresentamos no algoritmo de Feng, o motivo fica mais evidente. Ao procurarmos os candidatos gerados com um prefixo longo temos muitos vértices vermelhos, o que faz com que o grafo tenha muitos vértices amarelos. Ou seja, quanto mais arcos os caminhos da resposta possuem, menores as taxas de sucesso do algoritmo de Pascoal durante a geração de caminhos.

Além disso, uma maior disponibilidade de arestas também causa uma melhora no desempenho do algoritmo de Pascoal. Com maior razão $\frac{m}{n}$, temos menor sensibilidade a alterações nos grafos. Quando comparamos os grafos aleatórios com os grids, notamos a diferença entre a taxa de sucesso do algoritmo de Pascoal e o tamanho dos caminhos na resposta.

Para os grafos aleatórios, os caminhos na resposta têm tão poucos vértices que a taxa de sucesso da estratégia de Pascoal é muito alta, tanto em custo aleatório quanto em custo unitário, apesar de ainda ser maior nesse último. Unindo o que vimos nessa classe de grafos com o que foi visto nas malhas rodoviárias, vimos que o algoritmo proposto apresenta desempenho mais semelhante ao algoritmo de Feng, mas consegue ser acelerado nos casos em que o algoritmo de Pascoal tem altos índices de sucesso, como explicaremos a seguir.

Na média, o algoritmo de Feng encontra rapidamente um vértice verde, reduzindo muito o trabalho do algoritmo de Dijkstra. Nos casos em que o algoritmo de Pascoal tem sucesso, o algoritmo de Feng encontra no grafo amarelo um caminho de 3 vértices, formado pelo vértice de desvio, o vértice verde e finalmente o vértice artificial, ou 2 quando é formado apenas pelo arco entre o vértice de desvio e o vértice final. Vemos que o algoritmo de Feng se mantém consistemente encontrando caminhos de tamanho pequeno. Na tabela 6.6, podemos ver um resumo dos tamanhos médios de caminhos encontrados nos grafos amarelos para cada classe de grafo gerados aleatoriamente.

Notamos que o número médio de vértices dos caminhos encontrados no grafo auxiliar pelo algoritmo de Feng é sempre próximo de 3, o que nos sugere muitos casos de sucesso do algoritmo de Pascoal. Na figura 6.20, temos um gráfico que mostra a ocorrência de cada tamanho de caminho nos subgrafos nos induzidos durante o algoritmo de Feng. Podemos ver a predominância de casos com poucos vértices, 


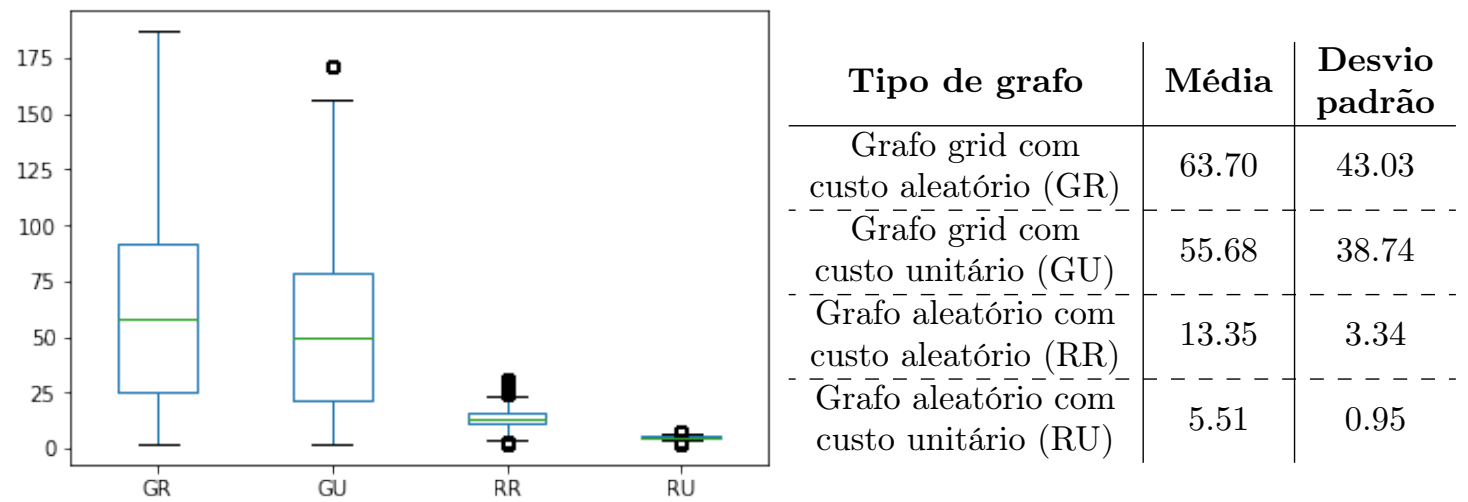

Figura 6.18: Número médio de vértices dos caminhos da resposta

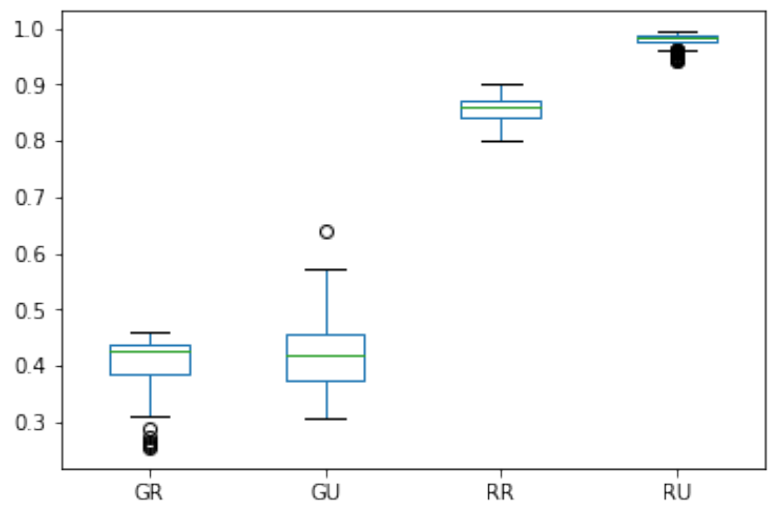

\begin{tabular}{|c|c|c|}
\hline Tipo de grafo & Média & $\begin{array}{l}\text { Desvio } \\
\text { padrão }\end{array}$ \\
\hline $\begin{array}{l}\text { Grafo grid com } \\
\text { custo aleatório (GR) }\end{array}$ & $40.0 \%$ & $5.97 \%$ \\
\hline $\begin{array}{l}\text { Grafo grid com } \\
\text { custo unitário (GU) }\end{array}$ & 42. & $\begin{array}{l}------ \\
7.64 \%\end{array}$ \\
\hline $\begin{array}{l}\text { Grafo aleatório com } \\
\text { custo aleatório (RR) }\end{array}$ & $\begin{array}{l}---- \\
85.6 \%\end{array}$ & $\begin{array}{l}--\cdots \\
2.28 \%\end{array}$ \\
\hline $\begin{array}{l}\text { Grafo aleatório com } \\
\text { custo unitário (RU) }\end{array}$ & $\begin{array}{l}---- \\
98.0 \%\end{array}$ & $\begin{array}{l}----- \\
1.20 \%\end{array}$ \\
\hline
\end{tabular}

Figura 6.19: Taxa média de sucesso da estratégia de Pascoal

apesar de vermos alguns poucos pontos com valores elevados.

Com isso, conseguimos entender melhor o resultado visto nos grafos aleatórios. Nesses grafos, quando o custo também é aleatório, temos taxas de sucesso próximas de $90 \%$. Nosso algoritmo híbrido apresentou um desempenho inferior ao algoritmo de Pascoal. Olhando para o tamanho dos caminhos na resposta, temos um conjunto resposta com tamanho médio de 13.35 vértices. O trabalho adicional de criar o grafo auxiliar, formado pelos vértices amarelos, arestas expressas e arestas artificiais, se mostra custoso demais para o beneficio que traz. Temos uma redução muito pequena do trabalho realizado pelo algoritmo de Dijkstra, em que os caminhos encontrados pela nossa variante no grafo auxiliar é formado por 3.34 vértices na média. O trabalho realizado para iterar pelas milhares de arestas para formar o grafo auxiliar nessa classe de grafos com caminhos na resposta tão curtos é maior do que a economia de tempo fornecida ao executar Dijkstra em um grafo menor.

Já nos grafos de malhas rodoviárias, os caminhos encontrados nos grafos auxiliares de Feng chegam a ter média de 18.15 vértices na baía de San Francisco, em um conjunto resposta que os caminhos têm em média 468.68 vértices. Essa baixa quantidade de vértices para terminar o funcionamento do algoritmo de Dijkstra favorece muito o algoritmo de Feng em grafos com caminhos longos, exatamente o oposto do algoritmo de Pascoal.

Na figura 6.20 temos no eixo $x$ o tamanho do caminho do vértice de desvio até um vértice verde encontrado pelo algoritmo de Feng no grafo auxiliar, e no eixo $y$ a frequência de ocorrências de cada 


\begin{tabular}{|c|c|c|c|}
\hline Tipo de grafo & Média & Desvio padrão & Máximo \\
\hline $\begin{array}{c}\text { Grafo grid com } \\
\text { custo aleatório (GR) }\end{array}$ & 3.37 & 0.55 & 10 \\
\hline Grafo grid com & $\begin{array}{r}-- \\
3.45\end{array}$ & $\begin{array}{r}------ \\
0.51\end{array}$ & $\begin{array}{c}------ \\
6\end{array}$ \\
\hline Grafo aleatório com & & ------ & \\
\hline custo aleatório ( $\mathrm{RR})$ & 3.18 & 0.78 & 11 \\
\hline $\begin{array}{l}\text { Grafo aleatório com } \\
\text { custo unitário (RU) }\end{array}$ & 3.00 & 0.06 & 5 \\
\hline
\end{tabular}

Tabela 6.6: Estatísticas relativas ao tamanho do caminho do vértice de desvio até um vértice verde encontrado pelo algoritmo de Feng no grafo auxiliar

caminho. Vemos uma alta ocorrência de caminhos com poucos vértices, tendo somente alguns poucos caminhos em que são necessários mais do que 5 vértices para encontrar um vértice verde.

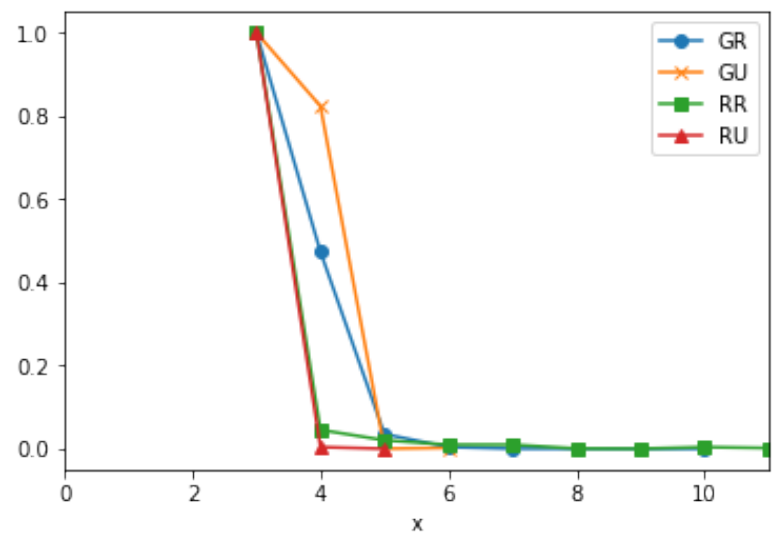

Figura 6.20: Tamanho dos caminhos encontrados utilizando o algoritmo de Dijkstra no subgrafo induzido pelos vértices amarelos do algoritmo de Feng 


\section{Capítulo 7}

\section{Conclusão}

Estudamos e implementamos alguns algoritmos para a resolução do Problema dos $K$ Menores Caminhos. O algoritmo de Pascoal é uma variação do algoritmo de Yen, em que é realizado um préprocessamento para gerar uma estrutura auxiliar que procura evitar a necessidade da execução do algoritmo de Dijkstra para gerar um candidato. Essa estratégia nem sempre funciona, e quando falha, o mesmo procedimento do algoritmo de Yen é utilizado. O algoritmo de Feng pode ser considerado uma generalização do algoritmo de Pascoal, que utiliza a mesma estrutura daquele algoritmo e apresenta uma maneira de reduzir o trabalho necessário para gerar cada candidato, mas executa Dijkstra em toda iteração. Propusemos uma variante do algoritmo de Feng que procura diminuir novamente o número de execuções do algoritmo de Dijkstra durante o funcionamento do algoritmo de Feng, ao mesmo tempo em que parte da atualização de suas estruturas extras não são realizadas nas iterações em que a estratégia de Pascoal é bem sucedida. Essa motivação resultou em uma variante que executa menos vezes o algoritmo de Dijkstra em grafos menores.

Apesar do algoritmo de Feng poder ser considerado uma generalização do algoritmo de Pascoal, ele apresenta desempenho inferior ao seu antecessor em alguns casos. Procuramos identificar e entender quando isso acontece. Os casos em que o algoritmo de Pascoal é bem-sucedido em sua estratégia também é favorável ao algoritmo de Feng, uma vez que o algoritmo de Dijkstra marca rapidamente o vértice alvo. Mas nos casos em que taxa de sucesso da estratégia de Pascoal é muito alta, mesmo com as execuções rápidas do algoritmo de Dijkstra, o algoritmo de Pascoal acaba sendo mais rápido, como nos grafos aleatórios com custos unitários, em que as taxas de sucesso da estratégia de Pascoal ficam próximas de $100 \%$.

Analisando o algoritmo de Pascoal utilizando as nomenclaturas apresentadas no algoritmo de Feng, identificamos as características que favorecem a estratégia de Pascoal. Nos nossos casos de teste, tanto os grafos que apresentavam respostas com caminhos curtos quanto aqueles que tinham menor sensibilidade a entrada forneciam melhores resultados do algoritmo de Pascoal. Os caminhos curtos fazem com que tenhamos menos vértices vermelhos ou amarelos, aumentando a chance da estratégia de Pascoal funcionar. E com uma menor sensibilidade do problema à mudanças, temos menos subcaminhos críticos que afunilam o DAG e comprometam sua taxa de sucesso.

A variante proposta busca evitar atualizar em toda iteração o grafo auxiliar, formado pelos vértices amarelos, arestas expressas e arestas artificiais. Procuramos fazer isso adotando a mesma estratégia do algoritmo de Pascoal, que também nos permite evitar algumas execuções do algoritmo de Dijkstra. 
Quando a estratégia de Pascoal falha, utilizamos as ideias do algoritmo de Feng para procurar o menor caminho no grafo auxiliar, que normalmente é bem menor do que $G$. Nos casos em que o algoritmo de Pascoal apresenta muitas falhas de sua estratégia, como nas malhas rodoviárias, o algoritmo proposto fica entre os dois algoritmos base, mas com desempenho mais semelhante ao algoritmo de Feng. Já nos casos em que a estratégia de Pascoal tem taxas de sucesso altas, nosso algoritmo se assemelha mais ao desempenho obtido por Pascoal. Nos casos intermediários das taxas de sucesso dessa estratégia, nosso algoritmo conseguiu obter o melhor desempenho dentre os algoritmos testados. 


\section{Referências Bibliográficas}

[AMO93] AHUJA, R. K., MAGNANTI, T. L. e ORLIN, J. B. Network Flows: Theory, Algorithms, and Applications. Prentice Hall, 1 edição, Fevereiro 1993.

[BKH58] BOCK, F., KANTNER, H. e HAYNES, J. An algorithm (the $r$-th best path algorithm) for finding and ranking paths through a network. Armour Research Foundation Technology Center, 1958.

[BLT12] BRODAL, G. S., LAGOGIANNIS, G. e TARJAN, R. E. Strict fibonacci heaps. Proceedings of the 44th symposium on Theory of Computing - STOC '12, página 1177, 2012.

[Cha07] CHAN, T. M. More algorithms for all-pairs shortest paths in weighted graphs. Em In Proceedings of 39th Annual ACM Symposium on Theory of Computing, páginas 590-598, 2007.

[CKR63] ClARKE, S., KRIKORIAN, A. e RAUSEN, J. Computing the N Best loopless Paths in a network. Journal of the Society for Industrial and Applied Mathematics, 11(4):1096-1102, 1963.

[CLRS01] CORMEN, T. H., LEISERSON, C. E., RIVEST, R. L. e STEIN, C. Introduction to algorithms, volume 6. MIT press Cambridge, 2001.

[Dij59] DIJKSTRA, E. W. A note on two problems in connexion with graphs. Numerische mathematik, 1(1):269-271, 1959.

[Dre69] DREYFUS, S. E. An Appraisal of Some Shortest-Path Algorithms. Operations Research, 17(3):395-412, 1969.

[EAEG93] EL-AMIN e EL-GHAMDI. An expert system for transmission line route selection. Em Int. Power Engineering Conf, volume 2, páginas 697-702. Nanyang Technol. Univ, 1993.

[Epp98] EPPSTEIN, D. Finding the k shortest paths. SIAM Journal on computing, 28(2):652-673, 1998.

[FDMP02] FENG, G., DOULIGERIS, C., MAKKI, K. e PISSINOU, N. Performance evaluation of delayconstrained least-cost qos routing algorithms based on linear and nonlinear lagrange relaxation. Em Communications, 2002. ICC 2002. IEEE International Conference on, volume 4, páginas 2273-2278. IEEE, 2002.

[Fen14] FENG, G. Finding k shortest simple paths in directed graphs: A node classification algorithm. Networks, 64(1):6-17, aug 2014.

[FMPD02] FENG, G., MAKKI, K., PISSINOU, N. e DOULIGERIS, C. Heuristic and exact algorithms for qos routing with multiple constraints. IEICE Transactions on Communications, 85(12):2838-2850, 2002.

[FT87] FREDMAN, M. L. e TARJAN, R. E. Fibonacci heaps and their uses in improved network optimization algorithms. Journal of the ACM, 34(3):596-615, 1987.

[GL09] GOTTHILF, Z. e LEWENSTEIN, M. Improved algorithms for the k simple shortest paths and the replacement paths problems. Information Processing Letters, 109(7):352-355, 2009. 
[HMS07] HERSHBERGER, J., MAXEL, M. e SURI, S. Finding the k shortest simple paths: A new algorithm and its implementation. ACM Trans. Algorithms, 3(4):45+, 2007.

[HP59] HOFFMAN, W. e PAVLEY, R. A Method for the Solution of the Nth Best Path Problem. Journal of the ACM, 6(4):506-514, 1959.

[JV06] JIA, Z. e VARAIYA, P. Heuristic methods for delay constrained least cost routing using/spl kappa/-shortest-paths. IEEE Transactions on Automatic Control, 51(4):707-712, 2006.

[KIM82] KATOH, N., IBARAKI, T. e MINE, H. An efficient algorithm for K shortest simple paths. Networks, 12(4):411-427, jan 1982.

[Law72] LAWLER, E. L. A Procedure for Computing the K Best Solutions To Discrete Optimization Problems and Its Application To the Shortest Path Problem. Management Science, 18(7):401406, 1972.

[MPS99] MARTINS, E. d. Q. V., PASCOAL, M. M. B. e SANTOS, J. L. E. D. Deviation algorithms for ranking shortest paths. International Journal of Foundations of Computer Science, 10(3):247262, 1999.

[Pas06] PASCOAL, M. M. B. Implementations and empirical comparison of K shortest loopless path algorithms. 9th DIMACS Implementation Challenge - Shortest Paths, 2006.

[Per86] PERKO, A. Implementation of algorithms for K shortest loopless paths. Networks, 16:149$160,1986$.

[Pet04] PETTIE, S. A new approach to all-pairs shortest paths on real-weighted graphs. Theoretical Computer Science, 312(1):47-74, 2004.

[Pis09] PISARUK, F. k-menores caminhos. Dissertação de Mestrado, Universidade de São Paulo, Brasil, 2009.

[Rod10] RODITTY, L. On the k Shortest Simple Paths Problem in Weighted Directed Graphs. SIAM Journal on Computing, 39(6):2363-2376, jan 2010.

[RZ05] RODITTY, L. e ZWICK, U. Replacement paths and k simple shortest paths in unweighted directed graphs. Em Automata, Languages and Programming, páginas 249-260. Springer, 2005 .

[Yen71] YEN, J. Y. Finding the K Shortest Loopless Paths in a Network. Management Science, $17(11): 712-716,1971$. 